\title{
Using Biosurfactants Produced from Agriculture Process Waste Streams to Improve Oil Recovery in Fractured Carbonate Reservoirs
}

\author{
Final Technical Progress Report \\ Reporting Period: October 1, 2004 - March 31, 2007 \\ Principal Investigator: Jenn-Tai Liang \\ The University of Kansas \\ jtliang@ku.edu, 785-864-2669 \\ Co-Principal Investigator: Gregory A. Bala \\ Idaho National Laboratory \\ Gregory.Bala@inl.gov, 208-526-8178
}

Report Date:

September 17, 2007

DOE Award Number:

DE-FC26-04NT15523

Contract Dates:

$10 / 01 / 2004$ to $09 / 30 / 2007$

Submitting Organizations: The University of Kansas Center for Research, Inc.

Tertiary Oil Recovery Project

$1530 \mathrm{~W} .15^{\text {th }}$ St.

Lawrence, KS 66045-7609

Idaho National Laboratory

2351 North Boulevard

Idaho Falls, ID 83451-2203

Research Contributors: $\quad$ Stephen J. Johnson, Mehdi Salehi, Karl Eisert (KU) Sandra L. Fox (INL)

Contracting Officer: $\quad$ Chandra Nautiyal, National Energy Technology Laboratory, U.S. Department of Energy 


\section{Disclaimer}

This report was prepared as an account of work sponsored by an agency of the United States Government. Neither the United States Government nor any agency thereof, nor any of their employees, makes any warranty, express or implied, or assumes any legal liability or responsibility for the accuracy, completeness, or usefulness of any information, apparatus, product, or process disclosed, or represents that its use would not infringe privately owned rights. Reference herein to any specific commercial product, process, or service by trade name, trademark, manufacturer, or otherwise does not necessarily constitute or imply its endorsement, recommendation, or favoring by the United States Government or any agency thereof. The views and opinions of authors expressed herein do not necessarily state or reflect those of the United States Government or any agency thereof. 


\section{Abstract}

This report describes the progress of our research during the first 30 months $(10 / 01 / 2004$ to $03 / 31 / 2007$ ) of the original three-year project cycle. The project was terminated early due to DOE budget cuts. This was a joint project between the Tertiary Oil Recovery Project (TORP) at the University of Kansas and the Idaho National Laboratory (INL). The objective was to evaluate the use of low-cost biosurfactants produced from agriculture process waste streams to improve oil recovery in fractured carbonate reservoirs through wettability mediation.

Biosurfactant for this project was produced using Bacillus subtilis 21332 and purified potato starch as the growth medium. The INL team produced the biosurfactant and characterized it as surfactin. INL supplied surfactin as required for the tests at KU as well as providing other microbiological services.

Interfacial tension (IFT) between Soltrol 130 and both potential benchmark chemical surfactants and crude surfactin was measured over a range of concentrations. The performance of the crude surfactin preparation in reducing IFT was greater than any of the synthetic compounds throughout the concentration range studied but at low concentrations, sodium laureth sulfate (SLS) was closest to the surfactin, and was used as the benchmark in subsequent studies.

Core characterization was carried out using both traditional flooding techniques to find porosity and permeability; and NMR/MRI to image cores and identify pore architecture and degree of heterogeneity. A cleaning regime was identified and developed to remove organic materials from cores and crushed carbonate rock. This allowed cores to be fully characterized and returned to a reproducible wettability state when coupled with a crude-oil aging regime. Rapid wettability assessments for crushed matrix material were developed, and used to inform slower Amott wettability tests. Initial static absorption experiments exposed limitations in the use of HPLC and TOC to determine surfactant concentrations. To reliably quantify both benchmark surfactants and surfactin, a surfactant ion-selective electrode was used as an indicator in the potentiometric titration of the anionic surfactants with Hyamine 1622.

The wettability change mediated by dilute solutions of a commercial preparation of SLS (STEOL CS-330) and surfactin was assessed using two-phase separation, and water flotation techniques; and surfactant loss due to retention and adsorption on the rock was determined. Qualitative tests indicated that on a molar basis, surfactin is more effective than STEOL CS-330 in altering wettability of crushed Lansing-Kansas City carbonates from oil-wet to water-wet state. Adsorption isotherms of STEOL CS-330 and surfactin on crushed Lansing-Kansas City outcrop and reservoir material showed that surfactin has higher specific adsorption on these oomoldic carbonates.

Amott wettability studies confirmed that cleaned cores are mixed-wet, and that the aging procedure renders them oil-wet. Tests of aged cores with no initial water saturation resulted in very little spontaneous oil production, suggesting that water-wet pathways into the matrix are required for wettability change to occur. Further investigation of spontaneous imbibition and forced imbibition of water and surfactant solutions into LKC cores under a variety of conditions - cleaned vs. crude oil-aged; oil saturated vs. initial water saturation; flooded with surfactant vs. 
not flooded - indicated that in water-wet or intermediate wet cores, sodium laureth sulfate is more effective at enhancing spontaneous imbibition through wettability change. However, in more oil-wet systems, surfactin at the same concentration performs significantly better. 


\section{Table of Contents}

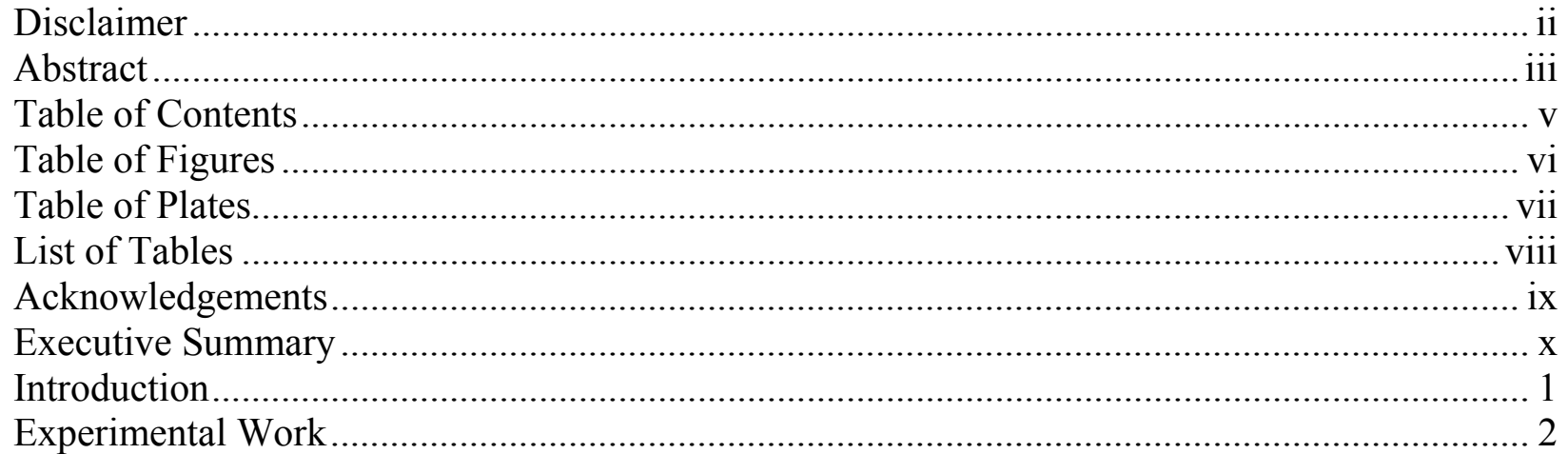

1. Produce, Screen and Characterize Biosurfactants Produced from Agriculture Process

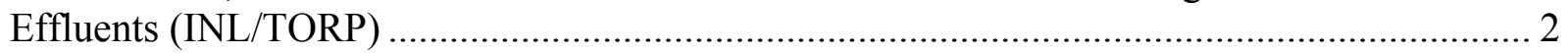

1.1. Production of Biological Surfactants ..................................................................... 2

1.2. Screening and Characterization of Biological Surfactants .................................... 2

Loss of surfactin activity: Microbial degradation of surfactin? .......................................... 3

1.3. Screening and Selection of Benchmark Chemical Surfactants.................................. 4

Surface tension/IFT of surfactants ............................................................................ 7

2. Evaluate the Biosurfactants for Improved Oil Recovery in Fractured Carbonate

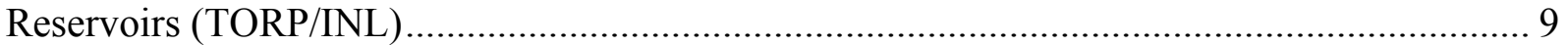

2.1. Effects of Wettability Change on Incremental Oil Recovery ……………….............. 9

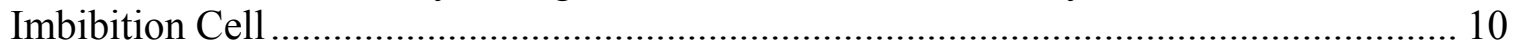

Core Flooding Apparatus ..................................................................................... 10

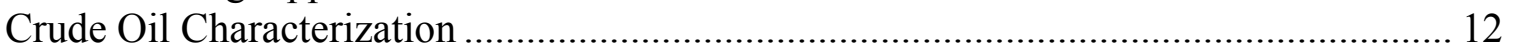

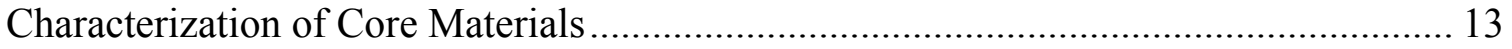

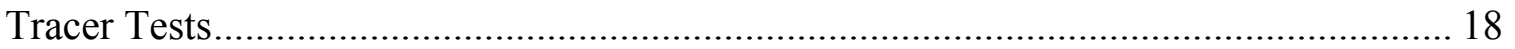

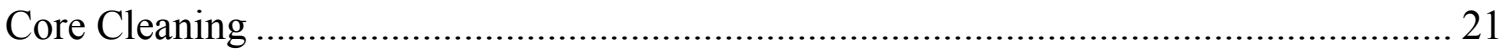

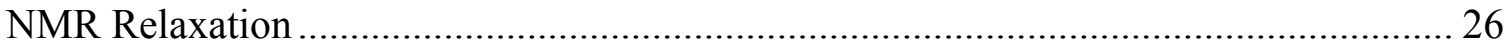

Preparation of crushed carbonate rock......................................................................... 26

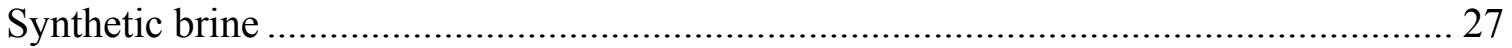

Rapid wettability assessment by two-phase separation ................................................ 27

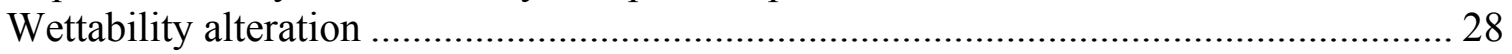

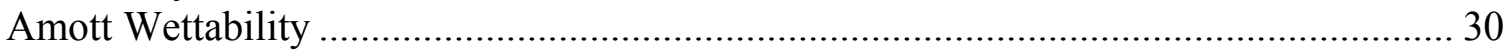

2.2. Surfactant Loss Due to Adsorption and Retention on Reservoir Rock .................... 40

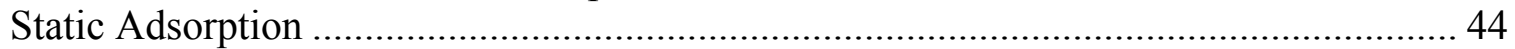

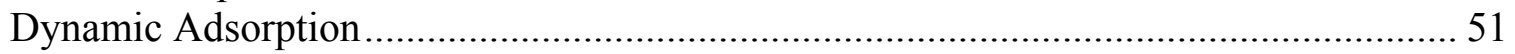

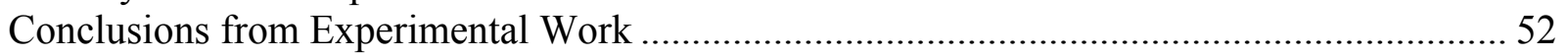

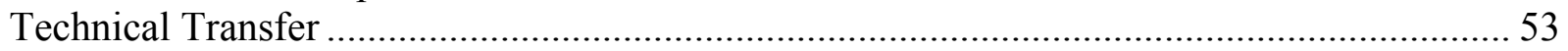

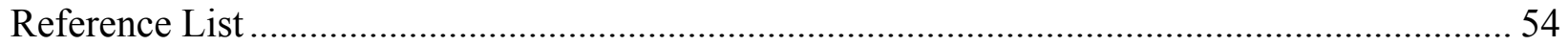

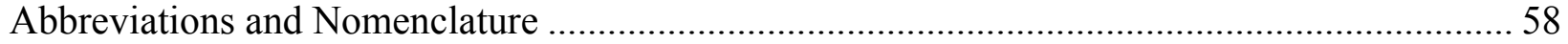




\section{Table of Figures}

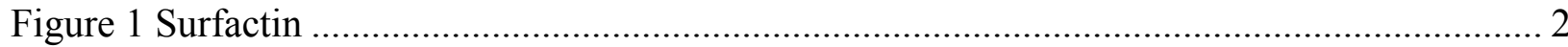

Figure 2 Surface tension of crude surfactin at different concentrations, measured using a hanging drop technique (INL) or ring tensiometer (TORP). Error bars on TORP data $=1$ Std. Dev., $n=3$

Figure 3 Candidate benchmark synthetic surfactants: A. Sodium dodecyl sulfate (SDS), B.

Sodium laureth sulfate (SLS), C. Sodium dodecylbenzene sulfonate

Figure 4 Interfacial tension between surfactant solutions and Soltrol 130. Error bars $=1 \mathrm{Std}$.

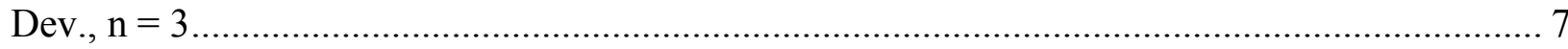

Figure 5 Core flooding apparatus to show valve positions .................................................... 11

Figure 6 Detail of Hassler type core holder showing valve positions ................................... 11

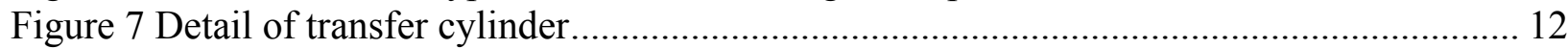

Figure 8 Location of Hall-Gurney Field on map of Lansing-Kansas City oil production in

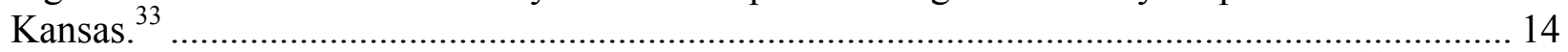

Figure 9 Paragenesis of limestone porosity, after Dubois, Byrnes and Watney $(2001)^{24} \ldots \ldots \ldots \ldots . . . . . .14$

Figure 10 Permeability of Bethany Falls outcrop core BF02 …....................................... 17

Figure 11 Porosity and permeability of Bethany Falls (BF), Heartland Quarry (HQ) and Luerman \#7 (L7), Joulters Cay (JC) and Miami (M) cores. Points marked in gray (W1-6) represent

Bethany Falls and Mound Valley oolites, digitized ${ }^{26}$ from Watney $(1994)^{25}$............................ 18

Figure 12 Alternate layout for aqueous tracer test.............................................................. 19

Figure 13 Alternate layout for oil tracer test................................................................... 19

Figure $14 \mathrm{UV}$ absorption calibration curves for $\mathrm{KNO}_{3}$ in water and in effluent from core BF02 at

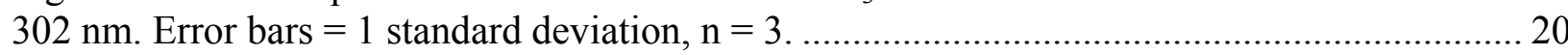

Figure 15 UV absorption calibration curve for trans-stilbene in dodecane at $228 \mathrm{~nm}$.............. 21

Figure 16 UV absorbance of dodecane effluent from core BF_02 ..................................... 23

Figure 17 Heterogeneous Bethany Falls oomoldic outcrop core $, \phi=0.21, \mathrm{k}=0.7 \mathrm{md} \ldots \ldots \ldots \ldots .25$

Figure 18 Relatively homogeneous Luerman \#7 oomoldic reservoir core, $\phi=0.24, \mathrm{k}=16 \mathrm{md} .25$

Figure 19 Heterogeneous Miami oolitic outcrop core, $\phi=0.42, \mathrm{k}=170 \mathrm{md}$........................ 25

Figure 20 Homogeneous Joulter's Cay oolitic outcrop core, $\phi=0.43, \mathrm{k}=1100 \mathrm{md}$.............. 25

Figure 21 NMR relaxation times for carbonate cores BF_01, L7_02, M_02 and JC_02 ........... 26

Figure 22 Particle size distribution of crushed carbonate rock. Only particles in the range 53-300

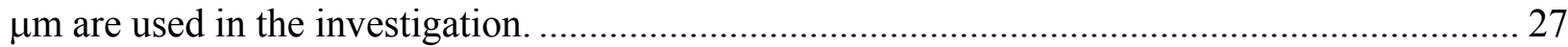

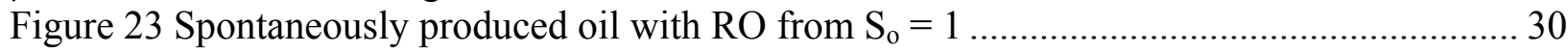

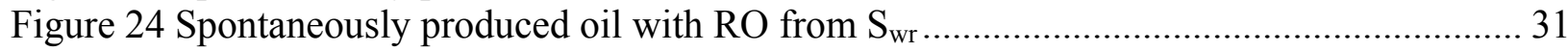

Figure 25 Spontaneously produced oil with RO after aging.............................................. 31

Figure 26 Spontaneously produced oil with 500 PPM STEOL CS-330 after aging .................. 32

Figure 27 Spontaneously produced oil with 500 PPM surfactin after aging ............................. 32

Figure 28 Imbibition of RO water (base case) and 500 ppm surfactant solutions into cleaned

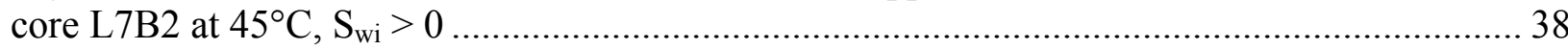

Figure 29 Imbibition of RO water (base case) and 500 ppm surfactant solutions into core L7B3,

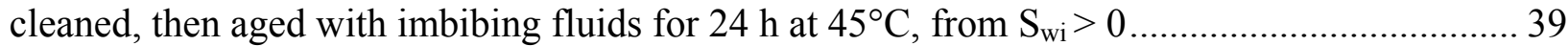

Figure 30 Imbibition of RO water followed by $500 \mathrm{ppm}$ surfactant solutions water into surfactant-aged oil-wet cores from $\mathrm{S}_{\mathrm{wi}}>0$

Figure 31 Adsorption isotherms for two surfactants showing different regions of surfactant adsorption behavior (I - IV). Graph digitized ${ }^{26}$ from Koopal et al. ${ }^{30}$ 
Figure 32 Comparison of Langmuir and Surface Excess models with experimental data. Graph

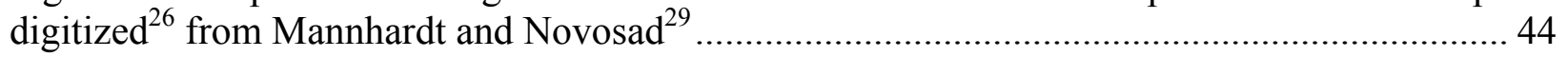

Figure 33 Adsorption of surfactants onto crushed carbonate after 24h .................................... 44

Figure 34 Hyamine 1622 (Benzethonium chloride) ……........................................................... 45

Figure 35 Example titration of anionic surfactant with $0.1 \mathrm{~mol} / 1$ Hyamine 1622 (data digitized ${ }^{39}$

from Radiometer Analytical ${ }^{40}$ ) with derivatives to show inflection point.................................... 45

Figure 36 Adsorption of $1.44 \mathrm{mmol} / \mathrm{l}$ STEOL CS-330 vs. mass of crushed BF and Miami rocks.

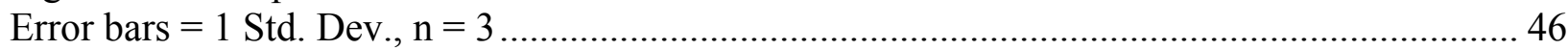

Figure 37 Adsorption of $0.37 \mathrm{mmol} / 1$ surfactin vs. mass of crushed BF and Miami rocks. Error

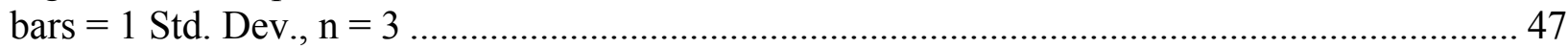

Figure 38 STEOL adsorption isotherms on different masses of crushed BF rock to show decline

in adsorption with increasing rock mass .................................................................................. 47

Figure 39 Residual concentrations versus rock mass for various initial concentrations of STEOL

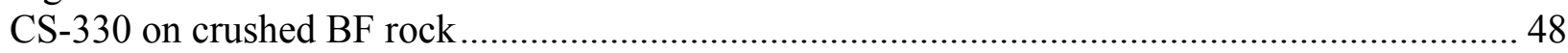

Figure 40 Adsorption isotherms of $30 \mathrm{ml}$ of $420 \mathrm{ppm}$ STEOL CS-330 and surfactin on $2.0 \mathrm{~g}$ of

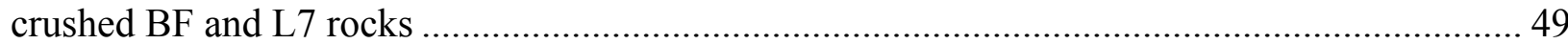

Figure 41 Typical adsorption isotherm of surfactant on rock indicating four regions ${ }^{41} \ldots \ldots \ldots \ldots \ldots . . . .50$

Figure 42 Suggested physical bases for the first three regions seen in a typical adsorption

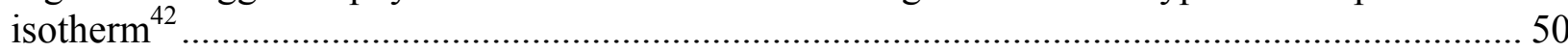

Figure 43 Dynamic absorption of SLS and surfactin on LKC cores (mg/g rock) ....................... 51

Figure 44 Dynamic adsorption of surfactants on LKC rock (mol/g rock).................................. 52

\section{Table of Plates}

Plate 1 Streak plate of contaminated surfactin solution on nutrient agar, cultured at $30{ }^{\circ} \mathrm{C}$.......... 4

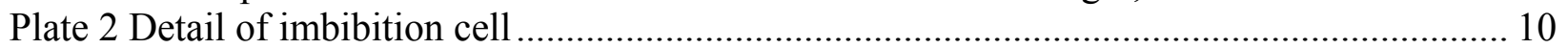

Plate $3 \mathrm{KU}$ personnel collecting outcrop material at Heartland Quarry, KS. (left - right) Stephen Johnson (TORP), Alan Byrnes (KGS), Jenn-Tai Liang (TORP) ……………………………..... 15

Plate 4 Core material: Bethany Falls outcrop (1), Miami outcrop (r)......................................... 15

Plate 5 Core material: Heartland Quarry/LKC outcrop (1), Luerman \#7 LKC reservoir (r)......... 16

Plate 6 Core material: Joulters Cay oolitic outcrop wrapped in PTFE tape ………….................. 16

Plate 7 Effluents from cleaning L7_02. Solvents are tetrahydrofuran (THF), chloroform,

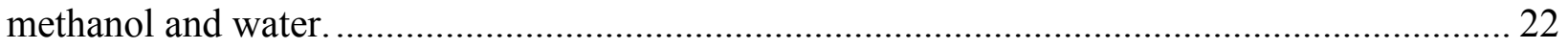

Plate 8 Core covered with Teflon ${ }^{\circledR}$ heat shrink material .......................................................... 22

Plate 9 Effluent from core BF02 dodecane flood. Time increases from left to right. The lower image shows the same samples $\sim 5 \mathrm{~s}$ after shaking to show the persistent foam associated with greater discoloration. The samples also exhibited appreciable UV absorbance (Figure 16) ........ 23 Plate 10 Crushed Miami oolite in RO water/Soltrol: (a) clean, (b) \& (c) with no initial water saturation after $2 \& 4$ weeks under crude oil at $65^{\circ} \mathrm{C}$ to show rapid change to oil wet state, (d) \& (e) with initial water saturation after $2 \& 4$ weeks under crude oil at $65^{\circ} \mathrm{C}$ to show slower

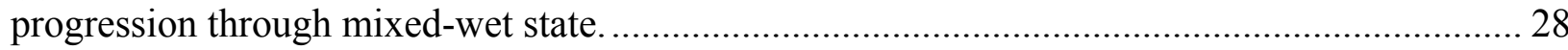
Plate 11 Two-phase (Soltrol 130/water) separation tests showing the effectiveness of surfactants in altering the wettability of crude oil-aged BF rock exposed to surfactant solutions for $24 \mathrm{~h}$ (left: No surfactant; center: STEOL CS-330; right: surfactin) …………………………......... 29 Plate 12 Water flotation tests showing the effectiveness of surfactants in altering the of crude oilaged BF rock exposed to surfactant solutions for $24 \mathrm{~h}$ (left: No surfactant; center: STEOL CS330; right: surfactin) 29 


\section{List of Tables}

Table 1 Properties of candidate benchmark surfactants ........................................................ 6

Table 2 Composition of oil at atmospheric pressure ............................................................. 12

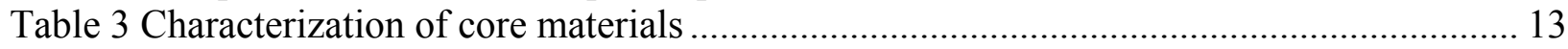

Table 4 L7 Core Characterization...................................................................................... 24

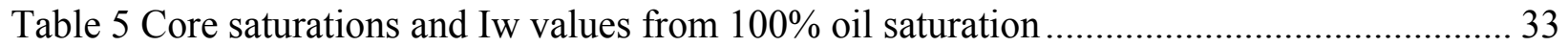

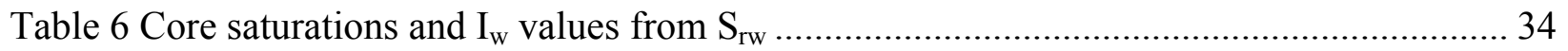

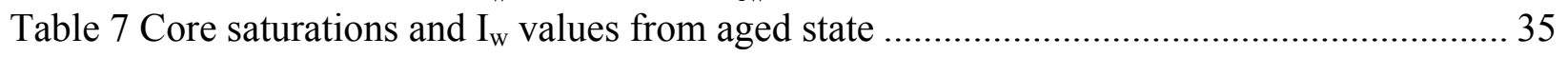

Table 8 Core saturations and $\mathrm{I}_{\mathrm{w}}$ values from aged state with STEOL CS-330 ......................... 36

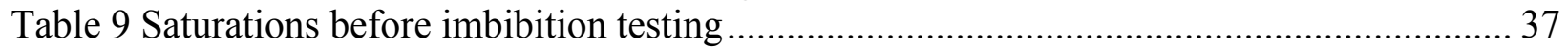

Table 10 Core saturations and $I_{w}$ values from aged state with surfactin ................................ 37 


\section{Acknowledgements}

We gratefully acknowledge the financial support from the United States Department of Energy (National Energy Technology Laboratory/Strategic Center for Natural Gas and Oil) and the State of Kansas. We also greatly appreciate those individuals who contribute to this project. Dr. Stephen Johnson played the major role in putting this report together and was also the main contributor for the work described in Section 1.3 and Chapter 2. Mr. Greg Bala and Ms. Sandy Fox of the Idaho National Laboratory were responsible for the work performed in Sections 1.1 and 1.2. Mr. Bala also contributed to the work described in Section 1.3. Mr. Mehdi Salehi and Mr. Karl Eisert, TORP graduate students, contributed to the core characterization and performed the core cleaning, wettability, adsorption and IFT measurements. Mr. James Pilch, TORP laboratory manager, carried out the TOC analysis. Dr. James Howard and Mr. David Zornes of ConocoPhillips, Bartlesville, OK provided MRI/NMR of cores. We would also like to thank Mr. Scott Ramskill at TORP for his invaluable contribution in fabricating parts and assembling the experimental stations. 


\section{Executive Summary}

This is the final technical report from the joint University of Kansas (KU)/ Idaho National Laboratory (INL) project performed under DOE contract number DE-FC26-04NT15523. The original 36-month project cycle was reduced to 30 months following DOE budget cuts. As a result, the scope of work was slightly reduced. Specifically, the original Task 3, which was to have been an economic analysis of the use of biosurfactant in enhanced oil recovery, was omitted, and Task 2 was curtailed slightly.

The objective of this project was to evaluate the use of low-cost biosurfactants produced from agriculture process waste streams to improve oil recovery in fractured carbonate reservoirs. Specifically, this project will examine the ability of the biosurfactants to mediate wettability changes that positively affect oil recovery in fractured carbonate rock by accelerating the spontaneous imbibition process during water flooding.

In the research proposal, we hypothesized that dilute solutions of biosurfactants produced from high-starch agriculture process waste streams (e.g., potato, corn or rice process effluents) can compete favorably both in performance and process economics with dilute chemical surfactants in mediating changes in wettability that positively impact oil recovery in fractured carbonate reservoirs. To test our hypothesis, we are evaluating the performance of the biosurfactants using the key variables that affect process economics. These key variables include incremental oil recovery, surfactant loss due to adsorption and retention, surfactant cost, and surfactant injection cost. A commercial chemical surfactant was selected as the benchmark for performance and process economics comparisons.

\section{Task 1: Produce, Screen, and Characterize Biosurfactants Produced from Agriculture Process Effluents}

Surfactin is an anionic, amphiphilic, lipopeptide compound. Prior work at the INL has characterized culture supernatants (from organisms grown on agricultural process residuals) under various environmental parameters to better define appropriate conditions for its use as an agent for enhanced oil recovery. In these studies, experiments were performed to examine the compatibility of the biosurfactants with the Lansing-Kansas City (LKC) brine. The impacts of $\mathrm{Na}^{+}, \mathrm{Ca}^{++}$, and $\mathrm{Mg}^{++}$contents on the solubility of the biosurfactants in the LKC brine have been quantified. INL provided lyophilized surfactin as required, as well as performing diagnostic work on microbial contaminants seen in surfactin solutions used at KU.

Candidates for benchmark chemical surfactants were evaluated to identify the one with the most desirable characteristics. The performance of the crude surfactin preparation in reducing IFT was greater than any of the synthetic compounds throughout the concentration range studied, however at low concentrations, sodium laureth sulfate (SLS) was closest in performance to the surfactin, and was used as the benchmark in the remainder of the work. 


\section{Task 2: Evaluate the Biosurfactants for Improved Oil Recovery in Fractured Carbonate Reservoirs}

In Task 2, the KU team evaluated the ability of the biosurfactants produced from agriculture process effluents (Task 1) to mediate wettability change that accelerates the spontaneous imbibition process. Experimental conditions reflected reservoir properties of the LansingKansas City (LKC) formation in central Kansas. The LKC formation is a fractured carbonate reservoir exhibiting intermediate wettability. Field and outcrop cores of the LKC and related formations have been obtained through the help of the Kansas Geological Survey (KGS).

Imbibition cells and several Hassler type core flood setups were constructed. They were tested and used to obtain porosity and permeability measurements of a variety of core materials. These data were compared to published values to confirm that they were representative of the range seen in LKC reservoirs. Cores were saturated with water and sent for nuclear magnetic resonance imaging by ConocoPhillips in Bartlesville, OK. Cores and crushed rock material were cleaned and their wettability assessed using a rapid two-phase separation techniques and Amott testing. Crushed material and intact cores were made more oil-wet by aging at elevated temperatures in crude oil and wettability has been assessed.

Propagation of surfactant through the reservoir is very important in EOR processes. Several factors can reduce the rate of propagation, including partitioning into immobile phases, precipitation and adsorption. Adsorption is probably the most important mechanism affecting retention. In this study, we first reviewed the literature to survey the adsorption models that have been developed to describe surfactant adsorption in porous media. To reliably quantify both benchmark surfactants and surfactin, a surfactant ion-selective electrode was used as an indicator in the potentiometric titration of the anionic surfactants with Hyamine 1622. The effect of wettability change on improved oil recovery and the surfactant loss due to retention and adsorption on reservoir rock was studied.

Fresh LKC reservoir material is mixed- to oil-wet. Methods were developed to control the wettability by a combination of cleaning and aging with crude oil. It was found that on a molar basis, surfactin is more effective than STEOL CS-330 in altering wettability of crushed LansingKansas City carbonates from oil-wet to water-wet state. Adsorption isotherms of STEOL CS-330 and surfactin on crushed Lansing-Kansas City outcrop and reservoir material show that surfactin has higher specific adsorption on these oomoldic carbonates. On a molar basis, the ultimate adsorption of surfactin is slightly lower than SLS, but surfactin-rock interaction is more pronounced at low concentrations. 


\section{Introduction}

Conventional surfactant flooding relies on the ability of the injected high-concentration surfactants to create ultra-low interfacial tension (IFT) between oil and water, thereby mobilizing the stranded oil. ${ }^{1 ; 2}$ Unfortunately, with the high cost of injecting high-concentration chemical surfactants, the economics of surfactant injection have rarely been favorable in actual field applications. To improve process economics, injection of dilute surfactant solutions has been considered. $^{3-5}$ The intent is to not achieve ultra-low IFT and thus to recover only part of the stranded oil. Several studies revealed that the injection of dilute surfactants into oil reservoirs could also modify the wettability of the reservoir rock. ${ }^{6-13}$ This phenomenon can be very useful in fractured carbonate reservoirs where the wettability change can improve oil recovery by accelerating the spontaneous imbibition process. ${ }^{14 ; 15}$

The overall objective of this project is to evaluate the use of low-cost biosurfactants produced from agriculture process waste streams to improve oil recovery in fractured carbonate reservoirs. Specifically, we examined the ability of the biosurfactants to mediate wettability changes that positively affects oil recovery in fractured carbonate rock by accelerating the spontaneous imbibition process during water flooding. Experimental conditions reflected reservoir properties of the Lansing-Kansas City (LKC) formation in central Kansas. The LKC formation is a fractured carbonate reservoir exhibiting intermediate wettability.

The hypothesis is that dilute solutions of biosurfactants from high-starch agricultural waste streams such as potato and rice process effluents can compare favorably with dilute chemical surfactants in terms of performance and process economics. Key variables to test this hypothesis include incremental oil recovery, surfactant loss due to adsorption and retention on reservoir rocks, surfactant cost and surfactant injection cost.

The economic feasibility of this process, like many other EOR applications, is determined by the improved oil recovery and the degree of retention of injected chemicals in the reservoir. In this work, dilute solutions of surfactin produced by bacteria grown on high-starch liquid media were assessed for their effectiveness in mediating the wettability change of carbonate rocks, and compared to similar molar concentrations of a benchmark chemical surfactant. Adsorption of surfactants considered for EOR applications has been studied extensively. ${ }^{16-21}$ Surfactant retention was evaluated by comparing the adsorption isotherm of surfactin with that of the benchmark chemical surfactant. 


\section{Experimental Work}

\section{Produce, Screen and Characterize Biosurfactants Produced from Agriculture Process Effluents (INL/TORP)}

\subsection{Production of Biological Surfactants}

Previous work at INL indicates there is no difference in the type or quality of surfactant (surfactin, Figure 1) produced by Bacillus subtilis 21332 from agricultural process effluents or chemically pure media. However, additional components found in process effluents may have an impact on experimental outcome. Therefore, the surfactin produced for initial experimentation was produced from defined microbiological growth media to constrain variables.

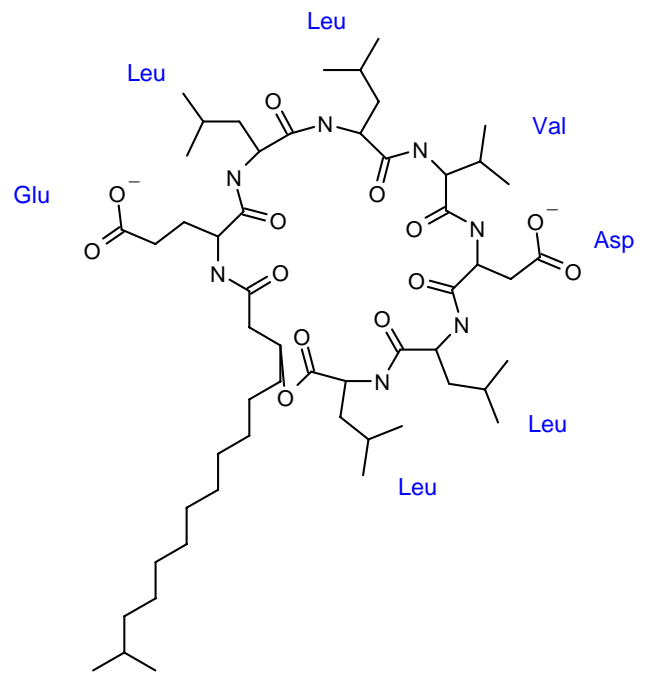

Figure 1 Surfactin

\subsection{Screening and Characterization of Biological Surfactants}

Surfactin is an anionic, amphiphilic, lipopeptide compound with a molecular weight (MW) of approximately $1047 \mathrm{~g} / \mathrm{mol}$. These properties are the reason for its ability to lower surface tension so effectively. ${ }^{22 ; 23}$ Surfactin is also an effective antimicrobial and antiviral agent, able to induce formation of ionic pores in phospholipid bilayers, ${ }^{24}$ and transport cations across membranes. ${ }^{25}$ Its cation-complexing property, due to two negative charges on the aspartyl and glutamyl residues, is probably fully utilized in systems containing ubiquitous amounts of $\mathrm{Ca}^{++}$and $\mathrm{Na}^{+}$ions.

Critical micelle concentrations (CMC) at $25{ }^{\circ} \mathrm{C}$ reported in the literature are $7.5 \mu \mathrm{mol} / 1,{ }^{26} 9.4$ $\mu \mathrm{mol} / \mathrm{L},{ }^{27}$ and $0.025 \mathrm{~g} / 1(24.1 \mu \mathrm{mol} / 1){ }^{28}$ Surface tensions of crude surfactin extract measured using an inverted pendant drop apparatus at INL, and with a ring tensiometer at TORP are shown in Figure 2.

Surfactin CMCs measured at INL are in the range 140-450 ppm depending on the medium, with a value of $0.23 \mathrm{~g} / \mathrm{L}(221 \mu \mathrm{mol} / \mathrm{L})$ in the mineral salts medium and $0.16 \mathrm{~g} / \mathrm{L}(154 \mu \mathrm{mol} / \mathrm{L})$ in a 
portion of crude surfactant from a simulated potato medium purified with methylene chloride. This increase in CMC in the presence of dissolved material, as well as at the elevated temperature found in the reservoir, was taken into account when designing the experiments in Task 2.

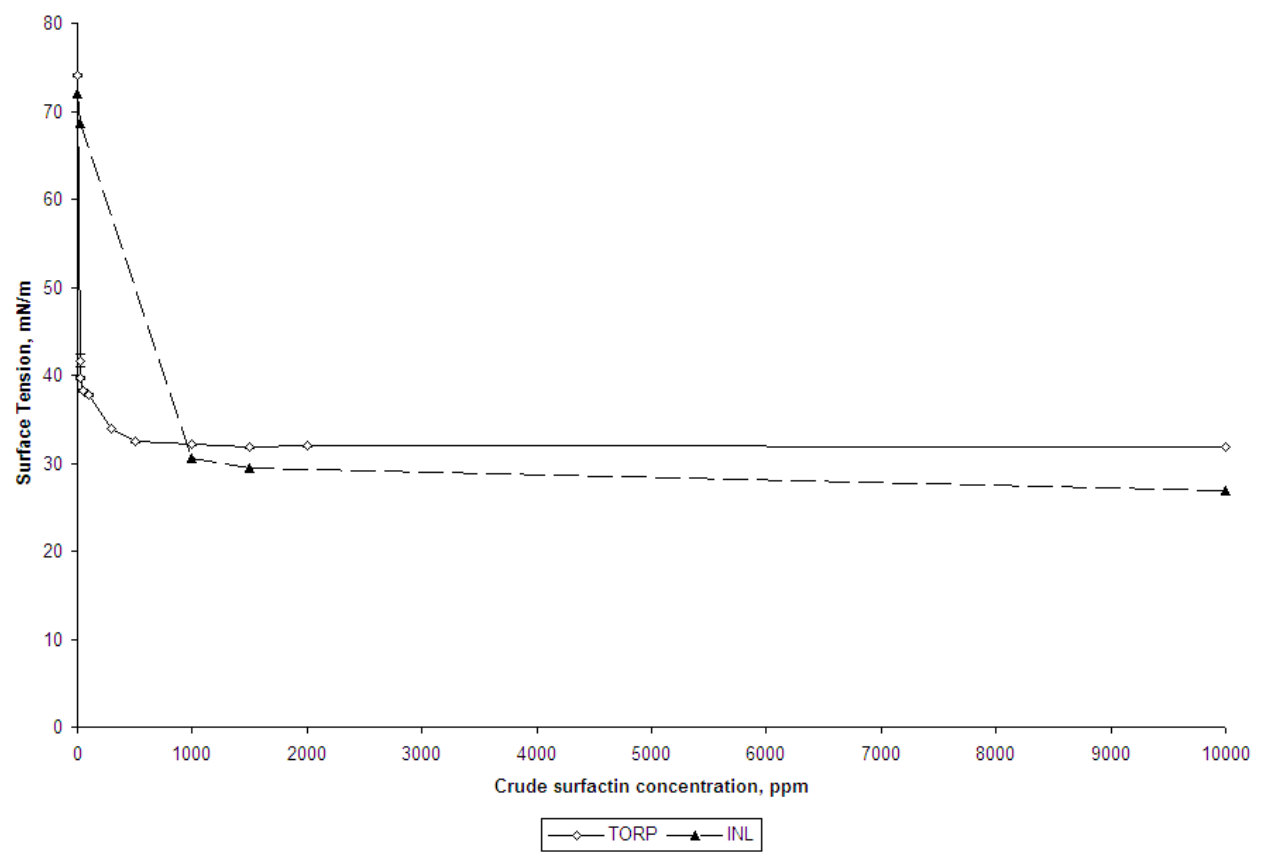

Figure 2 Surface tension of crude surfactin at different concentrations, measured using a hanging drop technique (INL) or ring tensiometer (TORP). Error bars on TORP data = 1 Std. Dev., $n=3$

\section{Loss of surfactin activity: Microbial degradation of surfactin?}

After several weeks of use, microbial growth was observed in solutions of surfactin used for wettability and adsorption studies at KU. In addition, the activity of the surfactin by potentiometric titration and by IFT measurements was reduced in the contaminated solution. Samples were sent to INL where they were streaked onto nutrient agar (NA) and cultured at 25 and $30^{\circ} \mathrm{C}$. Organisms other than Bacillus subtilis appeared to be present based on colony morphology (Plate 1).

It was not possible to positively identify the organisms by visual inspection of the colonies alone, and the culture experiments required to do so lie outside the scope and budget of the present project. However, the morphologies of the colonies are consistent with organisms associated with humans: Micrococcus luteus forms yellow colonies on NA and is found on the skin; Escherischia coli is a common gut organism and forms off-white colonies; Staphylococcus aureus (orange) and Staphylococcus epidermidis (small, white colonies) are found on the nasal membranes and skin, respectively. Whatever the contaminating organisms are, they were almost certainly introduced during use at KU since preparation at INL was done under aseptic conditions and in any case, the growth was not seen until after several weeks of use, and then not in all the solutions made from the original lyophilized material. 
Surfactin is known to have antimicrobial properties but the minimum inhibitory concentration (MIC) is $15-20 \mu \mathrm{mol} / \mathrm{ml},{ }^{26}$ which is rather higher than the concentration used in this work and so it is necessary to avoid microbial contamination during use. This is unlikely to be an issue in field application due to low nutrient and oxygen levels in the reservoir but antimicrobial agents may be required if surfactin is stored in solution for a period before injection.

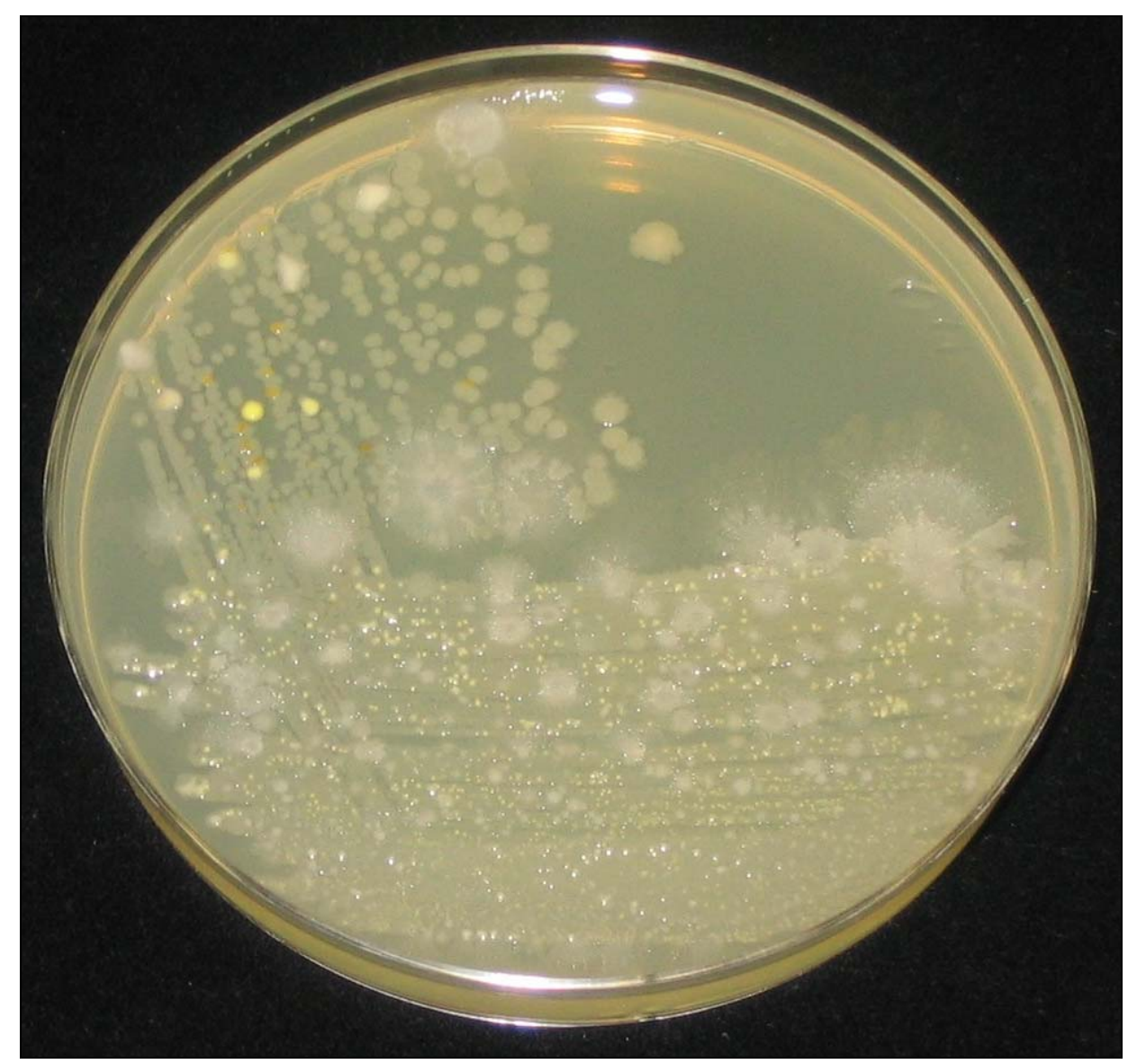

Plate 1 Streak plate of contaminated surfactin solution on nutrient agar, cultured at $30^{\circ} \mathrm{C}$

\subsection{Screening and Selection of Benchmark Chemical Surfactants}

1. A wide variety of surfactants have been assessed in the literature, both for their ability to reduce interfacial tension between brine and oil to ultra-low levels, and to mediate wettability changes in reservoir rocks.

Bearing in mind that the dominant charged species in the adsorbed hydrocarbon layer on the rock surface is negative $\left(\mathrm{COOH}^{-}\right)$and that of the carbonate rock (calcite) at basic $\mathrm{pH}$ is positive $\left(\mathrm{Ca}^{++}\right)$, three approaches seem to have been tried to alter wettability using surfactants:

a) Cationic surfactants

Standnes \& Austad $^{8}$ found that cationic surfactants changed the wettability of an oil-wet carbonate rock toward a more water-wet state by irreversibly removing adsorbed anionic 
carboxylates from the rock surface, i.e. the interaction is between the organic carboxylates adsorbed on the rock surface and surfactants not surfactants and the rock surface. This has a positive implication on surfactant loss because the electrostatic repulsion between the likecharged surfactant molecules and the rock surface after the wettability change. They also used anionic surfactants - mostly ethoxylated alkyl sulfates - and found that the anionic surfactants were less effective than cationic, probably because the interaction was reversible. The effectiveness of the anionic surfactants was found to increase with degree of ethoxylation.

b) Anionic surfactants plus an alkali

Hirasaki et al. at Rice University, Houston, TX evaluated the use of a range of ethoxylated and propoxylayed alkyl sulfates (anionic surfactants) with sodium carbonate ${ }^{12}$ to enhance oil recovery from fractured oil-wet carbonate rocks. The charge on calcite is positive below $\mathrm{pH} 9$ and negative above $\mathrm{pH}$ 9. The effect of the sodium carbonate is to make the charge negative at lower $\mathrm{pH}$. They found that altering the surface charge causes an electrostatic repulsion between the rock surface (calcite) and the adsorbed layer of anionic carboxylates. Incidentally, the alkali also causes some saponification of naphthenic acids, thus adding to the amount of surfactant in the system.

\section{c) Anionic surfactants alone in a typical injection brine}

Perhaps the most pertinent approach is that of a group at Phillips Petroleum. ${ }^{11}$ They dealt with cores from Kansas and describe an exemplar anionic surfactant, "Surfactant A" as an ammonium salt of ethoxylated and sulfated alcohols (C8-C10 alkyl ethers), injected in North Sea water.

Based on the above, some basic decisions can be made regarding the properties of suitable candidates for the role of benchmark surfactant:

1. Surfactin is an anionic surfactant; it carries two negative charges on the hydrophilic oligipeptide. None of the surfactants in the literature studied to date has a comparable charge density; however, the CMC of surfactin is much lower than synthetic surfactants so the total charge added to the system is not going to be comparable anyway. So long as the charge has the same sign, this should not be an issue.

2. Tail lengths of most of the anionic surfactants studied are comparable to surfactin, though longer tails seem to be more effective.

3. Most anions studied have been ethoxylated alkyl sulfates.

4. All studies have been with synthetic brine or seawater.

Likely candidates include sodium dodecyl sulfate (SDS, MW $=265$ ) as the simplest possible benchmark, or one of the ethoxylated alkyl sulfates such as sodium laureth sulfate (SLS, MW = $381)$. Another possibility is sodium dodecylbenzene sulfonate $(\mathrm{MW}=325)$. Samples of these candidate benchmark synthetic surfactants (Figure 3) were obtained from Stepan Company, Northfield, IL. 
A.

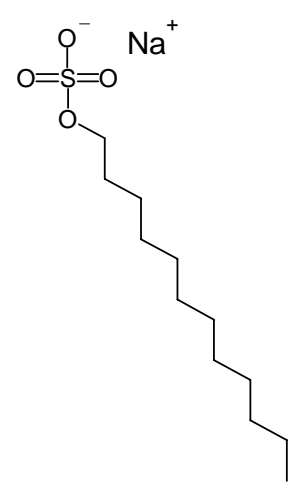

B.

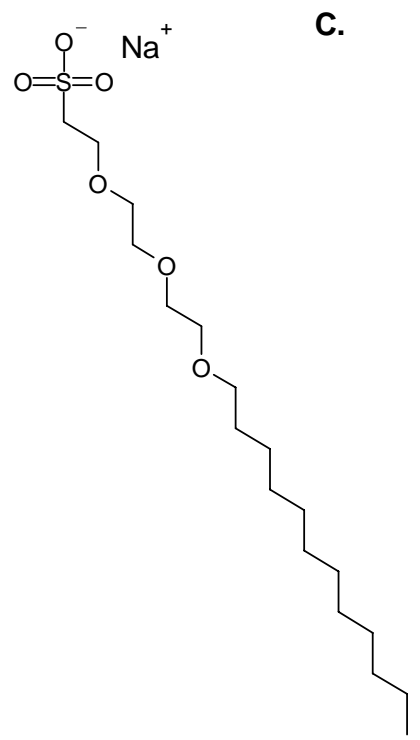

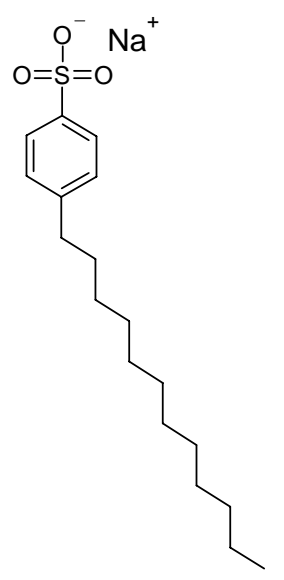

Figure 3 Candidate benchmark synthetic surfactants: A. Sodium dodecyl sulfate (SDS), B. Sodium laureth sulfate (SLS), C. Sodium dodecylbenzene sulfonate

The properties of the stock surfactants are summarized in Table 1.

Table 1 Properties of candidate benchmark surfactants

\begin{tabular}{|c|c|c|c|}
\hline & $\begin{array}{l}\text { STEPANOL WA- } \\
\text { EXTRA }\end{array}$ & STEOL CS-330 & BIO-SOFT D-40 \\
\hline Lot No. & 7106243 & 7071688 & 710385 \\
\hline Synonyms & $\begin{array}{r}\text { Sodium lauryl sulfate, } \\
\text { Sodium dodecyl } \\
\text { sulfate, SDS }\end{array}$ & $\begin{array}{r}\text { Sodium laureth } \\
\text { sulfate, SLS }\end{array}$ & $\begin{array}{r}\text { Sodium } \\
\text { dodecylbenzene } \\
\text { sulfonate }\end{array}$ \\
\hline Appearance @ 25ㄷ & Clear liquid & Clear liquid & $39.71 \%$ solids \\
\hline Appearance @ 30 C & & & Clear liquid \\
\hline $\mathrm{pH}\left(10 \%\right.$ in $\left.\mathrm{H}_{2} \mathrm{O}\right)$ & 7.71 & 8.36 & 7.59 \\
\hline Active component & $28.55 \%$ & $29.14 \%$ & $38.93 \%$ \\
\hline Unsulfated alcohol & $0.38 \%$ & $0.1 \%$ & $0.59 \%$ \\
\hline $\begin{array}{l}\text { Color transmittance } \\
(420 \mathrm{~nm})\end{array}$ & $91 \%$ & $92.5 \%$ & $41 \%$ \\
\hline Viscosity & $90 \mathrm{cp}$ & $73 \mathrm{cp}$ & \\
\hline Cloud point & $10^{\circ} \mathrm{C}$ & $5^{\circ} \mathrm{C}$ & \\
\hline Formaldehyde & $400 \mathrm{ppm}$ & $484 \mathrm{ppm}$ & \\
\hline $\mathrm{CMC}^{29}$ & $\begin{array}{r}8.18 \times 10^{-3} \mathrm{~mol} / \mathrm{L} \\
\left(@ 25^{\circ} \mathrm{C}\right) \\
\end{array}$ & $\begin{array}{r}1.00 \times 10^{-4} \mathrm{~mol} / \mathrm{L} \\
\left(@ 25^{\circ} \mathrm{C}\right)\end{array}$ & $\begin{array}{r}1.19 \times 10^{-3} \mathrm{~mol} / \mathrm{L} \\
\left(@ 75^{\circ} \mathrm{C}\right)\end{array}$ \\
\hline
\end{tabular}




\section{Surface tension/IFT of surfactants}

Interfacial tension of a range of surfactants with Soltrol 130 was determined using a ring tensiometer (Fisher Model 20, platinum-iridium wire ring with a circumference of $6 \mathrm{~cm}$ ). The instrument was calibrated according to the manufacturer's instructions ${ }^{30}$ and apparent surface tension, $\mathrm{P}$, was measured for a range of concentrations of several surfactants. These values were converted to true surface tension, $\mathrm{S}$, according to the formula:

$$
S=P \times F
$$

where $\mathrm{F}$ is a correction factor calculated as:

$$
F=0.725+\sqrt{\frac{0.01452 P}{C^{2} \times(D-d)}+0.04534-\frac{1.679 r}{R}}
$$

and

$\mathrm{P}=$ dial reading for apparent surface tension, dyne $/ \mathrm{cm}$

$\mathrm{C}=$ circumference of the ring, $\mathrm{cm}$

$\mathrm{r}=$ radius of the wire, $\mathrm{cm}$

$\mathrm{R}=$ radius of the ring, $\mathrm{cm}$

$\mathrm{D}=$ density of the lower phase, $\mathrm{g} / \mathrm{ml}$

$\mathrm{d}=$ density of the upper phase, $\mathrm{g} / \mathrm{ml}$

The variation of IFT with concentration of surfactants is shown in Figure 4.

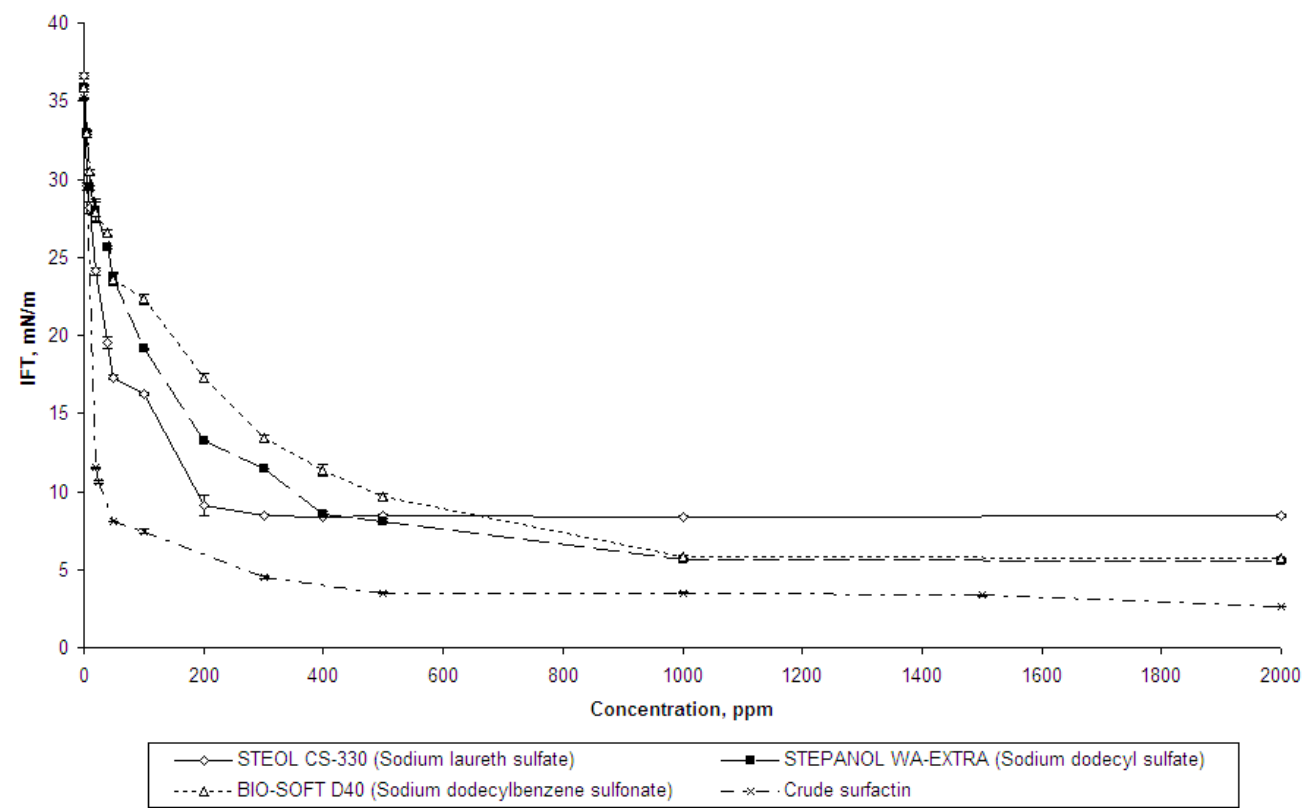

Figure 4 Interfacial tension between surfactant solutions and Soltrol 130. Error bars = 1 Std. Dev., $n=3$ 
It is clear from Figure 4 that, weight for weight, the crude surfactin has a greater effect on interfacial tension than do any of the potential benchmark surfactants. In fact, the magnitude of the difference between the crude surfactin and the synthetic surfactants is minimized when concentration is expressed in ppm. The molecular weight of surfactin is 2.7 times that of SLS, and 3.9 times that of SDS and so on a molar basis, surfactin appears to be between three and four times as effective as commonly used synthetic compounds - and this does not take into account the fact that the crude extract contains other components that do not contribute to the interfacial tension reduction. If this behavior equates to better performance in wettability alteration, then there will be obvious implications for process economics.

The full extent of the difference between surfactin and the synthetic surfactants will become clearer when the amount of surfactin in the crude extract is determined (see Section 2.2). The goal of this project is to investigate the ability of the surfactants to mediate wettability change at low concentrations; SLS has a greater effect on interfacial tension at low concentrations than the other two potential benchmark surfactants, even though it ultimately does not reach as low an IFT at higher concentrations. SLS is therefore the preferred benchmark candidate. The greater effect of surfactin might be due to the greater degree of hydrophilicity conferred by the two charges on the oligopeptide "head". 


\section{Evaluate the Biosurfactants for Improved Oil Recovery in Fractured Carbonate Reservoirs (TORP/INL)}

The objective of Task 2 was to evaluate the effectiveness of using biosurfactants produced from agriculture process waste streams (Task 1) to mediate favorable wettability change that positively impacts oil recovery in fractured carbonate reservoirs.

In fractured carbonate reservoirs, capillary forces and wettability of the reservoir rock control the amount of oil that can be recovered by waterflooding. ${ }^{25 ; 31}$ Several researchers reported that dilute solutions of chemical surfactants can alter the wettability of carbonate rock toward a more waterwet state. ${ }^{6-13}$ This wettability change can improve oil recovery in fractured carbonate reservoirs by accelerating the spontaneous imbibition process during water flooding. They also reported that surfactant loss due to adsorption and/or retention on reservoir rock can be significant even at dilute surfactant concentrations. Task 2 evaluates the ability of the biosurfactants produced from agriculture process effluents to mediate wettability change that accelerates the spontaneous imbibition process. Spontaneous and forced imbibition tests were performed to measure the incremental oil recovery at different dilute surfactant concentrations using reservoir and outcrop core plugs obtained from the LKC formation. To characterize adsorption behavior, bench-top and core experiments were performed to measure adsorption and retention of surfactants under reservoir conditions. Parallel experiments were conducted using the chemical surfactant, STEOL CS-330, selected in Task 1 to establish benchmarks for performance comparisons. Experimental conditions reflected reservoir properties of the Lansing-Kansas City formation in central Kansas. This is a fractured carbonate rock exhibiting intermediate wettability.

\subsection{Effects of Wettability Change on Incremental Oil Recovery}

Field and outcrop cores of the LKC formation (Figure 8) were obtained through the help of the Kansas Geological Survey (KGS). Imbibition cells and a Hassler type core flood setup were constructed and used to investigate the effects of wettability change on improved oil recovery and the surfactant loss due to retention and adsorption on reservoir rock.

Wettability of the core samples was assessed using the Amott Wettability Index. ${ }^{22}$ To measure the Amott Wettability Index, the core is first saturated with oil and then be immersed in brine in an imbibition cell. The volume of oil displaced by spontaneous imbibition is equal to the volume of brine imbibed and is measured in a graduated tube above the brine.

The core is then placed in a Hassler core holder and the remaining oil displaced by brine under pressure (Figure 5 et seq.). The additional volume of oil displaced is measured and the Amott wettability to water, $I_{w}$ is calculated using Equation 3.

$$
I_{w}=\frac{\Delta S_{w s}}{\left(\Delta S_{w s}+\Delta S_{w f}\right)},
$$


where $\Delta \mathrm{S}_{\mathrm{ws}}=$ change in water saturation due to spontaneous imbibition, and $\Delta \mathrm{S}_{\mathrm{wf}}=$ change in water saturation due to forced imbibition.

Apparatus for carrying out these tests was assembled and tested, and includes two complete setups. Standard operating procedures were developed for saturating and flooding cores, as well as carrying out tracer tests. These were adhered to in order to maintain experimental repeatability.

\section{Imbibition Cell}

Imbibition cells (Plate 2) were constructed by the KU glass blower and consisted of a tubular glass base into which the core was placed. The top was mated to the base via a ground glass joint lubricated with inert grease. The top incorporated a burette to allow the produced oil to be quantified. A magnetic stirrer bar under the core, and a bent wire inserted through the burette allowed for oil drops adhering to the core surface to be dislodged periodically. The cell was assembled and then filled with degassed water and produced oil was monitored at intervals.

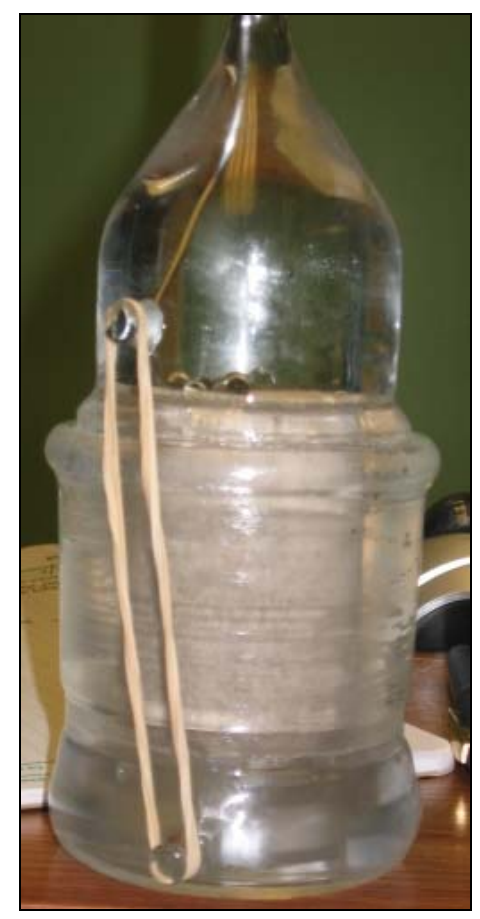

Plate 2 Detail of imbibition cell

\section{Core Flooding Apparatus}

The apparatus consists of a Hassler type core holder, Honeywell differential pressure transducer, Isco model 500D syringe pump, two transfer cylinders (TCs) and associated stainless steel tubing and valves (Figure 5 et seq.). The components are arranged in such a way as to allow the pump to be filled with oil, the first TC with brine or water and the second TC with oil. By controlling the flow path the core may be flooded with either oil or brine, with the pump providing the motive force. The pump should never come into contact with water or brine and thus the possibility of corrosion in the pump is much reduced. Alternate layouts may be used to carry out tracer tests using water (Figure 12) or oil (Figure 13.) 


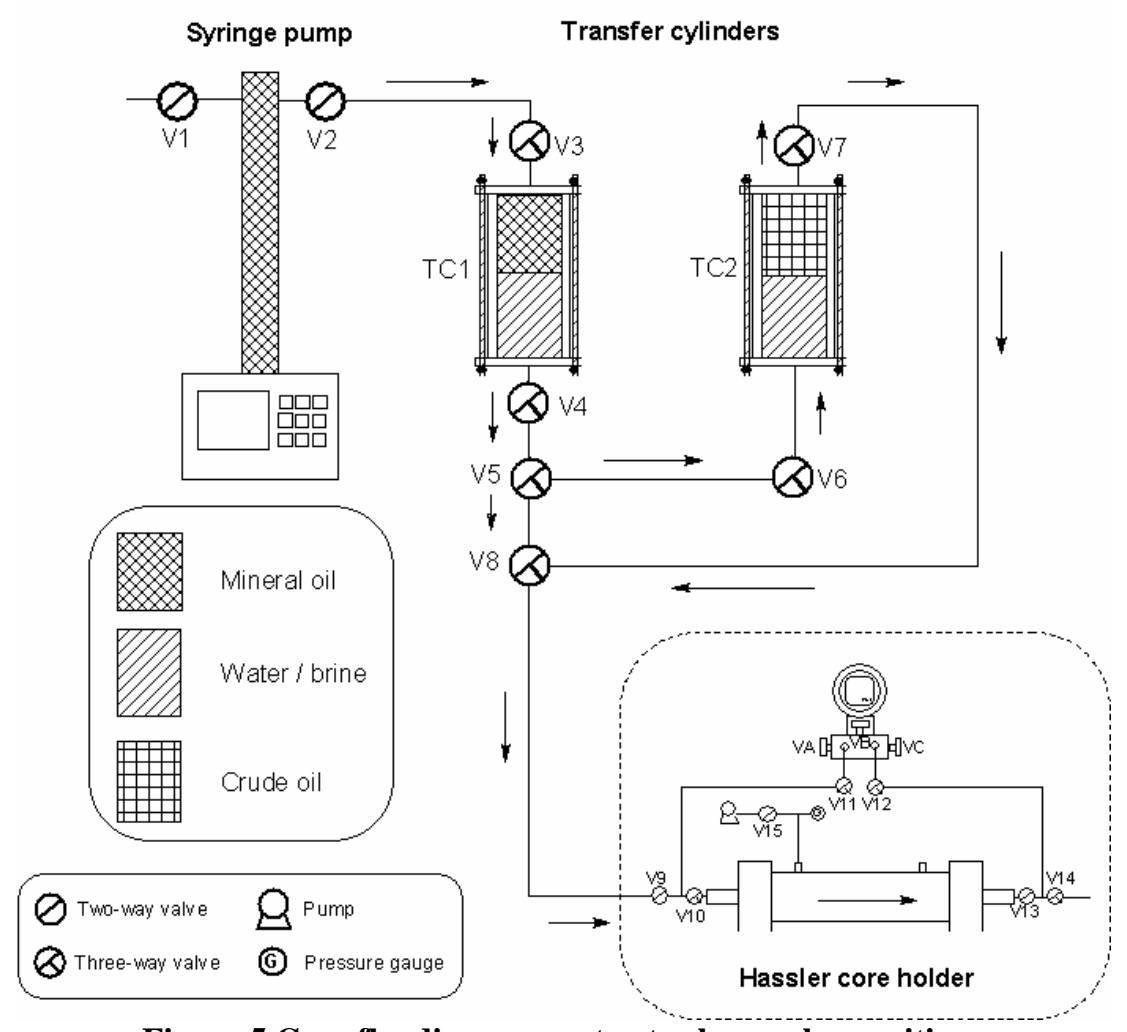

Figure 5 Core flooding apparatus to show valve positions

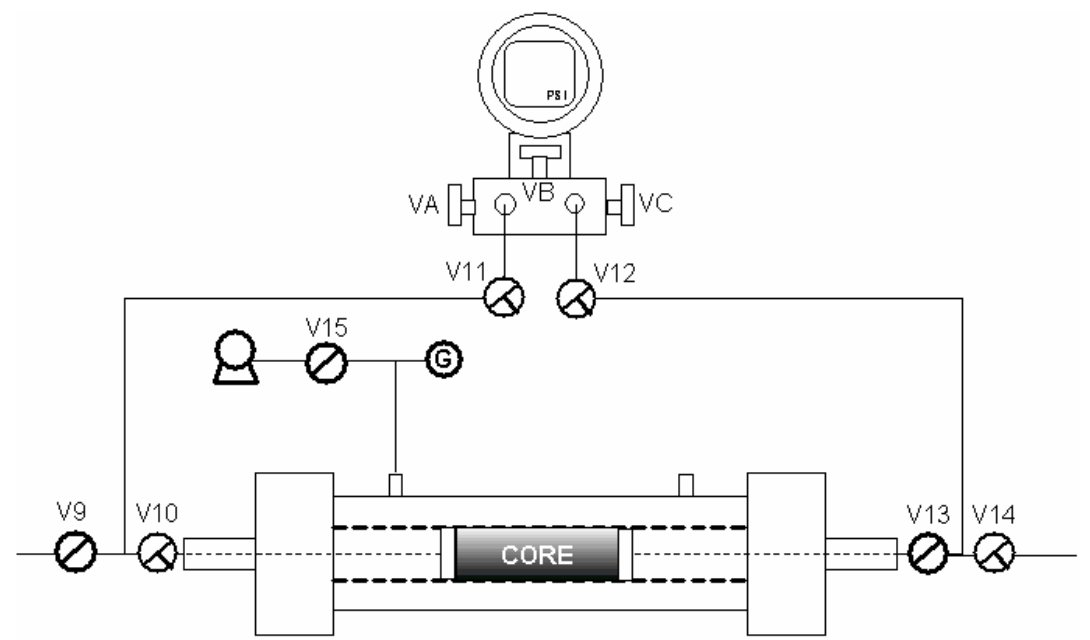
$\oslash$ Two-way valve
9 Pump
Q Three-way valve
(G) Pressure gauge

Figure 6 Detail of Hassler type core holder showing valve positions 


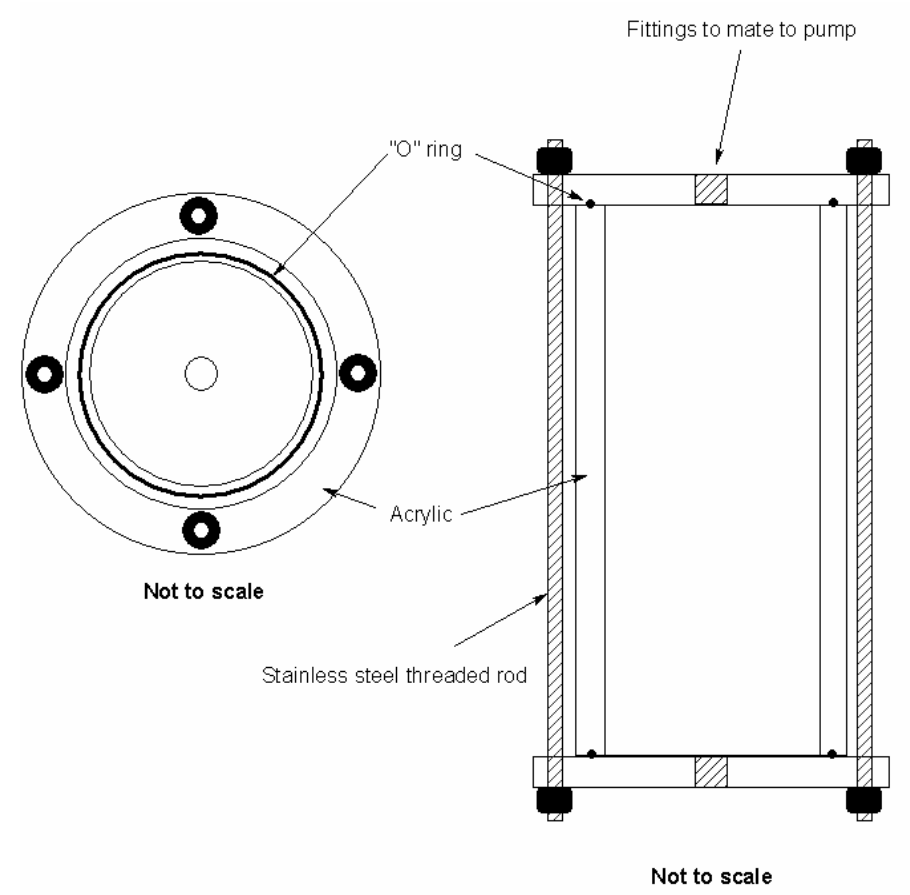

Figure 7 Detail of transfer cylinder

\section{Crude Oil Characterization}

A crude oil sample was obtained from the Lansing - Kansas City field C Zone at $\sim 880 \mathrm{~m}$ ( $\sim 2900$ $\mathrm{ft}$ ). The oil was used to restore the wettability of the field cores to their original wetting state, and modify the wettability of the outcrop cores by aging the core plugs in the stabilized crude oil at elevated temperatures. ${ }^{22}$ Crude oil from the same field had previously been characterized by TORP staff (Table 2).

Table 2 Composition of oil at atmospheric pressure

\begin{tabular}{|lrrrrrrr|}
\hline Component & SCN & Mole $\%$ & Weight \% & $\begin{array}{l}\text { Density, } \\
\text { (g/cm3) }\end{array}$ & MW & $\begin{array}{c}\text { Volume } \\
\%\end{array}$ \\
\hline$\leq$ iso-Butane & 3 & 0.45 & 0.10 & 0.507 & 44.1 & 0.17 \\
\hline n-Butane & 4 & 3.95 & 1.16 & 0.584 & 58.1 & 1.64 \\
\hline iso-Pentane & 5 & 1.45 & 0.53 & 0.624 & 72.2 & 0.70 \\
\hline n-Pentane & 5 & 5.13 & 1.87 & 0.631 & 72.2 & 2.45 \\
\hline Hexanes & 6 & 7.14 & 3.03 & 0.685 & 84.0 & 3.65 \\
\hline Heptanes & 7 & 10.81 & 5.24 & 0.722 & 96.0 & 6.00 \\
\hline Octanes & 8 & 11.99 & 6.48 & 0.745 & 107.0 & 7.19 \\
\hline Nonanes & 9 & 8.53 & 5.21 & 0.764 & 121.0 & 5.63 \\
\hline Decanes & 10 & 6.87 & 4.65 & 0.778 & 134.0 & 4.94 \\
\hline Undecanes & 11 & 5.87 & 4.36 & 0.789 & 147.0 & 4.57 \\
\hline Dodecanes & 12 & 4.44 & 3.61 & 0.800 & 161.0 & 3.73 \\
\hline Tridecanes & 13 & 4.57 & 4.04 & 0.811 & 175.0 & 4.11 \\
\hline Tetradecanes & 14 & 3.70 & 3.55 & 0.822 & 190.0 & 3.57 \\
\hline Pentadecanes & 15 & 3.29 & 3.42 & 0.832 & 206.0 & 3.40 \\
\hline Hexadecanes & 16 & 2.68 & 3.00 & 0.839 & 222.0 & 2.96 \\
\hline
\end{tabular}




\begin{tabular}{|llllllr|}
\hline Heptadecanes & 17 & 2.43 & 2.91 & 0.847 & 237.0 & 2.84 \\
\hline Octadecanes & 18 & 2.23 & 2.83 & 0.852 & 251.0 & 2.74 \\
\hline Nonadecanes & 19 & 1.93 & 2.57 & 0.857 & 263.0 & 2.48 \\
\hline Eicosanes & 20 & 1.58 & 2.20 & 0.862 & 275.0 & 2.11 \\
\hline Heneicosanes & 21 & 1.18 & 1.73 & 0.867 & 291.0 & 1.65 \\
\hline Docosanes & 22 & 1.29 & 1.98 & 0.872 & 305.0 & 1.88 \\
\hline Tricosanes & 23 & 1.06 & 1.70 & 0.877 & 318.0 & 1.60 \\
\hline Tetracosanes & 24 & 0.90 & 1.50 & 0.881 & 331.0 & 1.40 \\
\hline Pentacosanes & 25 & 0.76 & 1.32 & 0.885 & 345.0 & 1.23 \\
\hline Hexacosanes & 26 & 0.76 & 1.38 & 0.889 & 359.0 & 1.28 \\
\hline Heptacosanes & 27 & 0.71 & 1.35 & 0.893 & 374.0 & 1.25 \\
\hline Octacosanes & 28 & 0.66 & 1.30 & 0.896 & 388.0 & 1.20 \\
\hline Nonacosanes & 29 & 0.51 & 1.03 & 0.899 & 402.0 & 0.95 \\
\hline$\geq$ Triacontanes & 30 & 3.13 & 25.95 & 0.945 & 1641.6 & 22.69 \\
\hline TOTAL & & $\mathbf{1 0 0}$ & $\mathbf{1 0 0}$ & & & $\mathbf{1 0 0}$ \\
\hline SOT Jyn-Syra & & & & &
\end{tabular}

Source: Jyun-Syung Tsau, TORP

\section{Characterization of Core Materials}

Core materials were obtained from several sources (Table 3). These include high permeability oolitic limestone outcrop from Florida and the Bahamas as well as low-to-medium permeability oomoldic outcrop and reservoir samples from Missouri and Kansas. Cores were provided by Alan Byrnes, Kansas Geological Survey (KGS). Porosity and permeability of the cores are being measured as part of the experimental work.

The core materials exhibit a variety of pore architectures (oolitic vs. oomoldic) and porosity (Figure 9), and as a result, they represent a wide range of permeability. The different pore architectures will have a great influence on the residual oil saturation. Large pores, combined with small pore throats seen in oomoldic material favors trapping of oil. ${ }^{32}$

Table 3 Characterization of core materials

\begin{tabular}{|c|c|c|c|c|c|}
\hline & Miami Outcrop & $\begin{array}{l}\text { Bethany Falls } \\
\text { Outcrop }\end{array}$ & $\begin{array}{l}\text { Heartland } \\
\text { Quarry (LKC) } \\
\text { Outcrop }\end{array}$ & $\begin{array}{l}\text { Joulters } \\
\text { Cay } \\
\text { Outcrop }\end{array}$ & $\begin{array}{l}\text { Luerman \#7 } \\
\text { LKC Reservoir* }\end{array}$ \\
\hline Abbreviation & M_nn & BF_nn & HQ_nn & JC_nn & L7_nn \\
\hline Structure & Oolitic & Oomoldic & Oomoldic & Oolitic & Oomoldic \\
\hline Porosity & $\begin{array}{l}0.31^{\text {(M_01) }} \\
0.42^{\text {(M_02) }}\end{array}$ & $\begin{array}{l}0.21^{\text {(BF_01) }} \\
0.21^{\text {(BF_02) }}\end{array}$ & $\begin{array}{l}0.31^{\text {(HQ_01) }^{\text {(HQ_02) }}} \\
0.22^{\text {He }}\end{array}$ & $0.43^{\left(\mathrm{JC} \_01\right)}$ & $\begin{array}{l}0.26^{\left(\mathrm{L} 7 \_01\right)} \\
0.26^{\left(\mathrm{L} 7 \_02\right)} \\
0.24^{(\mathrm{L} 7003)}\end{array}$ \\
\hline Permeability, md & $\begin{array}{r}5^{\left(\mathrm{M}_{-} 01\right)} \\
320^{\left(\mathrm{M}_{-} 02\right)} \\
100^{\left(\mathrm{MO}_{-} 3\right)}\end{array}$ & $\begin{array}{l}0.7^{\text {(BF_01) }} \\
2.1^{\text {(BF_02) }}\end{array}$ & $\begin{aligned} 43^{\left(\mathrm{HQ} \_01\right)} & 2^{\left(\mathrm{HQ} \_02\right)}\end{aligned}$ & $1100^{\left(\mathrm{JC} \_01\right)}$ & $\begin{array}{l}42.8^{\text {(L7_01) }} \\
15.8^{\left(\mathrm{L} 7 \_02\right)} \\
12.2^{\text {(L7_03) }}\end{array}$ \\
\hline Bulk density, $\mathrm{g} / \mathrm{cm}^{3}$ & 1.43 & 2.09 & $1.84-2.02$ & 2.05 & $2.05-2.09$ \\
\hline Grain density, $\mathrm{g} / \mathrm{cm}^{3}$ & 2.09 & 2.67 & 2.68 & 2.67 & 2.67 \\
\hline
\end{tabular}

*T15S R12W Sec 28, Hall-Gurney Field, Gore Oil Company, Luerman \#7. Total lease has been productive since 1945. Cumulative production to date $=761,381$ BO. Collected $933 \mathrm{~m}$ below ground level. 
The majority of this work was concentrated on the reservoir and corresponding outcrop material of the Lansing-Kansas City formation, which is of major economic importance to the state of Kansas (Figure 8).

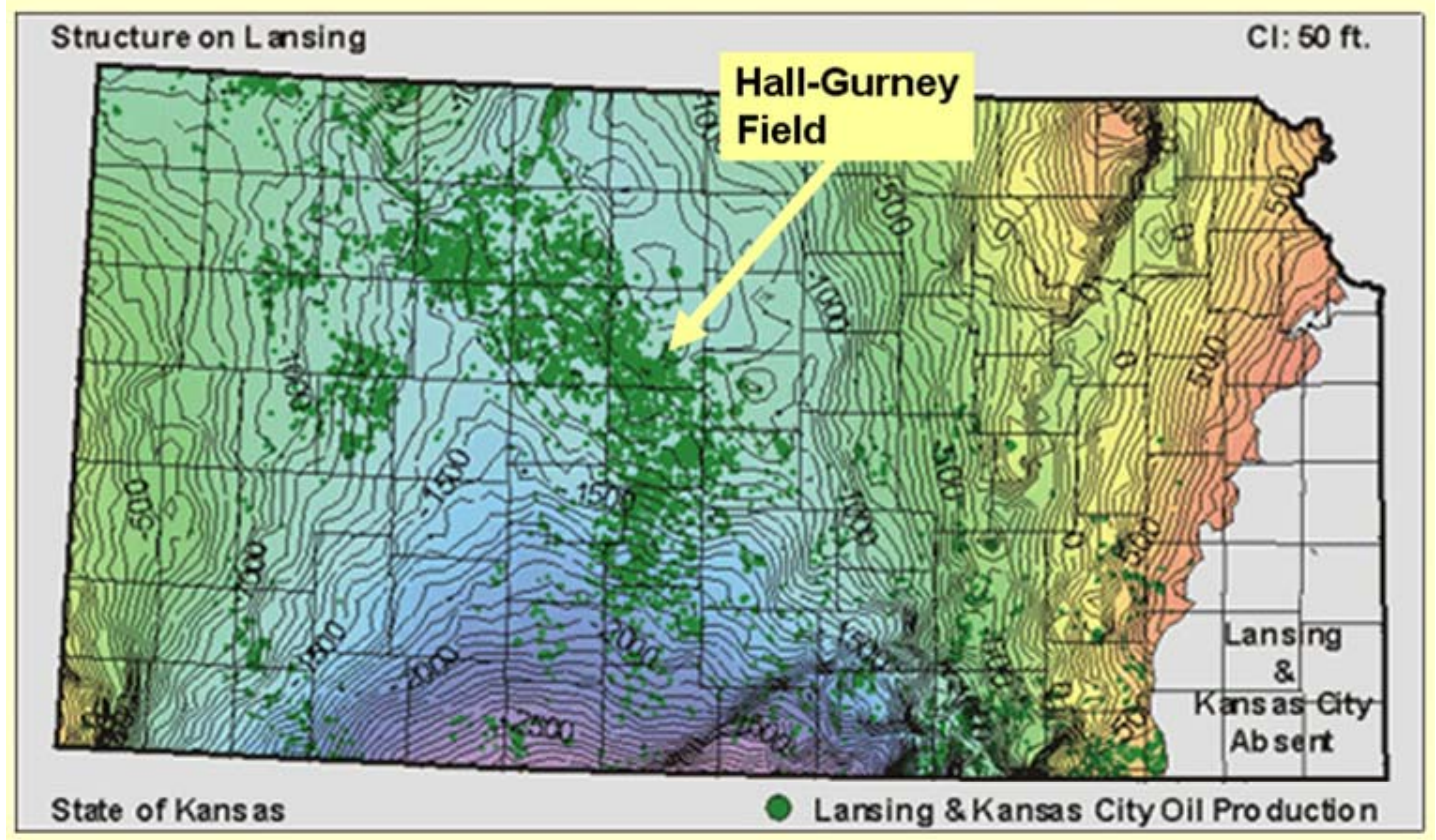

Figure 8 Location of Hall-Gurney Field on map of Lansing-Kansas City oil production in Kansas. ${ }^{33}$
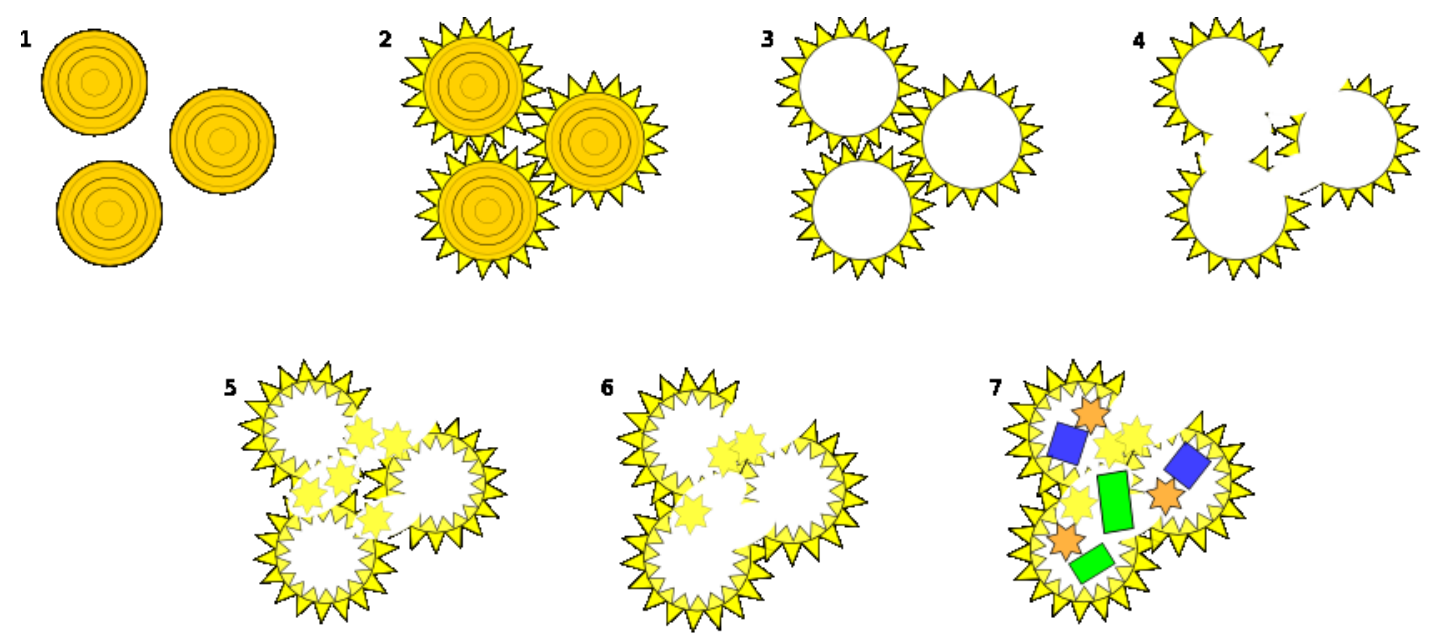

1. Oolluc porosity

2. Calcite crystallizes, occludes porosity

3. Oolds dissolve, unconnected moldic porosity

4. Calcite cement dissolves, porosity becomes connected

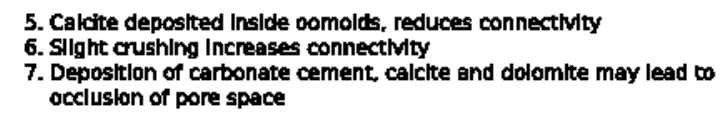

Figure 9 Paragenesis of limestone porosity, after Dubois, Byrnes and Watney (2001) ${ }^{24}$ 


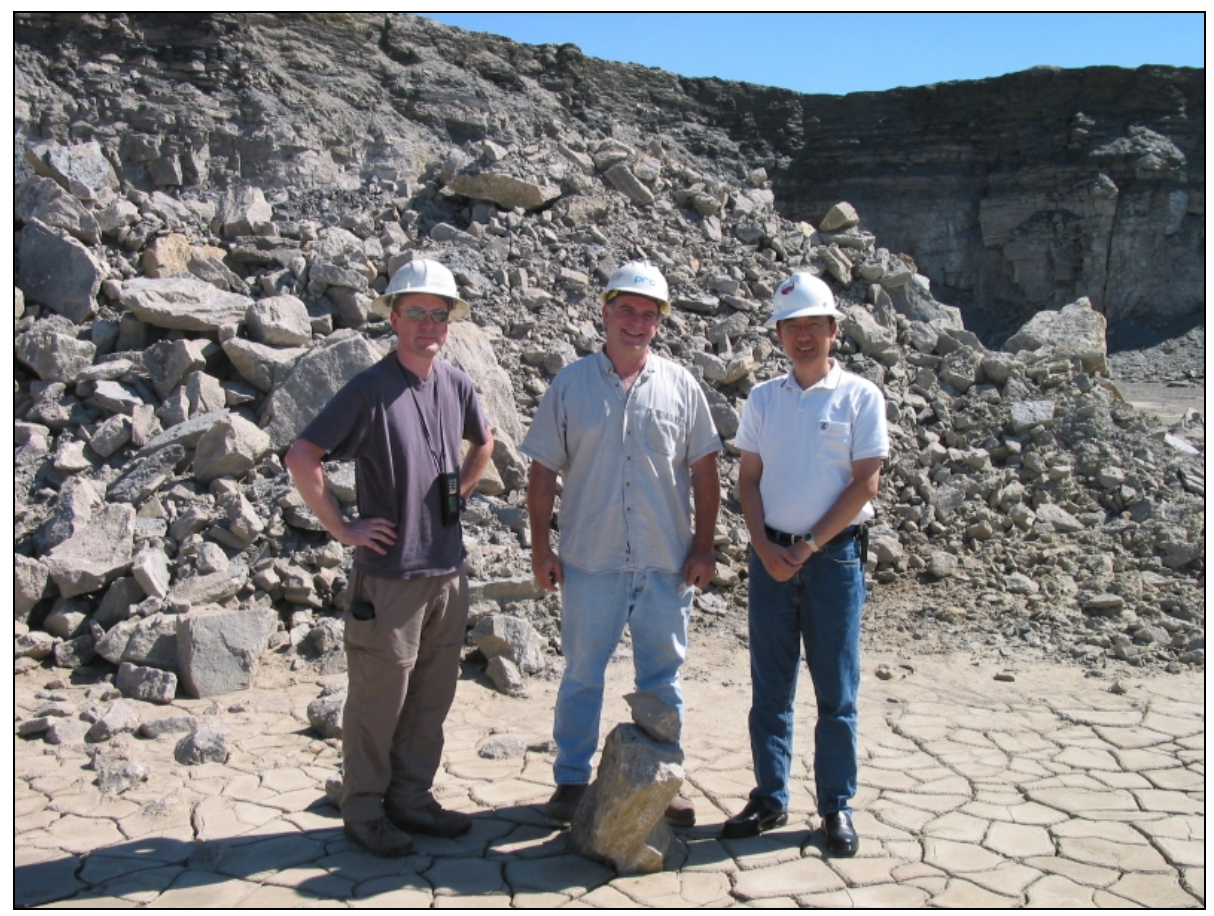

Plate $3 \mathrm{KU}$ personnel collecting outcrop material at Heartland Quarry, KS. (left - right) Stephen Johnson (TORP), Alan Byrnes (KGS), Jenn-Tai Liang (TORP)

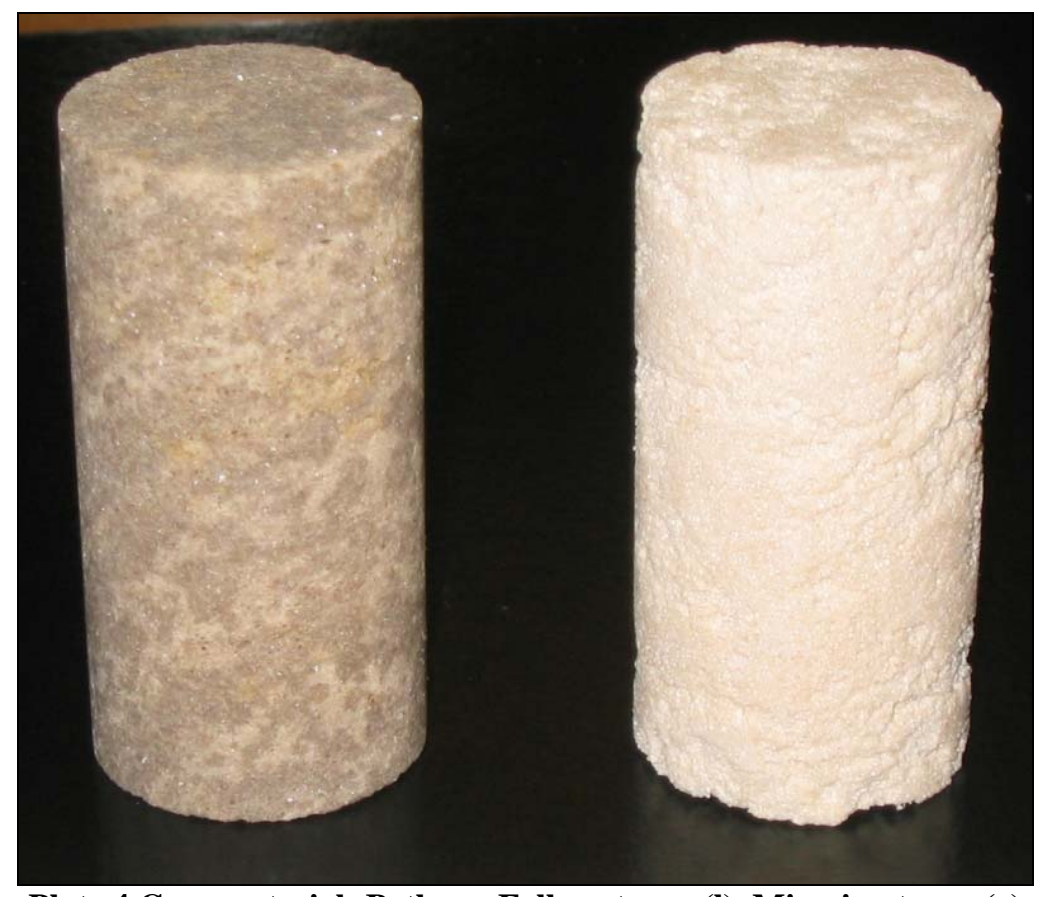

Plate 4 Core material: Bethany Falls outcrop (l), Miami outcrop (r) 


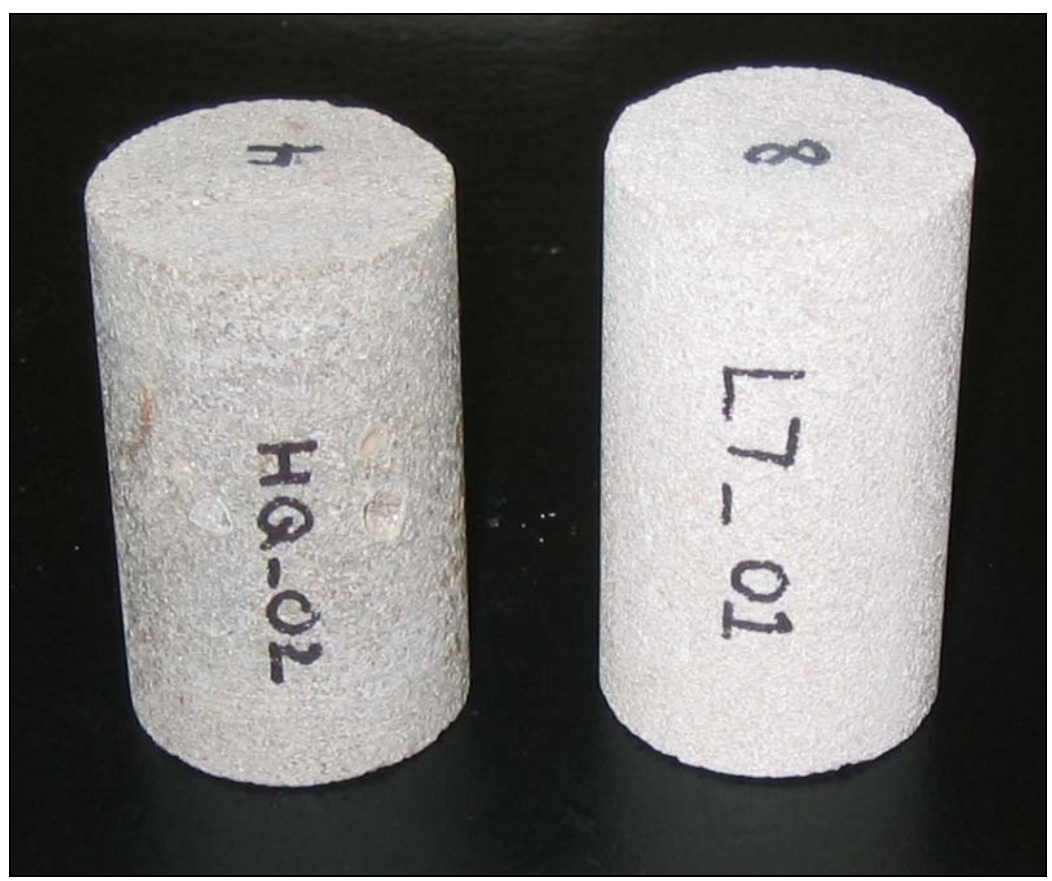

Plate 5 Core material: Heartland Quarry/LKC outcrop (l), Luerman \#7 LKC reservoir (r)

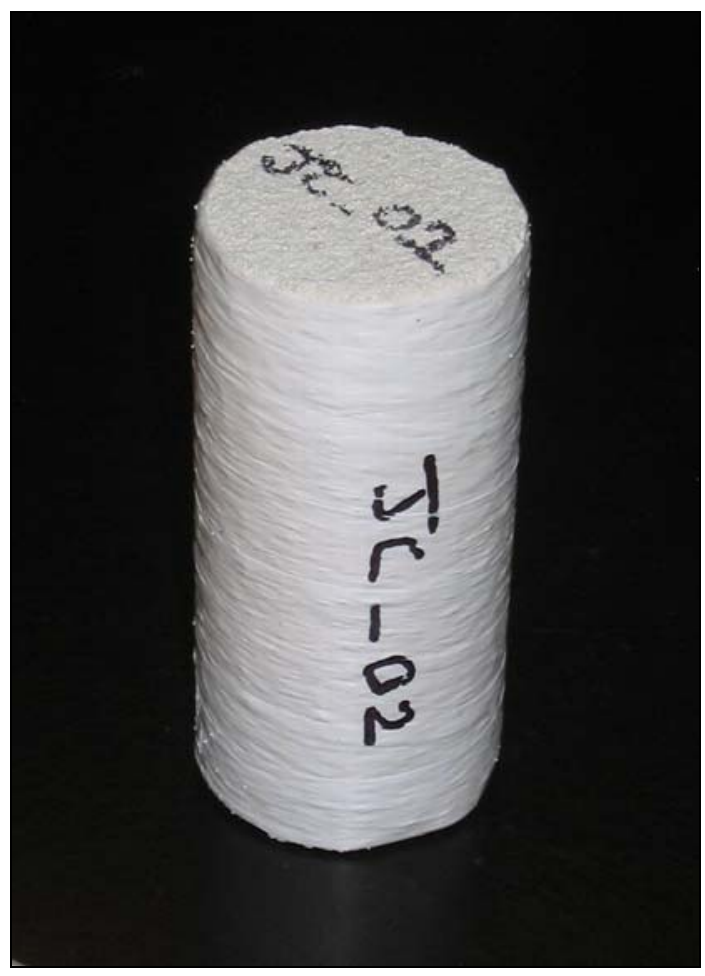

Plate 6 Core material: Joulters Cay oolitic outcrop wrapped in PTFE tape 
Cores were evacuated and saturated with deionized water or oil. Porosity was calculated from the core weight before and after saturation, and the density of the saturating phase. To obtain a permeability value, oil or brine was flowed through the core at a constant, known rate and the pressure drop was measured. The data were recorded using LabVIEW, which was also used to calculate the permeability using Darcy's law of single phase flow (Equation 2).

$$
k=\frac{\mu L Q}{A \Delta P},
$$

where $\mathrm{k}=$ permeability (Darcy); $\mu=$ viscosity $(\mathrm{cp}), \mathrm{L}=$ core length $(\mathrm{cm}), \mathrm{Q}=$ flow rate $(\mathrm{ml} / \mathrm{s})$, $\mathrm{A}=$ core area $\left(\mathrm{cm}^{2}\right), \Delta \mathrm{P}=$ pressure drop across core (atm). Viscosity of the fluids used to flood the core was measured using a Brookfield viscometer.

Flow rate, pressure drop and calculated permeability data for a representative core are shown in Figure 10. Note that permeability is independent of flow rate because as flow rate increases, so does the pressure drop across the core. The dimensions of the core were, of course, constant, as was the viscosity of the fluid (Newtonian) used to flood the core. Any change in permeability with flow rate (or pressure) would be indicative of a leak in the apparatus.

Permeability of Core BF02

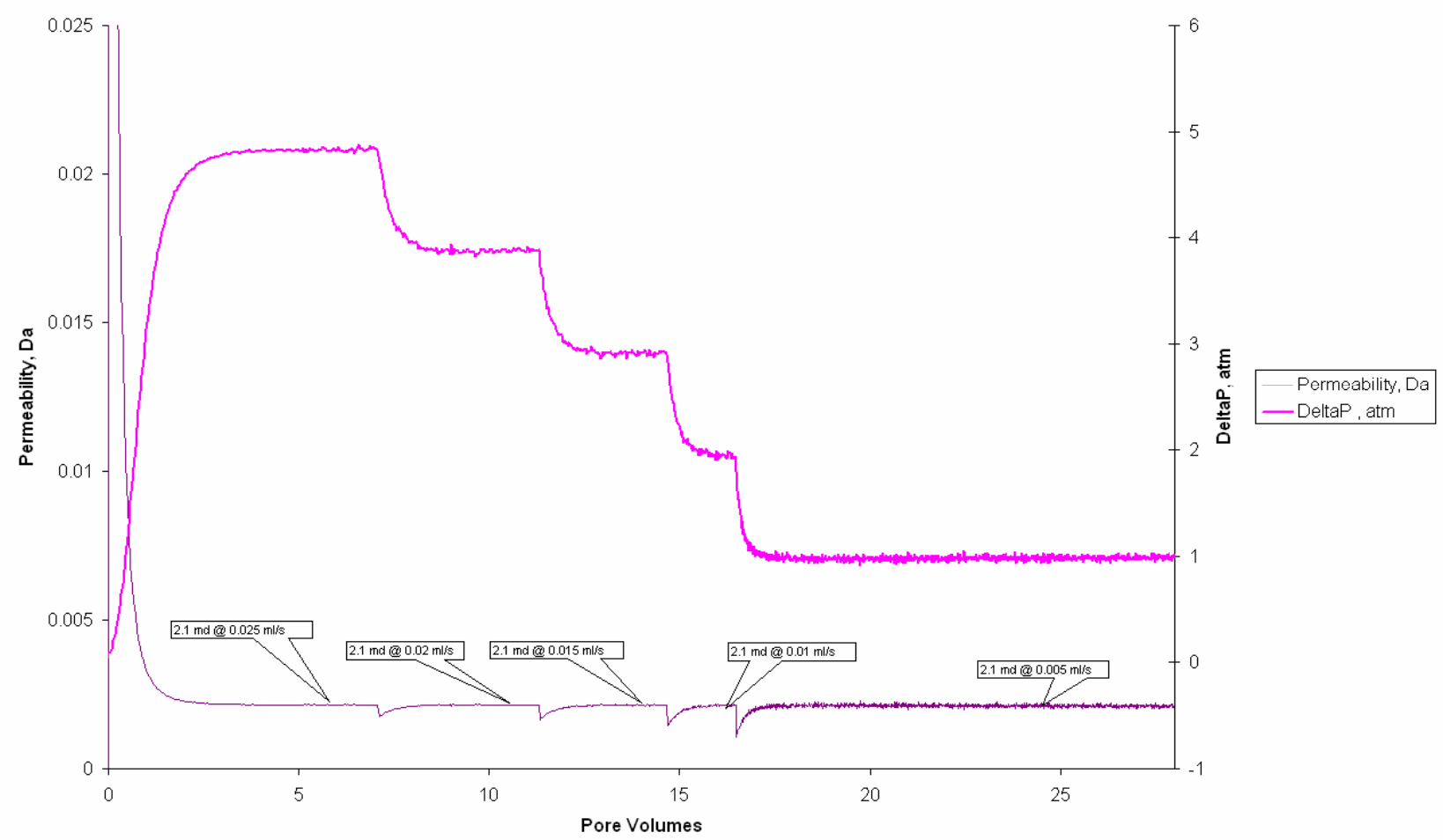

Figure 10 Permeability of Bethany Falls outcrop core BF02 
Figure 11 shows porosity and permeability values for all the cores characterized to date, overlaid on similar data from Watney (1994). ${ }^{25}$ Watney characterized Bethany Falls and Mound Valley oolites and found a wide range of porosity and permeability. Dubois et al. ${ }^{24}$ noted that the LKC was very similar to modern Caribbean oolites and our experimental data for moldic LKC outcrop and reservoir cores, as well as Miami and Joulters Cay oolite agree well with the published values for similar material. This confirms that the core-flooding protocol is effective, and that the material is representative of the range of porosity, permeability and pore architecture seen across the LKC.

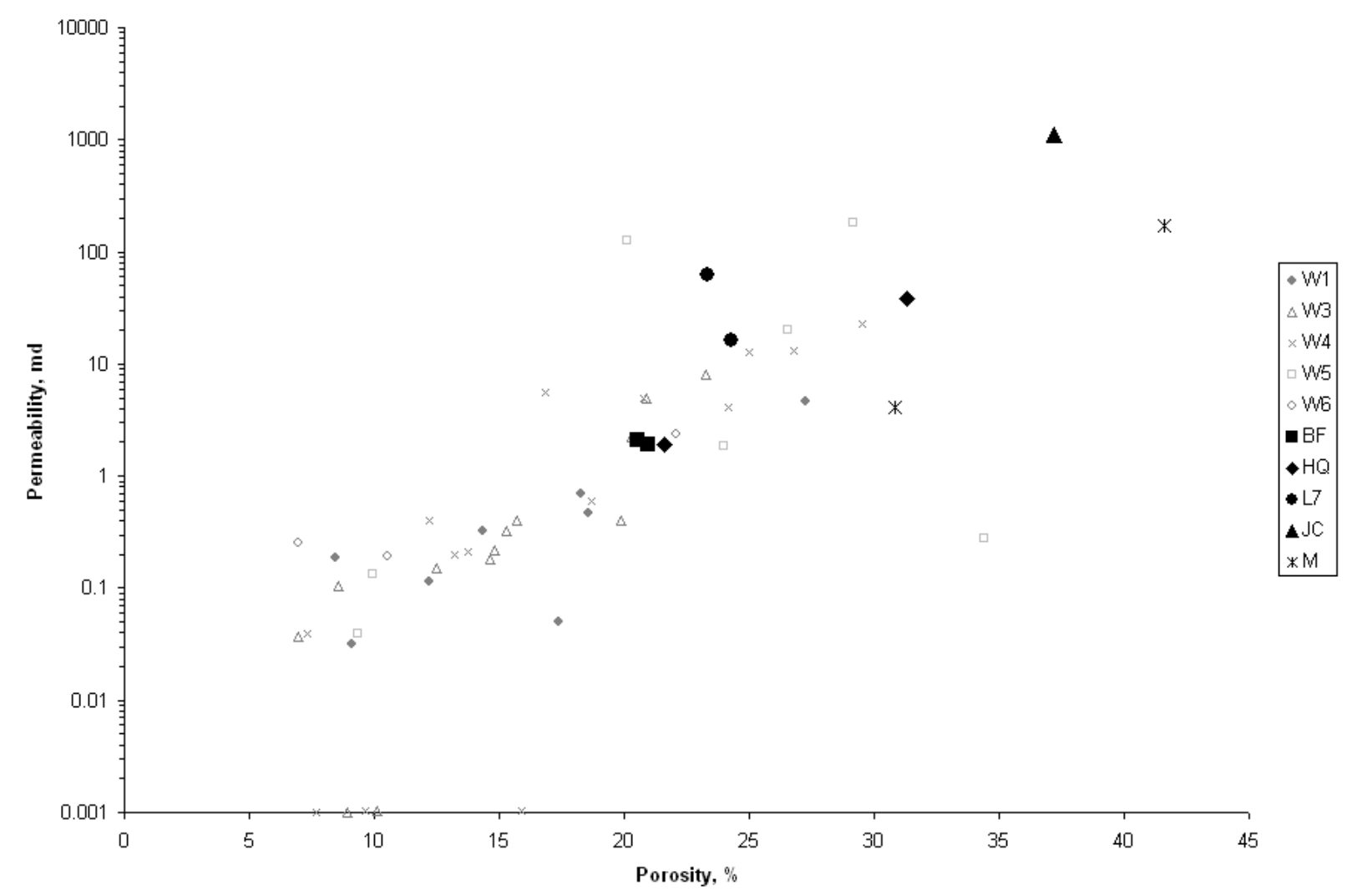

Figure 11 Porosity and permeability of Bethany Falls (BF), Heartland Quarry (HQ) and Luerman \#7 (L7), Joulters Cay (JC) and Miami (M) cores. Points marked in gray (W1-6) represent Bethany Falls and Mound Valley oolites, digitized ${ }^{26}$ from Watney $(1994)^{25}$

\section{Tracer Tests}

In addition to the permeability measurements, the core flooding apparatus allows for the performance of tracer tests. These test can confirm the pore volume of a core, and provide information on the homogeneity or otherwise of the pore space.

Tracer tests proceed as per a standard oil or water flood except that the flooding phase can be switched between the pure phase and one containing the tracer by turning a single valve (Figure 12 and Figure 13). The effluent from the core may be monitored in real time by passing it through an in-line UV/visible spectrometer whose output is recorded in LabVIEW, or after the flood by collecting fractions and analyzing in a scanning UV/visible spectrometer. 


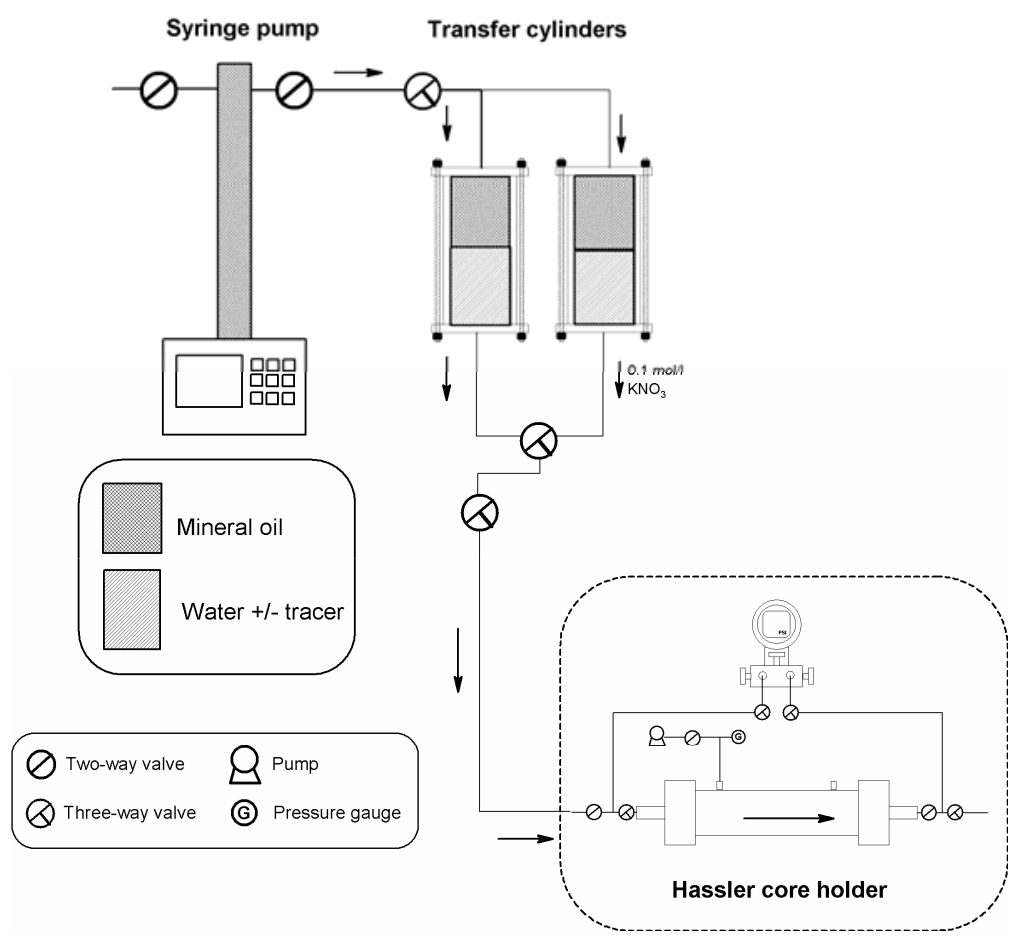

Figure 12 Alternate layout for aqueous tracer test

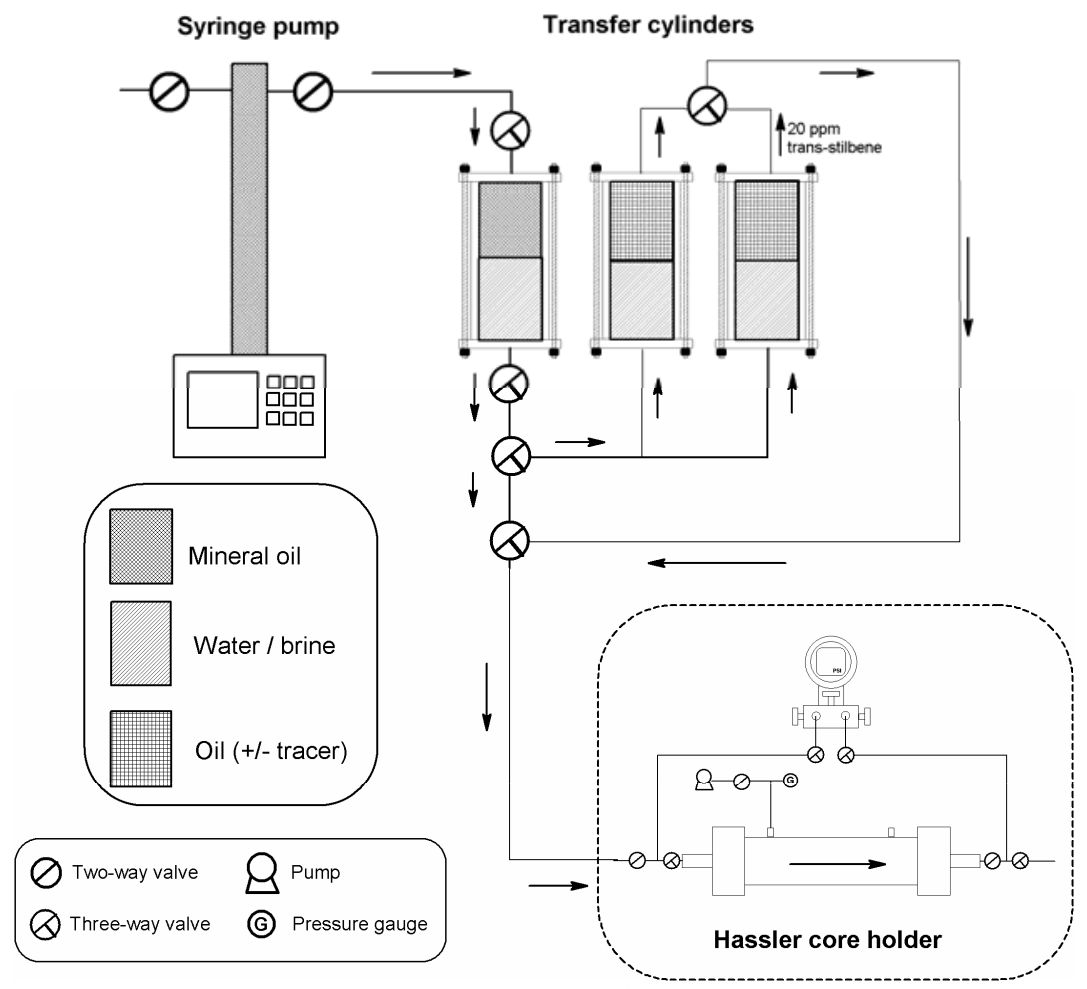

Figure 13 Alternate layout for oil tracer test 
A variety of possible tracers were assessed and the most appropriate found to be $0.1 \mathrm{~mol} / 1 \mathrm{KNO}_{3}$ in water (302 nm, Figure 14) or $20 \mathrm{ppm}$ trans-stilbene in oil (228 nm, Figure 15). The concentrations and wavelength have been chosen because they obey the Beer-Lambert law (Equation 3), giving a linear relationship between concentration and absorbance.

$$
A=a_{\lambda} \times b \times c
$$

where $\mathrm{A}$ is the measured absorbance, $a_{\lambda}$ is a wavelength-dependent absorptivity coefficient, $\mathrm{b}$ is the path length, and $\mathrm{c}$ is the analyte concentration.

KNO3 I Varian 340 calibration

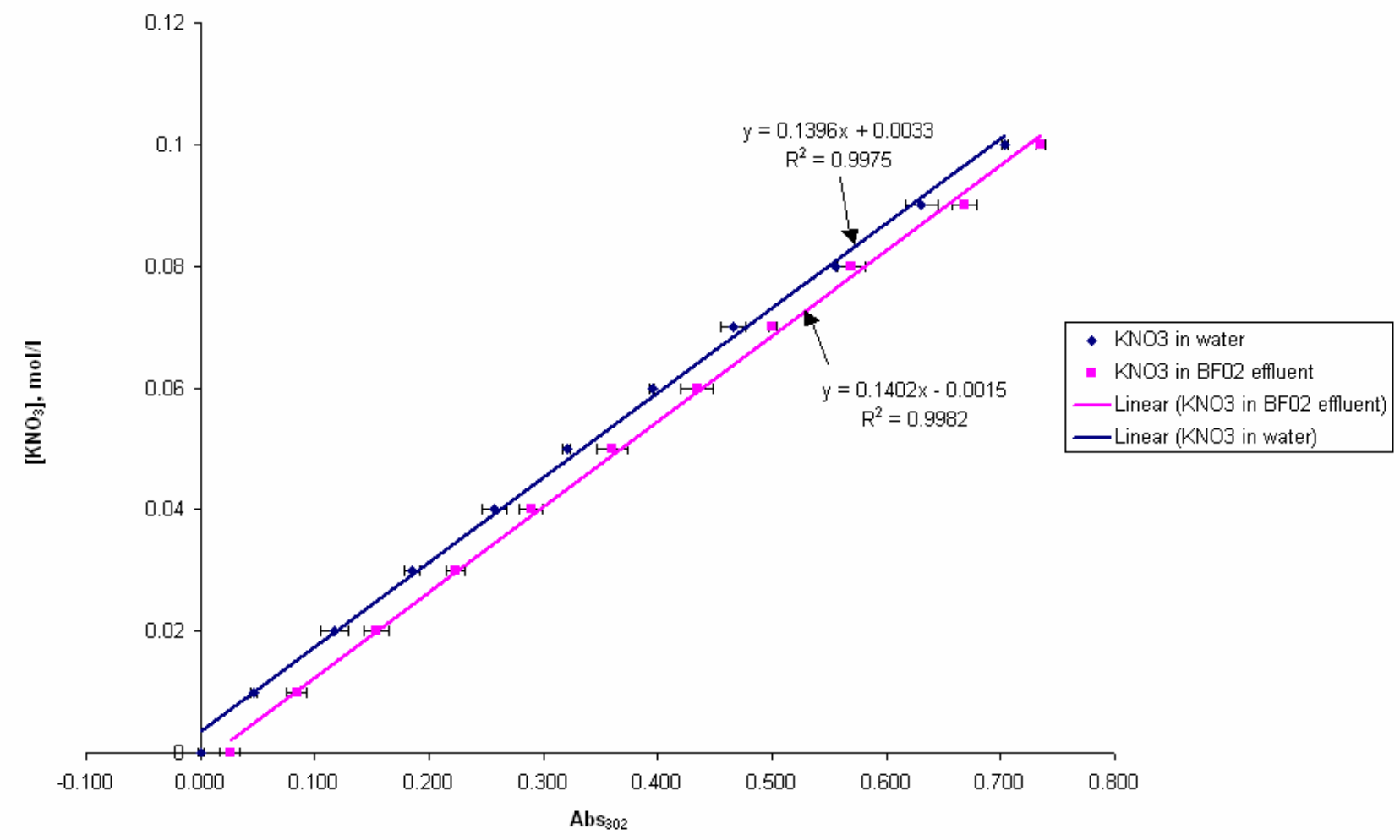

Figure $14 \mathrm{UV}$ absorption calibration curves for $\mathrm{KNO}_{3}$ in water and in effluent from core BF02 at $302 \mathrm{~nm}$. Error bars $=1$ standard deviation, $\mathbf{n}=3$. 


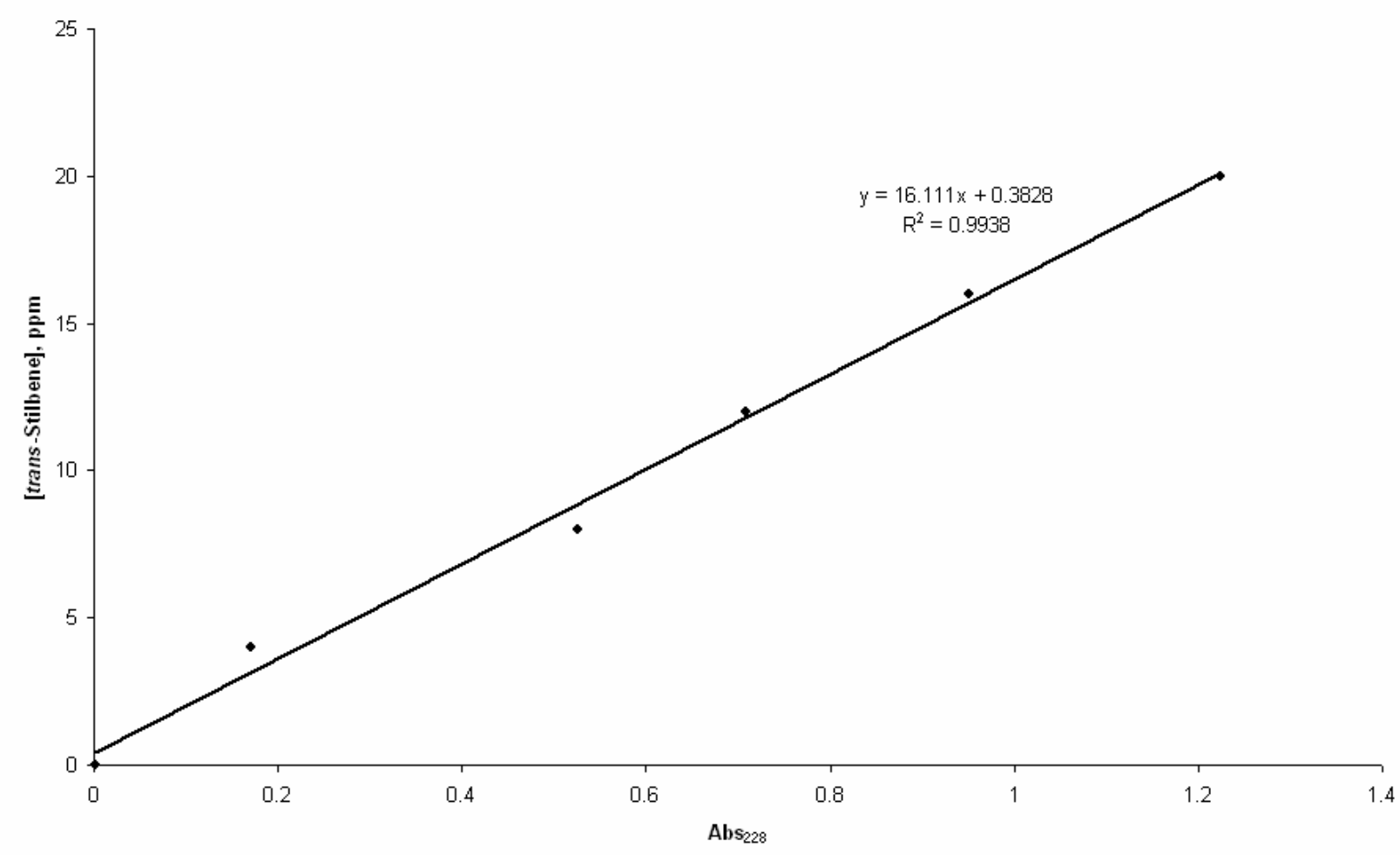

Figure $15 \mathrm{UV}$ absorption calibration curve for trans-stilbene in dodecane at $\mathbf{2 2 8} \mathbf{~ n m}$

\section{Core Cleaning}

Early oil flooding investigations exposed a problem with the cleaning of the core materials. Cores were cleaned by Soxhlet extraction using a toluene/methanol azeotrope and dried to constant weight before being saturated. However, on flooding with oil, all cores produced effluent that was yellowish in color and supported relatively stable foam on shaking. The effluent oil also absorbed strongly in the ultraviolet. The colored material was filtered through an $\mathrm{Al}_{2} \mathrm{O}_{3}$ column but the UV-absorbing component was only retained very weakly, suggesting that it represents non-polar organic compounds that had been trapped in the core.

The presence of UV-absorbing, oil-soluble material is problematic because it (a) is likely to be active in determining the wettability of the carbonate surface (b) leads to inaccuracies in porosity measurements and (c) interferes with the detection of stilbene tracer. To ameliorate these problems, an additional, more aggressive cleaning regime was adopted. ${ }^{34}$

Cleaning was carried out by flooding the core with tetrahydrofuran (THF) and allowing to soak for up to three days at $45^{\circ} \mathrm{C}$. This was repeated until the effluent was colorless. The THF was displaced with chloroform, followed by methanol and finally water (Plate 7). 


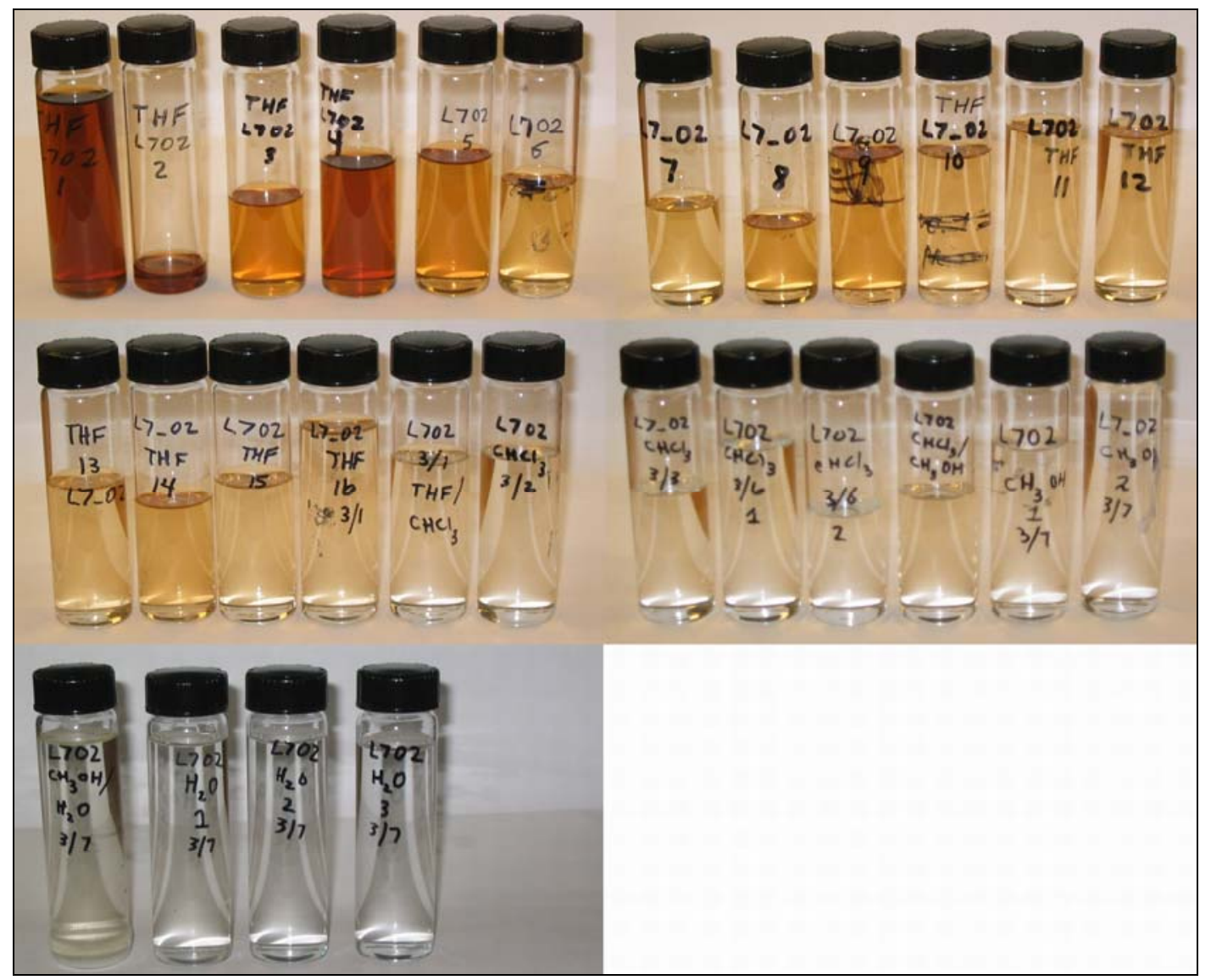

Plate 7 Effluents from cleaning L7_02. Solvents are tetrahydrofuran (THF), chloroform, methanol and water.

The Viton sleeves used in the core holder proved to be sensitive to THF and so the cores, along with the distribution plugs, were shrink-wrapped in an oven at $190{ }^{\circ} \mathrm{C}$ using 1.6:1 FEP Teflon ${ }^{\circledR}$ heat-shrinkable tubing (Zeus Industrial Products Inc, Orangeburg, SC) before placing them in the core holder (Plate 8).

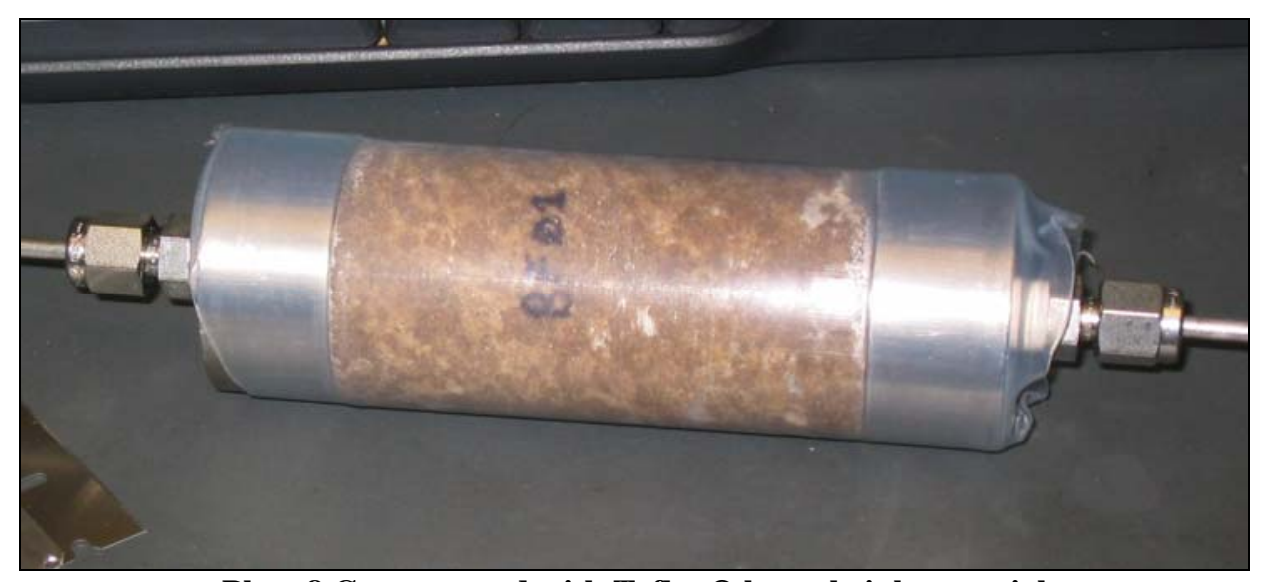

Plate 8 Core covered with Teflon ${ }^{\circledR}$ heat shrink material

After cleaning, cores were flooded with RO water and weighed to determine porosity, then returned to the core holder and flooded with $\mathrm{RO}$ water to obtain permeability. A tracer test was 
carried out using $0.1 \mathrm{~mol} / 1 \mathrm{KNO}_{3}(302 \mathrm{~nm})$ to confirm the porosity and check the homogeneity of the core. The tracer is displaced with $\mathrm{RO}$ water and the core is removed and dried to constant weight. Then the core is flooded with Soltrol 130, weighed, and a tracer test is performed using 20-ppm trans-stilbene in Soltrol 130 (323 nm).

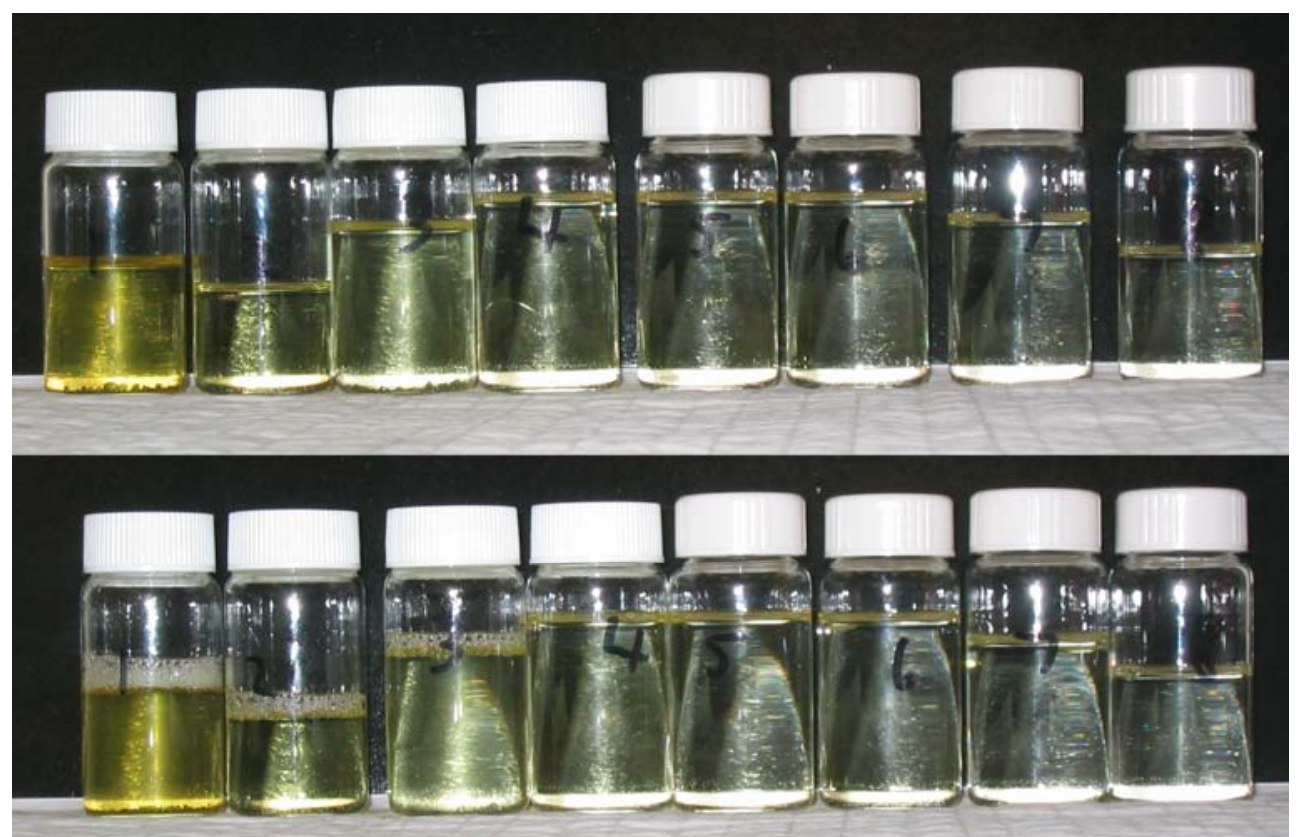

Plate 9 Effluent from core BF02 dodecane flood. Time increases from left to right. The lower image shows the same samples $\sim 5 \mathrm{~s}$ after shaking to show the persistent foam associated with greater discoloration. The samples also exhibited appreciable UV absorbance (Figure 16)

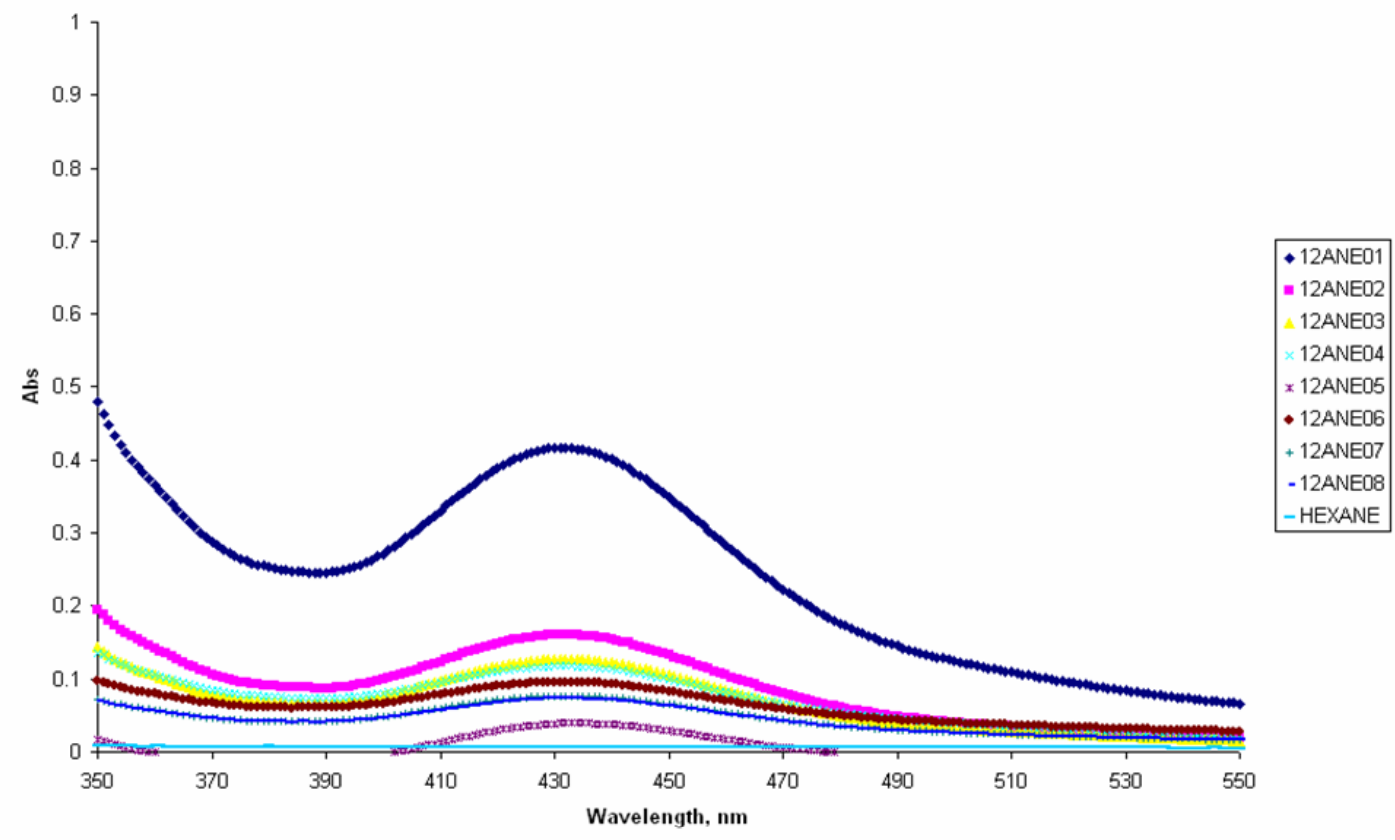

Figure 16 UV absorbance of dodecane effluent from core BF_02 


\section{Details of $L 7$ Core Characterization Data}

The most complete data is from the L7 reservoir material. Detailed L7 core characterization data are shown in Table 4. Cores were cleaned (see page 26) before characterization.

Table 4 L7 Core Characterization

\begin{tabular}{|c|c|c|c|}
\hline Core & L7_01 & L7_02 & L7_03 \\
\hline \multicolumn{4}{|l|}{ INITIAL DATA } \\
\hline Length, L (cm) & 6.68 & 4.29 & 6.66 \\
\hline Area, $A\left(\mathrm{~cm}^{2}\right)$ & 11.34 & 11.38 & 11.35 \\
\hline Bulk Volume, BV $\left(\mathrm{cm}^{3}\right)$ & 75.73 & 48.79 & 75.64 \\
\hline Oven Dried Weight (g) & 146.62 & 93.17 & 151.65 \\
\hline PV $(m L)\left(S_{w}=1\right)$, by weight & 20.00 & 12.08 & 17.67 \\
\hline PV $(m L)\left(S_{w}=1\right)$, by tracer & 19.04 & 13.23 & 19.20 \\
\hline PV $(m L)\left(S_{o}=1\right)$, by weight & 20.32 & 12.46 & 18.22 \\
\hline$P V(m L)\left(S_{o}=1\right)$, by tracer & 20.80 & 12.16 & 18.49 \\
\hline Mean PV (mL) & 20.0 & 12.5 & 18.4 \\
\hline Porosity (fraction) & 0.26 & 0.26 & 0.24 \\
\hline Absolute permeability, $\left(S_{w}=1\right)(m d)$ & 40.0 & 16.0 & 11.0 \\
\hline Absolute permeability, $\left(S_{o}=1\right)(\mathrm{md})$ & 45.5 & 15.5 & 13.3 \\
\hline Mean Absolute Permeability, k (md) & 42.8 & 15.8 & 12.2 \\
\hline
\end{tabular}

The three L7 cores have similar porosities, but L7_01 has significantly higher permeability than the other two. L7_02 is shorter than the other two cores due to damage during an early cleaning which was removed. All these cores were cut from a short ( $\sim 6$ inch) section of vertical core and this data illustrates the heterogeneity present in the LKC.

\section{Magnetic Resonance Imaging of Pore Architectures}

To visualize and confirm the pore architectures of our carbonate cores, samples of core materials were saturated with water and sent to ConocoPhillips, Bartlesville, OK for magnetic resonance imaging (MRI). The image data has been analyzed to obtain pore-body and pore-throat size distributions of the different carbonate cores. This information will be useful in future explanations of the distribution of residual fluid saturations after imbibition tests.

Cores were fully saturated with water, which was visualized by MRI to show the pore volume. Color bar is a qualitative indicator of relative water saturation. The resulting images demonstrate the varying degrees of heterogeneity in the cores. Raw NMR data at a resolution of $\sim 1 \mathrm{~mm}$ is also available. Magnetic resonance imagery of core materials is shown in Figure 17-Figure 20. 


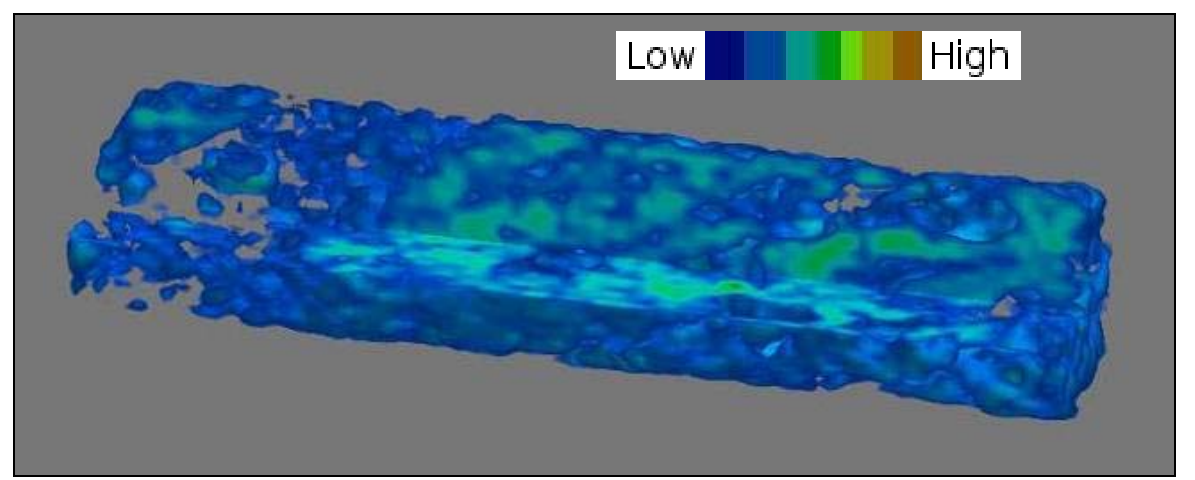

Figure 17 Heterogeneous Bethany Falls oomoldic outcrop core $, \phi=0.21, \mathrm{k}=0.7 \mathrm{md}$

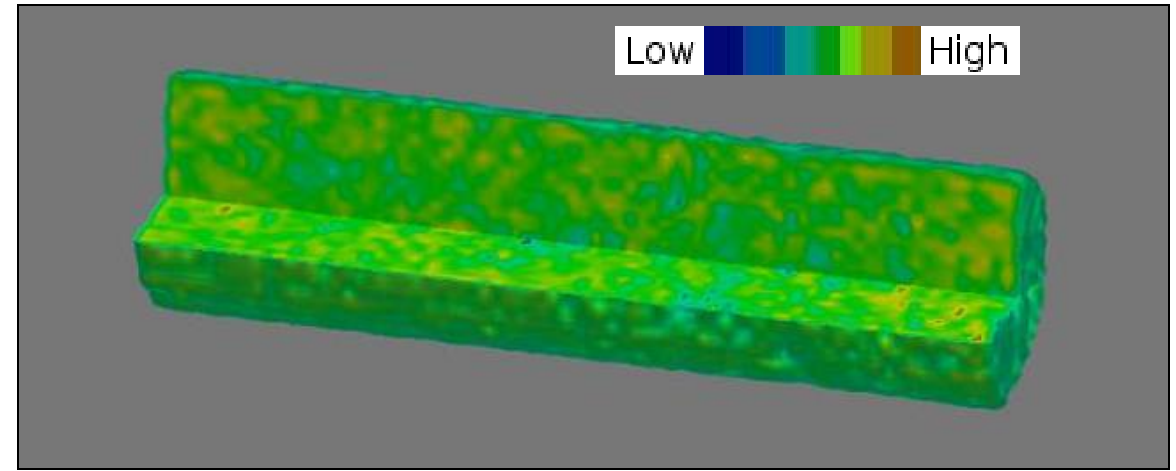

Figure 18 Relatively homogeneous Luerman \#7 oomoldic reservoir core, $\phi=0.24, \mathrm{k}=16 \mathrm{md}$

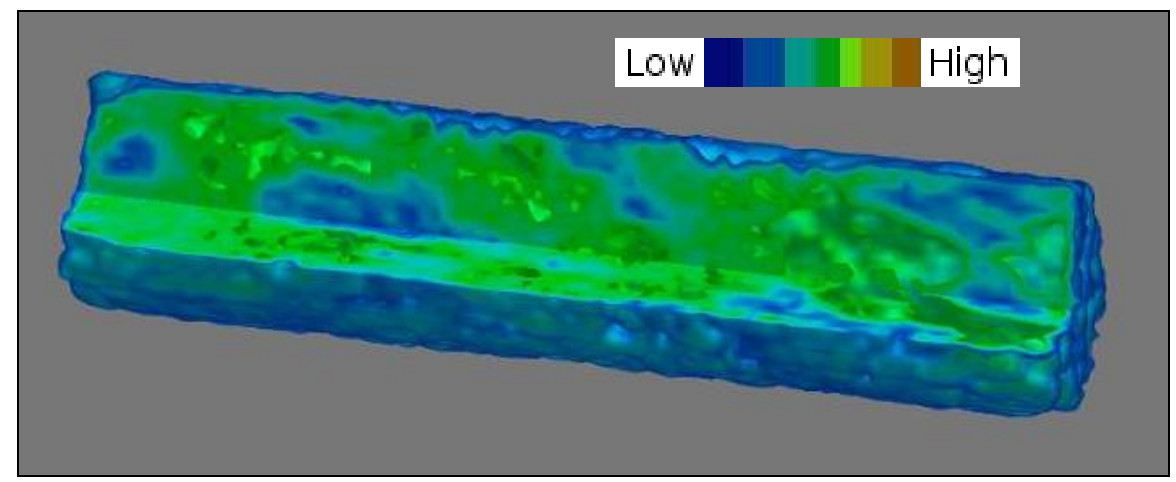

Figure 19 Heterogeneous Miami oolitic outcrop core, $\phi=0.42, k=170$ md

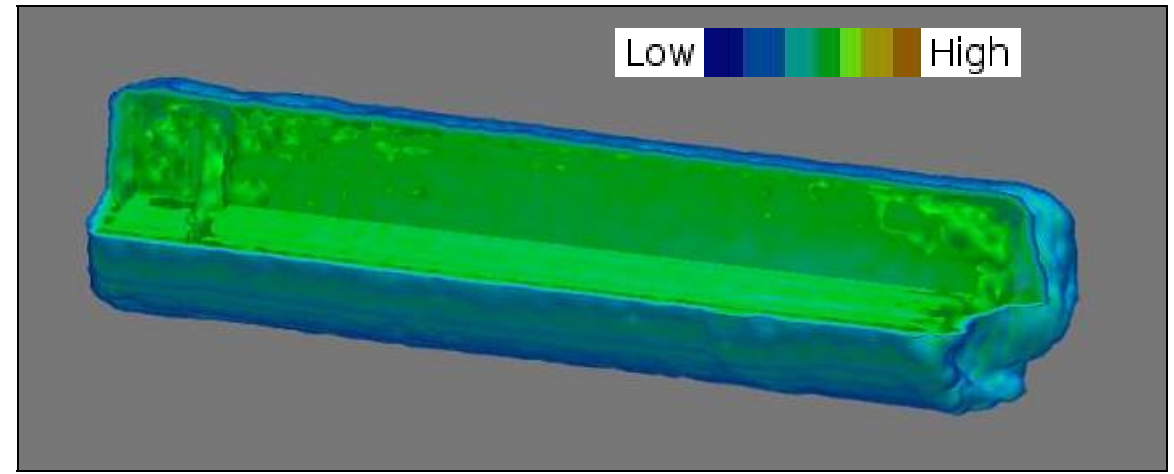

Figure 20 Homogeneous Joulter's Cay oolitic outcrop core, $\phi=0.43, \mathrm{k}=1100 \mathrm{md}$ 


\section{NMR Relaxation}

NMR relaxation times T1 and T2 (Figure 21) respond to different aspects of the nuclei spin states. The spin-lattice relaxation time $\mathrm{T} 1$, is a measure of the time for the longitudinal magnetization to recover and the spin-spin relaxation time T2, is a measure of the interaction between spins in each nucleus. Relaxation times are indicative of characteristic length and hence of pore size distribution, the simplified expression is

$$
1 / T i=\rho \times \frac{S}{V},
$$

where Ti is either T1 or T2, $\rho$ is the surface relaxivity $(\mathrm{cm} / \mathrm{s}), \mathrm{S}$ is the surface area $\left(\mathrm{cm}^{2}\right)$, and $\mathrm{V}$ is volume $\left(\mathrm{cm}^{3}\right) . \mathrm{V} / \mathrm{S}$ is sometimes referred to as hydraulic radius and has units of length. Hence the relaxation rate $(1 / \mathrm{Ti})$ is proportional to inverse length. Surface relaxivity is a measure of the relaxation provoking power of the surfaces, which for many sandstones and carbonates tends to be constant. A value of 1 to $5 \times 10^{-4} \mathrm{~cm} / \mathrm{sec}$ is typical for carbonates.

BF_01
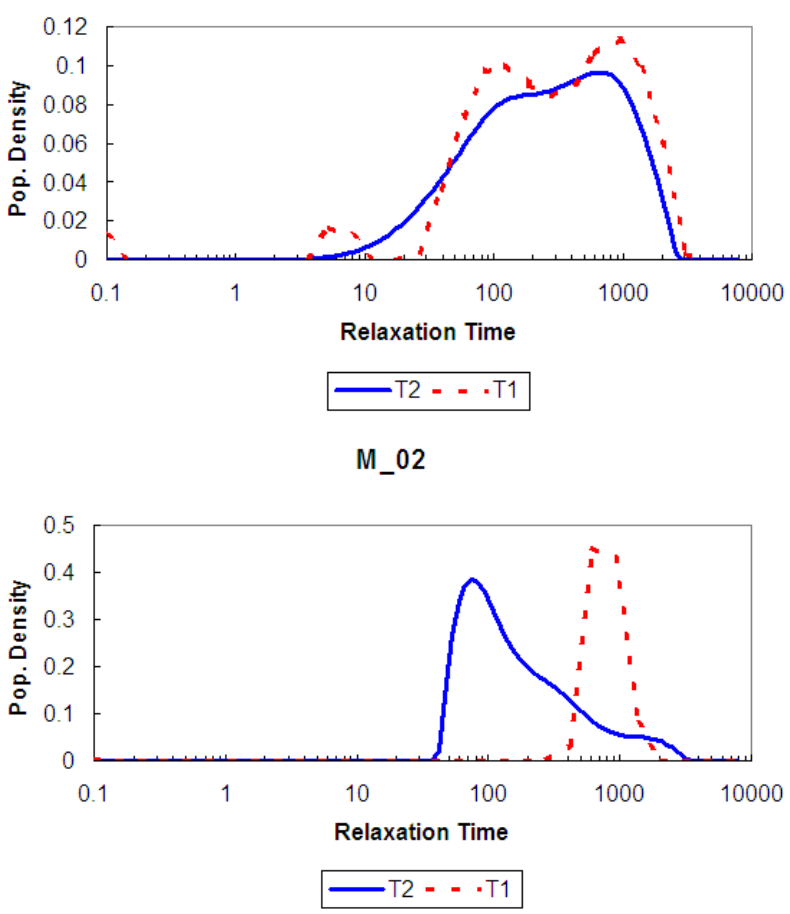

L7_02
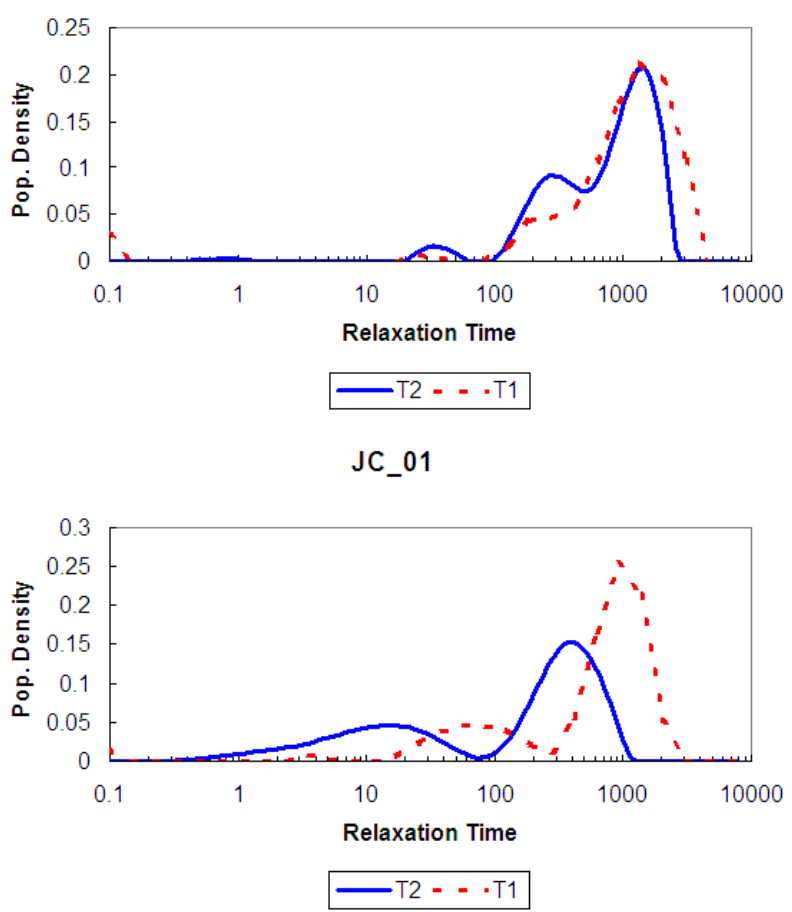

Figure 21 NMR relaxation times for carbonate cores BF_01, L7_02, M_02 and JC_02

\section{Preparation of crushed carbonate rock}

Crushed reservoir material is used for static wettability and adsorption testing. In order to produce a reproducible particle size distribution, small samples of material $\left(\sim 10 \mathrm{~cm}^{3}\right)$ were crushed in a ball mill (Spex Certiprep Model 8000M, provided by Kansas Geological Survey). 
Samples were pooled and blended before being sieved to check the size distribution (Figure 22) and to remove particles $>300 \mathrm{~mm}$ and $<53 \mathrm{~mm}$.

The surface area per unit mass was measured using a Gemini II Surface Area Analyzer (Model Number 2370, Micromeritics Instrument Corporation, Norcross, GA). Crushed rock samples were cleaned using the same sequence of solvents as the cores.

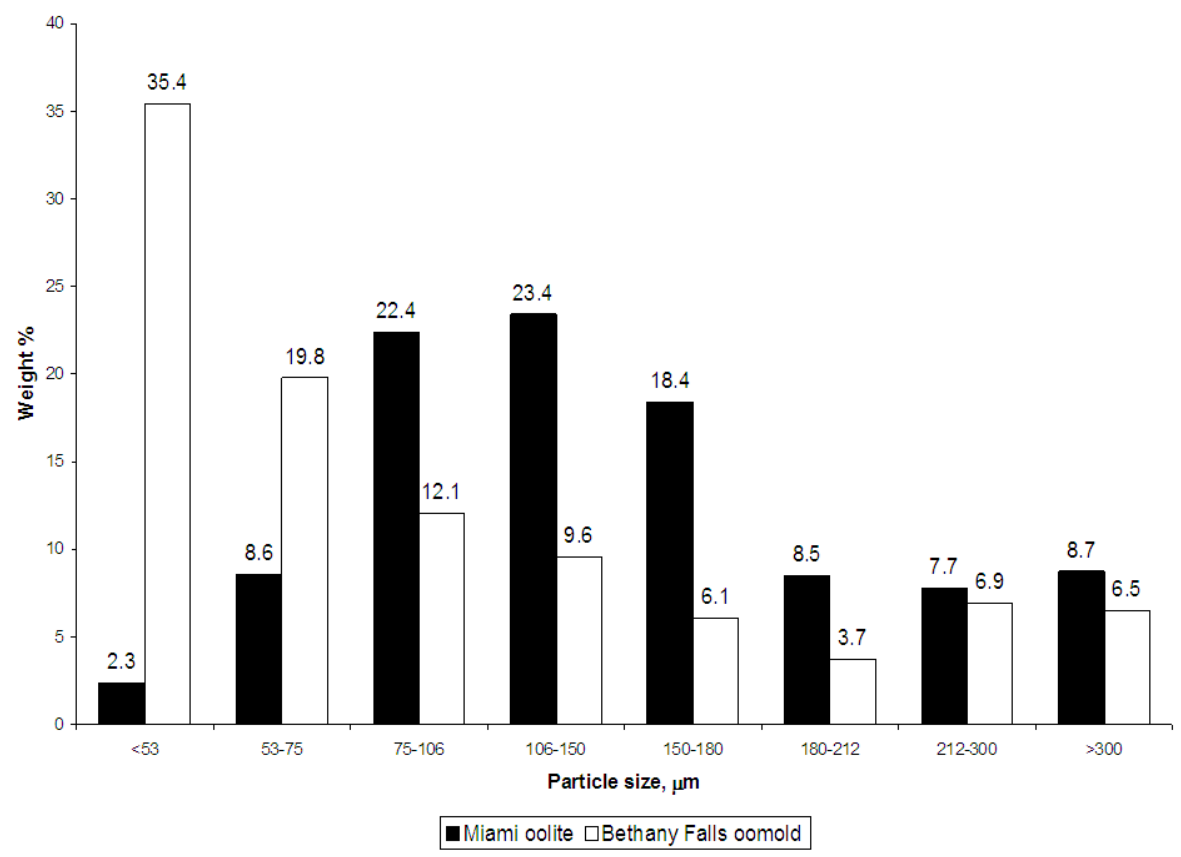

Figure 22 Particle size distribution of crushed carbonate rock. Only particles in the range 53-300 $\mu \mathrm{m}$ are used in the investigation.

\section{Synthetic brine}

Surfactin was checked for stability in brine and found to be sensitive to salt concentration, especially divalent cations. In order to avoid precipitation of surfactants, all aqueous tests were performed using reverse-osmosis (RO) water. This will have implications for potential use in the field.

\section{Rapid wettability assessment by two-phase separation}

To evaluate the effectiveness of surfactants in mediating wettability, samples of crushed BF rock were aged in crude oil (from the Lansing - Kansas City Field C Zone at $\sim 880 \mathrm{~m} \mathrm{(} \mathrm{2900} \mathrm{ft))} \mathrm{at}$ $90{ }^{\circ} \mathrm{C}$ for $7 \mathrm{~d}$, rinsed with Soltrol 130 and immersed in $420 \mathrm{ppm}$ surfactant solutions for $24 \mathrm{~h}$. The samples were centrifuged and the rocks were separated and dried. Following drying, two qualitative tests were performed: a two-phase separation (adapted from Somasundaran \& Zhang ${ }^{35}$ ) and a flotation test. ${ }^{36}$ In the two-phase separation test $0.2 \mathrm{~g}$ of dried rock following treatment with surfactant was mixed with $20 \mathrm{ml}$ of RO-water in a $40 \mathrm{ml}$ glass scintillation vial and $20 \mathrm{ml}$ Soltrol 130 was added. The samples were shaken gently and allowed to settle for $1 \mathrm{~h}$. A visual inspection of the distribution of rock between the aqueous and oil phases gives a qualitative indication of wettability. Similarly, in the flotation test, $0.2 \mathrm{~g}$ rock was added to a test 
tube containing $10 \mathrm{ml}$ of $\mathrm{RO}$ water and the mass of rock sinking to the bottom of the water column indicated the wettability change mediated by the surfactant.

\section{Wettability alteration}

To alter the wettability of the clean core material towards a more oil-wet state, samples were placed in a glass container under crude oil at $65^{\circ} \mathrm{C}$ and the wettability of subsamples was determined at intervals (Plate 10). To investigate the efficiency of the crude oil in altering the wettability the samples were dried to constant weight and then either exposed to the crude oil directly, or moistened with RO water before being added to the crude. It was found that while the wettability of the dry material changed rapidly, the material with water remained hydrophilic for a much longer period. It was clear that the layer of water on the particle surfaces prevented the oil from coming into direct contact with the rock. This has obvious implications for the alteration of wettability of cores.

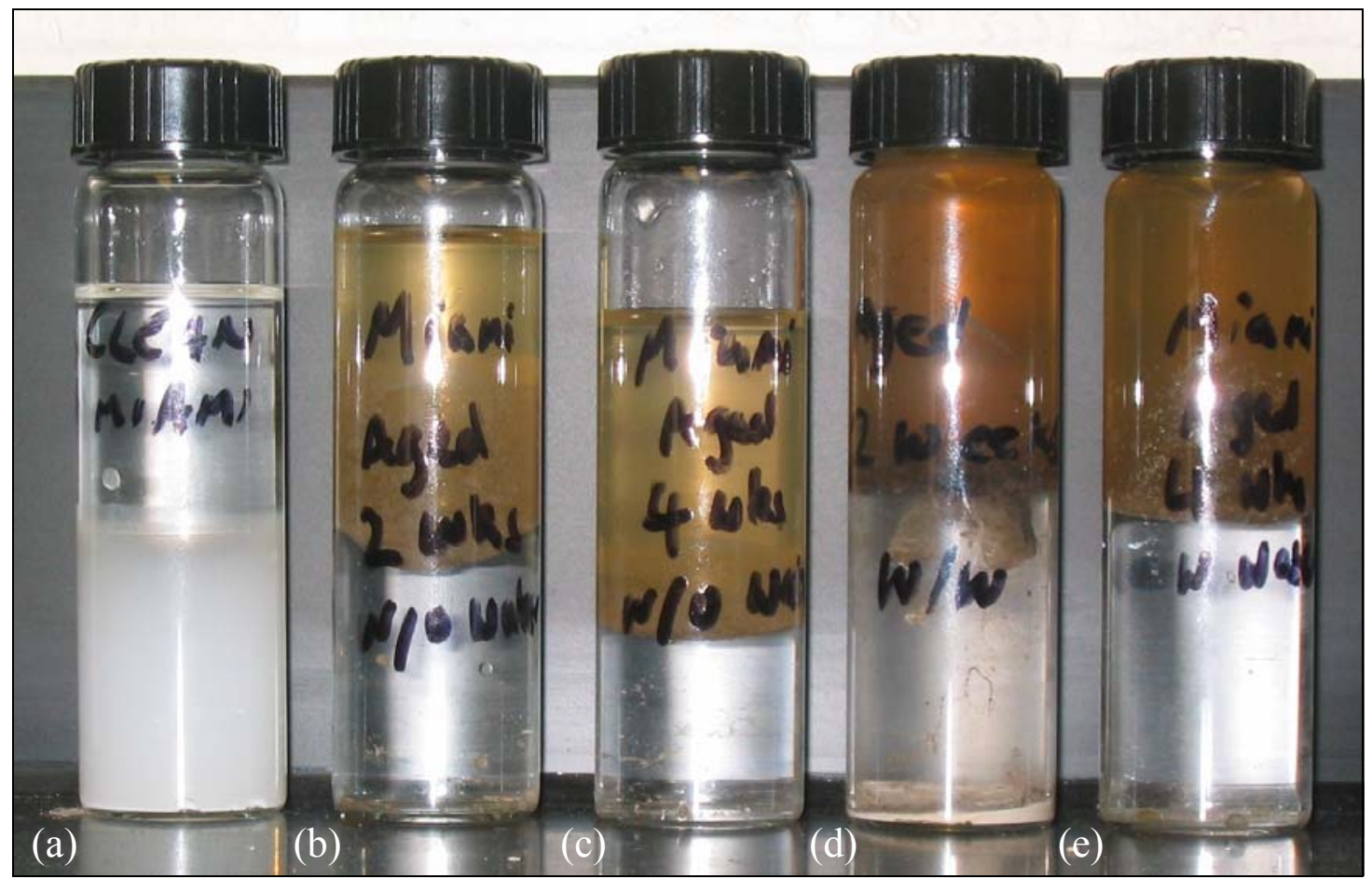

Plate 10 Crushed Miami oolite in RO water/Soltrol: (a) clean, (b) \& (c) with no initial water saturation after 2 \& 4 weeks under crude oil at $65^{\circ} \mathrm{C}$ to show rapid change to oil wet state, (d) \& (e) with initial water saturation after $2 \& 4$ weeks under crude oil at $65^{\circ} \mathrm{C}$ to show slower progression through mixed-wet state.

The effectiveness of surfactants in mediating wettability changes was observed through two qualitative tests: a two-phase separation test and a flotation test. It was concluded from both tests that surfactin is more effective on a molar basis in reversing the wettability of oil-wet crushed carbonate rocks. Plate 11 shows the results of a two-phase separation test and demonstrates the effectiveness of surfactin in changing the wettability. These results were confirmed by performing a flotation test on the oil-wet rock samples in contact with both surfactants (Plate 12). 


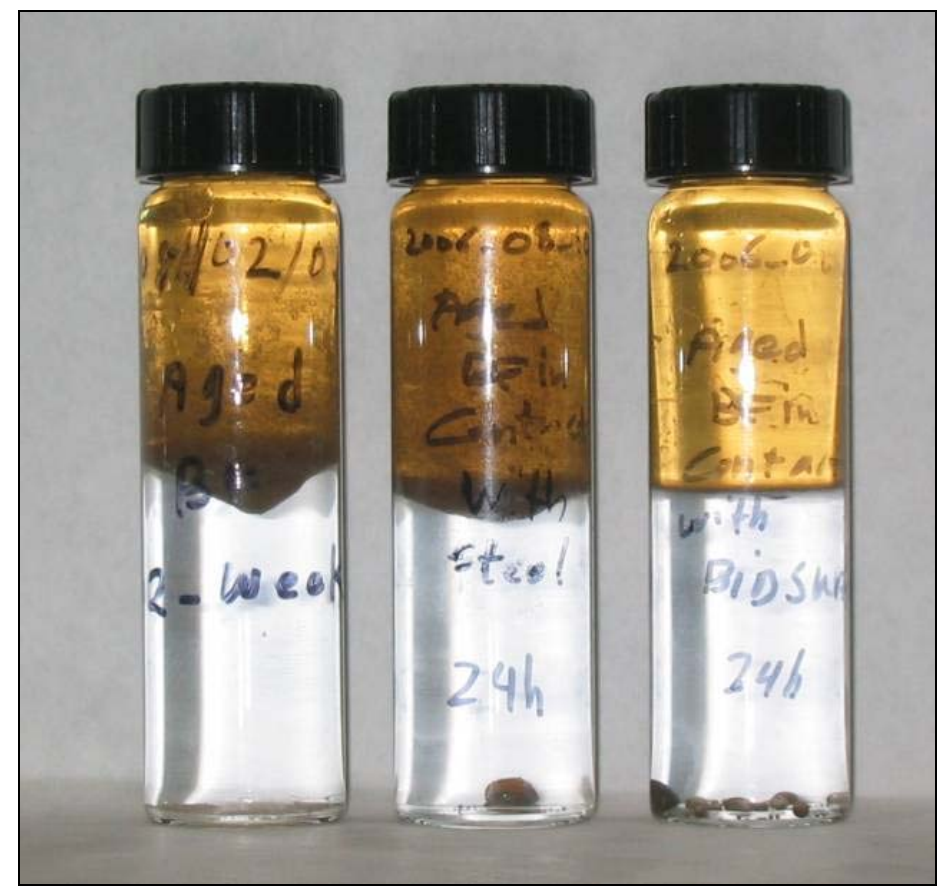

Plate 11 Two-phase (Soltrol 130/water) separation tests showing the effectiveness of surfactants in altering the wettability of crude oil-aged BF rock exposed to surfactant solutions for $24 \mathrm{~h}$ (left: No surfactant; center: STEOL CS-330; right: surfactin)

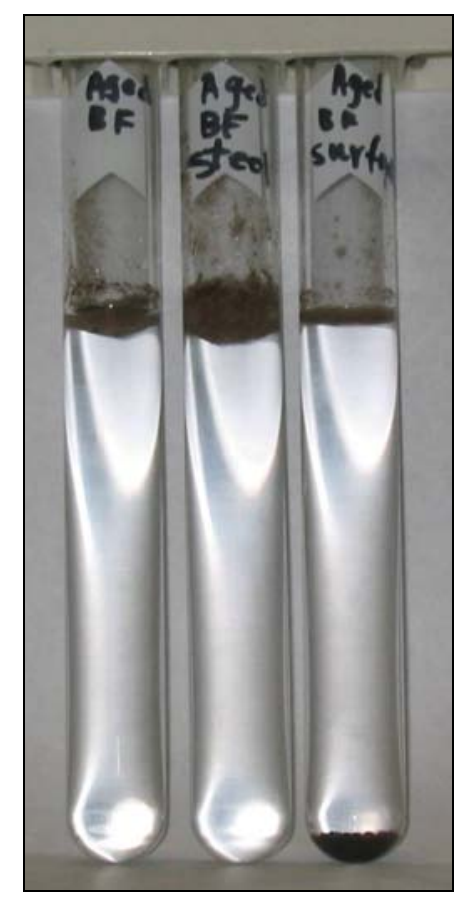

Plate 12 Water flotation tests showing the effectiveness of surfactants in altering the of crude oil-aged BF rock exposed to surfactant solutions for $24 \mathrm{~h}$

(left: No surfactant; center: STEOL CS-330; right: surfactin) 


\section{Amott Wettability}

Wettability of the core samples is assessed using the Amott Wettability Index (Equation 3): ${ }^{37}$

\section{L7 Core Imbibition and Wettability Data}

The following graphs show imbibition data for the $\mathrm{L} 7$ cores from different starting conditions.

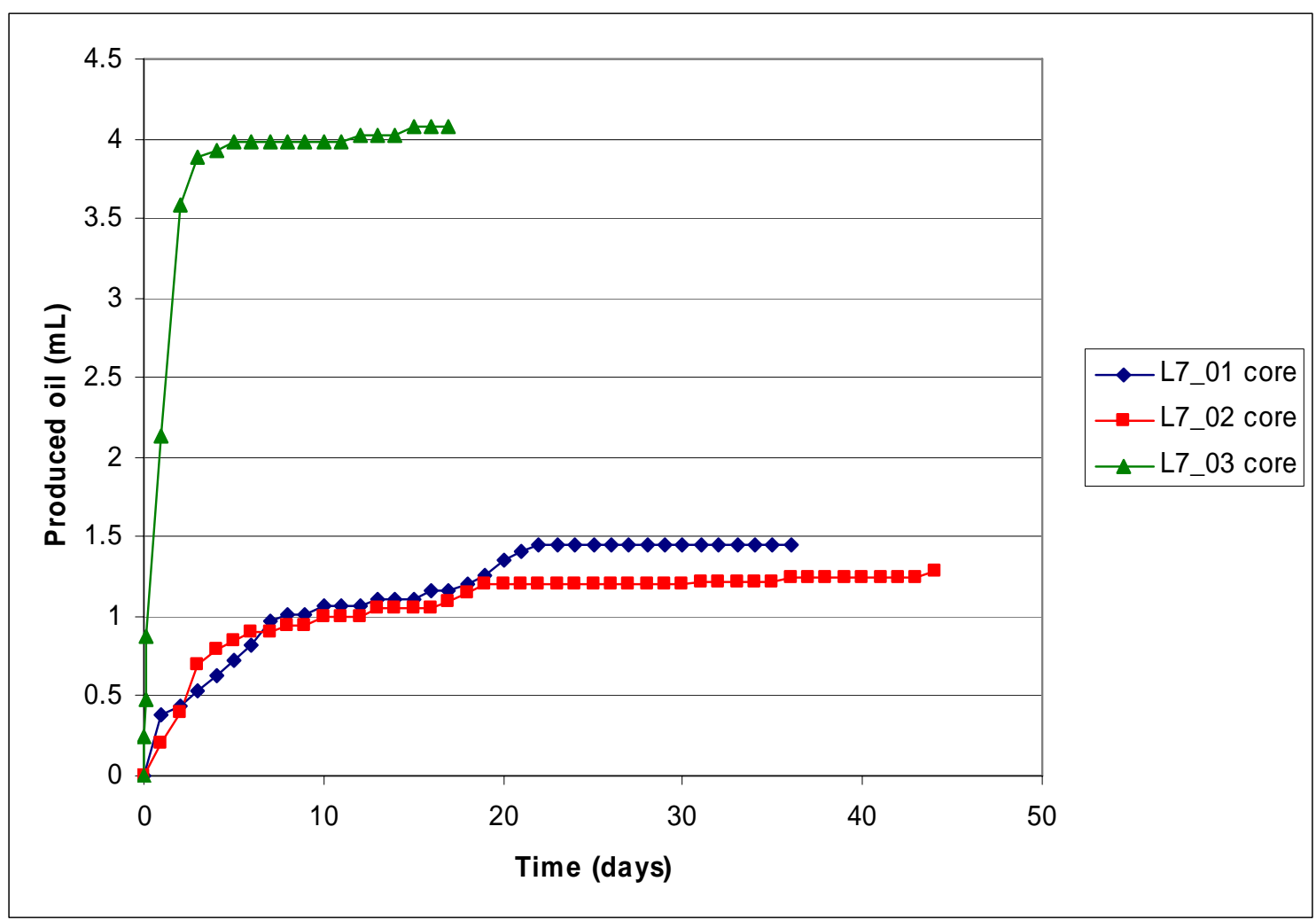

Figure 23 Spontaneously produced oil with RO from $S_{0}=1$ 


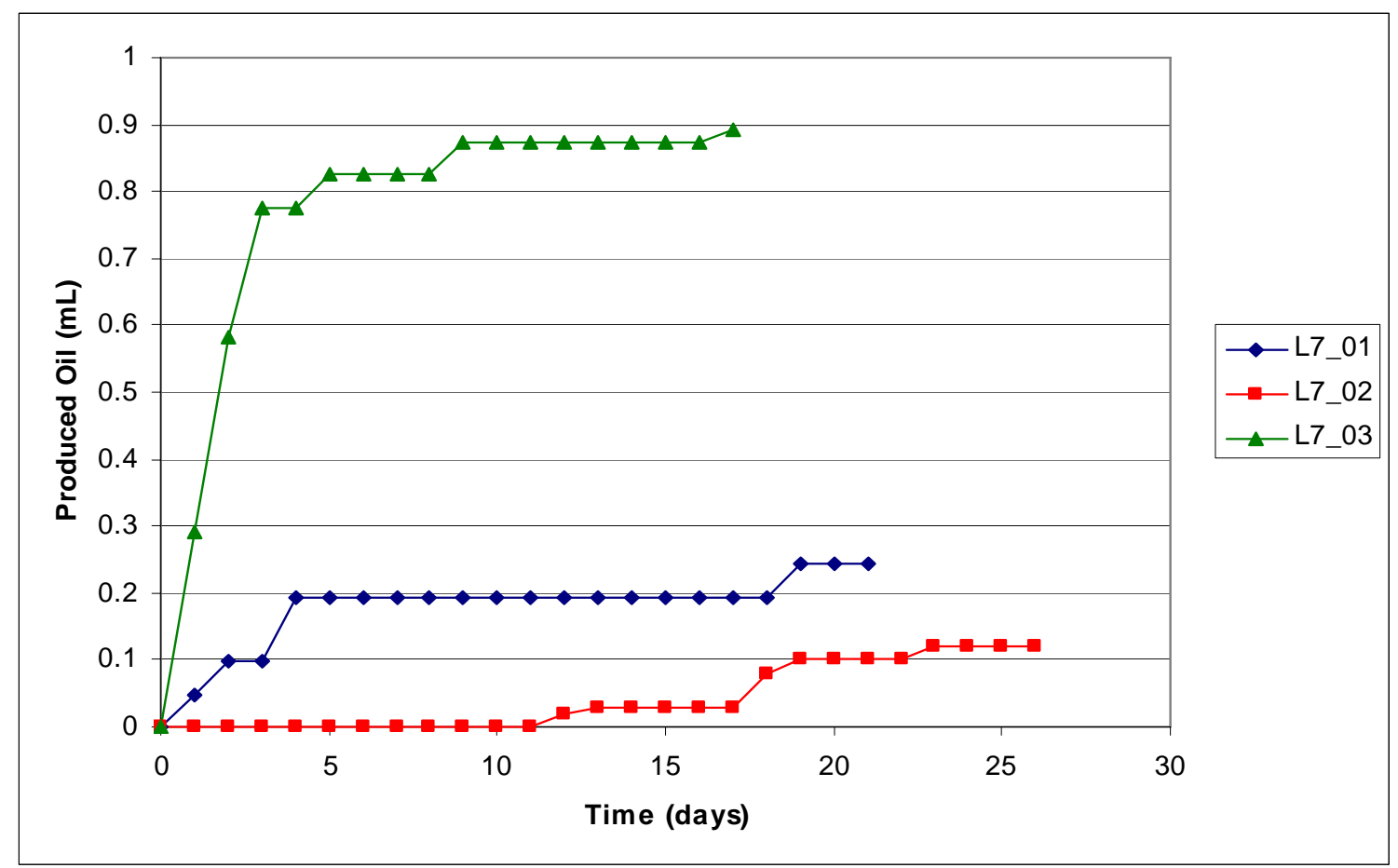

Figure 24 Spontaneously produced oil with $R O$ from $S_{w r}$

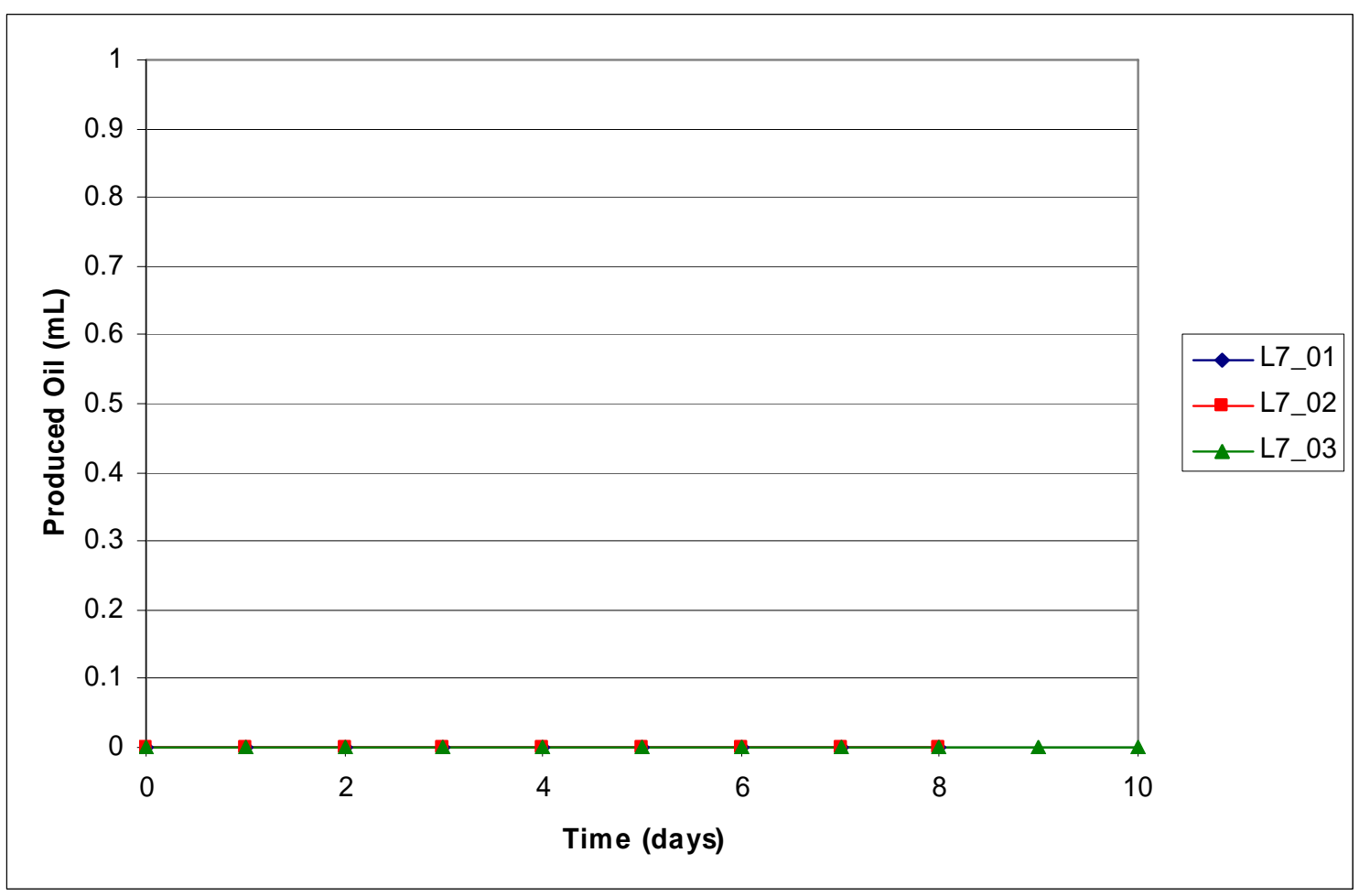

Figure 25 Spontaneously produced oil with RO after aging 


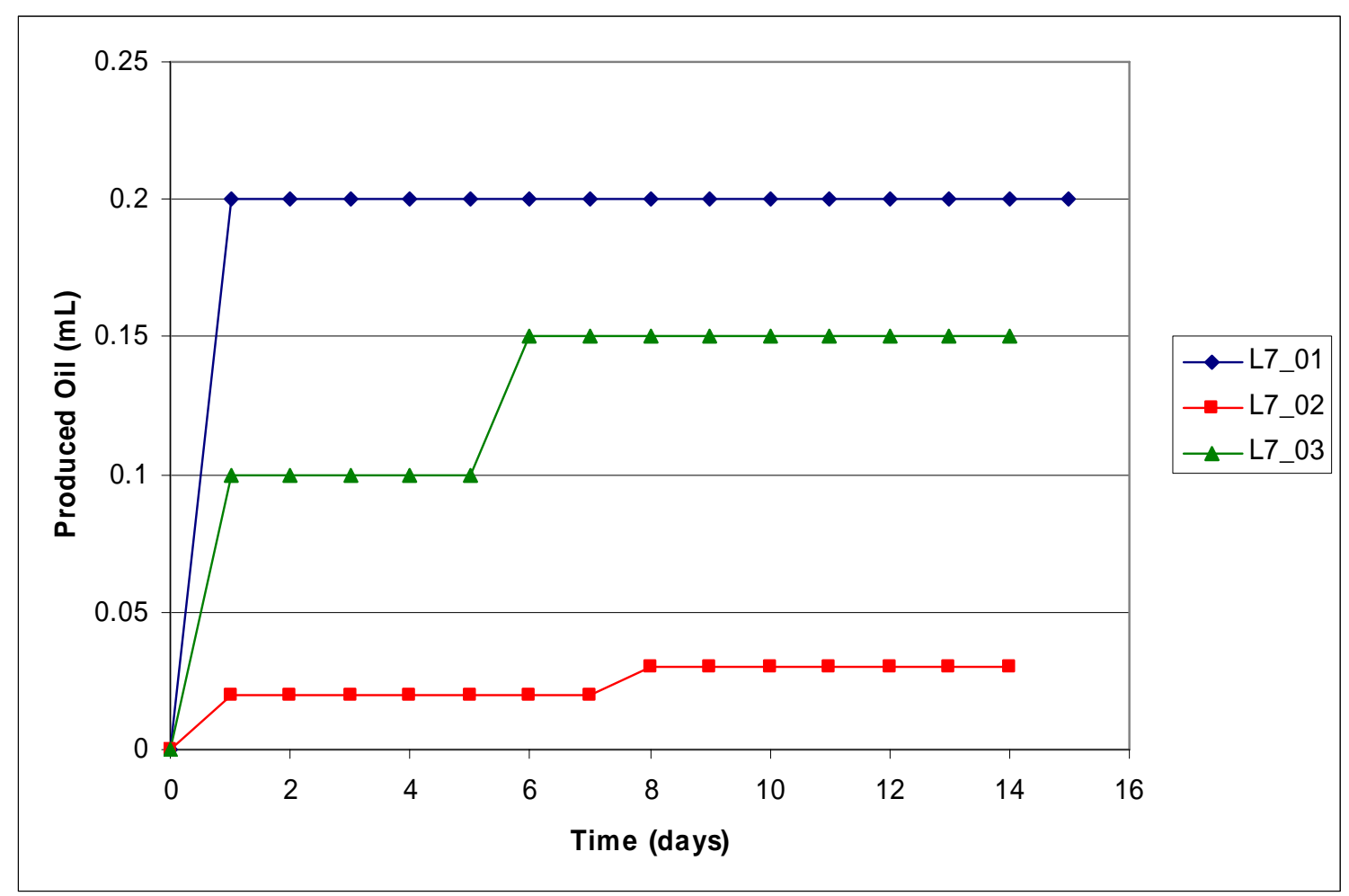

Figure 26 Spontaneously produced oil with 500 PPM STEOL CS-330 after aging

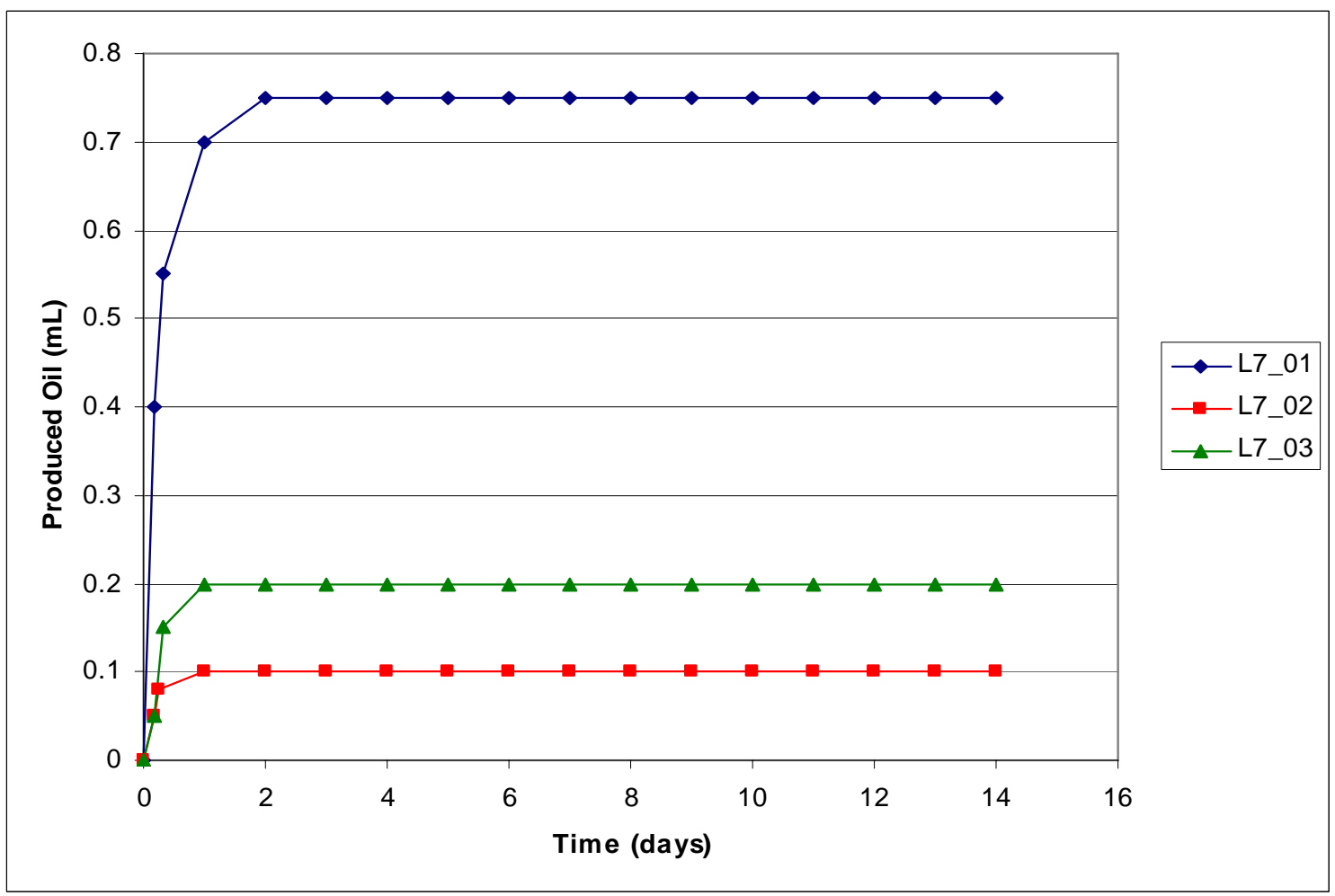

Figure 27 Spontaneously produced oil with 500 PPM surfactin after aging 
Table 5 shows final saturations for each core after spontaneous imbibition and forced imbibition of RO water starting from an initial $100 \%$ Soltrol 130 oil saturation. Baseline wettability to water is also shown.

\begin{tabular}{|c|c|c|c|}
\hline Core & L7_01 & L7_02 & L7_03 \\
\hline \multicolumn{4}{|l|}{ SPONTANEOUS IMBIBITION OF WATER (from $\mathrm{S}_{0}=1$ ) } \\
\hline Initial oil (mL) & 20.04 & 12.48 & 18.40 \\
\hline Spontaneously produced oil (mL) & 1.45 & 1.28 & 4.08 \\
\hline Oil remaining after spontaneous imbibition $(\mathrm{mL})$ & 18.59 & 11.20 & 14.32 \\
\hline $\mathrm{S}_{\mathrm{o}}$ after spontaneous imbibition & 0.93 & 0.90 & 0.78 \\
\hline $\mathrm{S}_{\mathrm{w}}$ after spontaneous imbibition & 0.07 & 0.10 & 0.22 \\
\hline \multicolumn{4}{|l|}{ FORCED IMBIBITION OF WATER TO $S_{\text {or }}$} \\
\hline Oil produced by forced imbibition $(\mathrm{mL})$ & 10.30 & 7.40 & 6.80 \\
\hline $\mathrm{K}_{\mathrm{w}}$ at $\mathrm{S}_{\mathrm{or}}(\mathrm{md})$ & 27.50 & 6.30 & 4.80 \\
\hline Tracer indicated water volume $(\mathrm{mL})$ & 15.30 & 9.80 & 10.50 \\
\hline$S_{w}$ at $S_{o r}$ by water tracer & 0.76 & 0.79 & 0.57 \\
\hline Baseline wettability to water, $\mathrm{I}_{\mathrm{b}}$ & 0.09 & 0.13 & 0.39 \\
\hline
\end{tabular}

Results indicate baseline wettability to water values ranging from 0.09 to 0.39 . This indicates that cleaned cores are oil wet after cleaning. The L7_03 core produced significantly more oil under spontaneous imbibition than did the L7_01. It is thought that this is due to greater capillary pressure in the lower permeability L7_03 core. Baseline wettability was calculated based upon tracer indicated saturations and not material valance values because the exact material balances were lost for our cores. Loss of material balance was due to operator inexperience and early mishaps (primarily improper collection of effluent during forced imbibition and tracer testing). 
Table 6 shows primary data from oil flooding the cores to residual water saturation and imbibition testing from $\mathrm{S}_{\mathrm{wr}}$. Amott wettability index to water using tracer data is also listed.

Table 6 Core saturations and $I_{w}$ values from $S_{r w}$

\begin{tabular}{|c|c|c|c|}
\hline Core & L7_01 & L7_02 & L7_03 \\
\hline \multicolumn{4}{|l|}{ SOLTROL FLOOD TO $\underline{S}_{w r}$} \\
\hline Water produced by oil flooding $(\mathrm{mL})$ & 13.00 & 7.00 & 7.70 \\
\hline $\mathrm{K}_{\mathrm{o}}$ at $\mathrm{S}_{\mathrm{wr}}(\mathrm{md})$ & 20.00 & 8.40 & 7.90 \\
\hline Tracer indicated oil volume $(\mathrm{mL})$ & 13.04 & 6.84 & 11.30 \\
\hline$S_{o}$ at $S_{w r}$ indicated by oil tracer & 0.65 & 0.55 & 0.61 \\
\hline $\mathrm{S}_{\mathrm{wr}}$ indicated by oil tracer & 0.35 & 0.45 & 0.39 \\
\hline \multicolumn{4}{|l|}{ SPONTANEOUS IMBIBITION OF WATER (from $\mathrm{S}_{w r}$ ) } \\
\hline Spontaneously produced oil (mL) & 0.24 & 0.12 & 0.89 \\
\hline Oil remaining after spontaneous imbibition $(\mathrm{mL})$ & 12.80 & 6.72 & 10.41 \\
\hline $\mathrm{S}_{\mathrm{o}}$ after spontaneous imbibition & 0.64 & 0.54 & 0.57 \\
\hline \multicolumn{4}{|l|}{ FORCED IMBIBITION OF WATER TO S } \\
\hline Oil produced by forced imbibition (mL) & 10.50 & 6.50 & 7.70 \\
\hline$K_{w}$ at $S_{o r}(m d)$ & 18.00 & 6.30 & 5.00 \\
\hline Tracer indicated water volume $(\mathrm{mL})$ & 15.23 & 9.40 & 8.73 \\
\hline$S_{w}$ at $S_{o r}$ indicated by water tracer & 0.76 & 0.75 & 0.47 \\
\hline$S_{\text {or }}$ indicated by water tracer & 0.24 & 0.25 & 0.53 \\
\hline Amott wettability to water, $I_{w}$ & 0.03 & 0.03 & 0.54 \\
\hline
\end{tabular}

Amott wettability to water values range from 0.03 to 0.54 . Note that much less oil was produced by spontaneous imbibition of water when starting from residual water saturation. This again indicates that the cleaned cores were oil-wet to mixed-wet. 
Table 7 shows saturations and wettability for each core after being aged with crude oil and then spontaneous imbibition tested with RO water.

Table 7 Core saturations and $I_{w}$ values from aged state

\begin{tabular}{|c|c|c|c|}
\hline \multirow{2}{*}{ Core } & \\
\hline & L7_01 & L7_02 & L7_03 \\
\hline \multicolumn{4}{|l|}{ SOLTROL FLOOD TO S } \\
\hline Water produced by oil flooding $(\mathrm{mL})$ & 11.15 & 6.80 & 9.00 \\
\hline $\mathrm{K}_{\mathrm{o}}$ at $\mathrm{S}_{\mathrm{wr}}(\mathrm{md})$ & 24.00 & 8.40 & 6.90 \\
\hline Calculated $S_{w r}$ (material balance value) & 0.20 & 0.21 & 0.00 \\
\hline \multicolumn{4}{|l|}{ CRUDE OIL FLOOD TO DISPLACE SOLTROL } \\
\hline Water produced by crude oil flooding (mL) & 0.00 & 0.00 & 0.00 \\
\hline$\underline{K_{o}}$ (crude) at $S_{w r}(\mathrm{md})$ & 40.00 & 8.20 & 10.30 \\
\hline \multicolumn{4}{|l|}{ SOLTROL FLOOD TO DISPLACE CRUDE } \\
\hline $\mathrm{K}_{\mathrm{o}}$ (soltrol) at $\mathrm{S}_{\mathrm{wr}}(\mathrm{md})$ & 46.00 & 17.50 & 14.40 \\
\hline Water Produced during soltrol displacing crude $(\mathrm{mL})$ & 0.00 & 0.00 & 0.00 \\
\hline Tracer indicated oil volume $(\mathrm{mL})$ & 23.60 & 13.90 & 19.50 \\
\hline$S_{o}$ indicated by oil tracer & 1.00 & 1.00 & 1.00 \\
\hline \multicolumn{4}{|l|}{ SPONTANEOUS IMBIBITION OF WATER (after aging) } \\
\hline Spontaneously produced oil (mL) & 0.00 & 0.00 & 0.00 \\
\hline Wettability to water & 0.00 & 0.00 & 0.00 \\
\hline
\end{tabular}

Tracer testing verified that all residual water had apparently evaporated and been displaced with crude during the aging process. Furthermore, a test done with $1 \mathrm{~mL}$ RO water and $9 \mathrm{~mL}$ crude oil in a $10 \mathrm{~mL}$ graduated cylinder placed in an oven at $90{ }^{\circ} \mathrm{C}$ confirmed that the water level dropped by $0.15 \mathrm{~mL}$ over a week period, thereby indicating that evaporation of water in the cores was possible. Note that permeability increased for the L7_01 and L7_03 cores during crude oil flooding, but that no water was visibly produced during these floods. Permeability significantly increased for all cores after aging. No oil was produced from the aged cores during spontaneous imbibition of RO water. Wettability to water was calculated as zero (strongly oil wet) for all three aged cores. 
Table 8 shows saturations for each core after being aged with crude oil and then spontaneous imbibition tested with 500 PPM STEOL CS-330 chemical surfactant from $100 \%$ Soltrol oil saturation. Imbibition testing was followed by forced imbibition of RO water. Calculated wettability for each core is also listed.

Table 8 Core saturations and $I_{w}$ values from aged state with STEOL CS-330

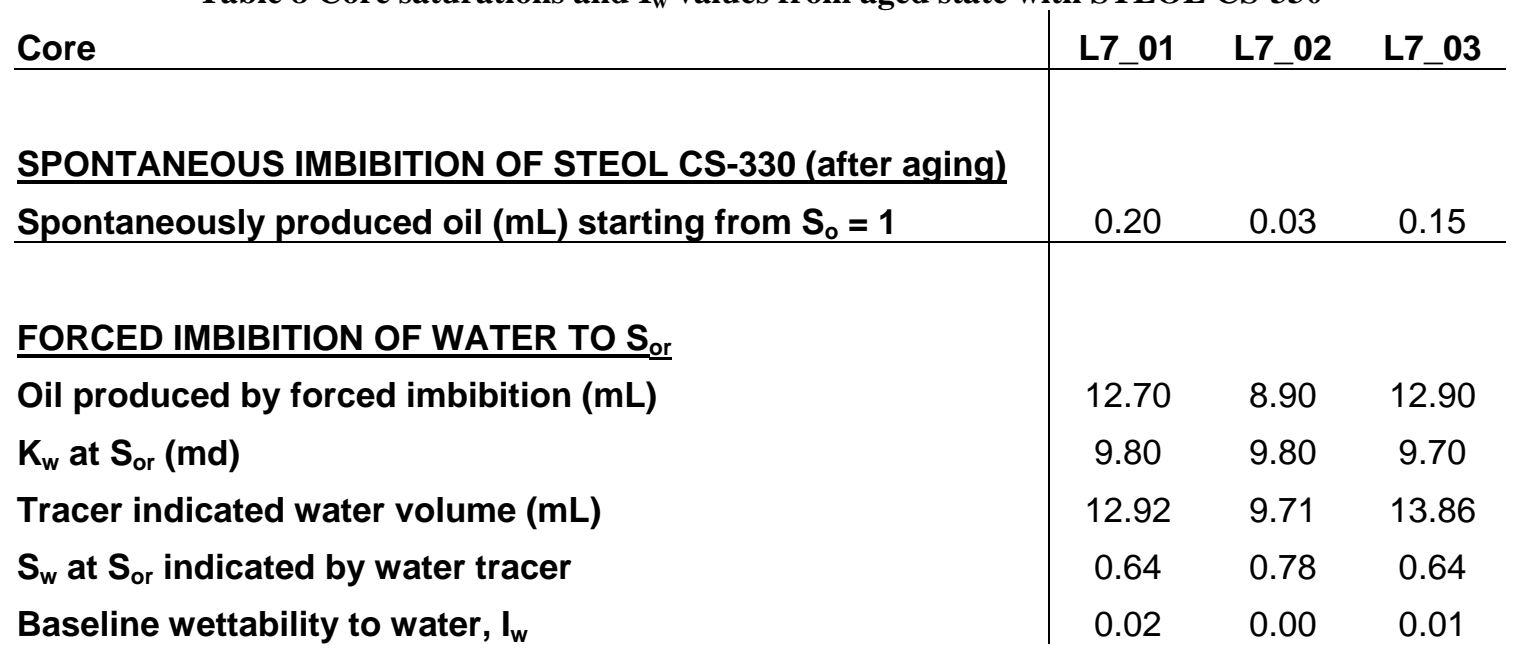

Only a small amount of oil was produced from the aged cores with STEOL CS-330 surfactant. After forced imbibition Amott wettability index to water was calculated as being nearly equal to zero for all three cores, indicating that the STEOL CS-330 was not very effective at changing the aged core wettability. It is believed that the STEOL was not able to penetrate into the oil wet cores but only produced oil from the core surface.

After testing with STEOL CS-330 the L7 cores were cleaned. They were then dried to constant weight, saturated and flooded with Soltrol 130, flooded with crude oil, and aged. Table 9 shows the steps performed to bring the cores back to the same aged state before imbibition testing with 500 PPM surfactin. 
Table 9 Saturations before imbibition testing

\begin{tabular}{|c|c|c|c|}
\hline Core & L7_01 & L7_02 & L7_03 \\
\hline \multicolumn{4}{|c|}{ SATURATION OF CLEANED CORES TO $\underline{S}_{0}=1$} \\
\hline Volume of oil into each dry core $(\mathrm{mL})$ & 19.0 & 10.5 & 15.2 \\
\hline \multicolumn{4}{|c|}{ SOLTROL FLOOD WITH 40 PSI BPR AT $\underline{S}_{0}=1$} \\
\hline$K_{0}$ (soltrol) at $S_{0}=1(\mathrm{md})$ & 40.00 & 14.20 & 12.90 \\
\hline \multicolumn{4}{|c|}{ CRUDE OIL FLOOD TO DISPLACE SOLTROL } \\
\hline $\mathrm{K}_{\mathrm{o}}$ (crude) (md) & 64.00 & 24.30 & 21.10 \\
\hline \multicolumn{4}{|l|}{ SOLTROL FLOOD TO DISPLACE CRUDE } \\
\hline $\mathrm{K}_{\mathrm{o}}$ (soltrol) at $\mathrm{S}_{\mathrm{o}}=1$ (md) & 43.50 & 13.10 & 11.90 \\
\hline Weight of oil saturated core (g) & 161.96 & 102.43 & 165.55 \\
\hline
\end{tabular}

In each case the oil amount was close to $1 \mathrm{PV}$, indicating that oil saturation was near $100 \%$. Oil saturation was also verified by permeability during Soltrol flooding as well as saturated core weights taken after displacing crude oil with Soltrol.

Table 10 shows saturations for each aged core after spontaneous imbibition testing with both RO water and 500 PPM surfactin from $100 \%$ Soltrol oil saturation. Spontaneous imbibition with RO water confirmed $100 \%$ wettability to oil.

Table 10 Core saturations and $I_{w}$ values from aged state with surfactin

\begin{tabular}{|c|c|c|c|}
\hline Core & L7_01 & L7_02 & L7_03 \\
\hline \multicolumn{4}{|l|}{ SPONTANEOUS IMBIBITION OF RO WATER (after aging) } \\
\hline Spontaneously produced oil $(\mathrm{mL})$ starting from $\mathrm{S}_{\mathrm{o}}=1$ & 0.0 & 0.0 & 0.0 \\
\hline \multicolumn{4}{|l|}{ SPONTANEOUS IMBIBITION OF SURFACTIN (after aging) } \\
\hline Spontaneously produced oil $(\mathrm{mL})$ starting from $\mathrm{S}_{\mathrm{o}}=1$ & 0.75 & 0.1 & 0.2 \\
\hline \multicolumn{4}{|l|}{ FORCED IMBIBITION OF RO WATER TO $\mathrm{S}_{\text {or }}$} \\
\hline Oil produced by forced imbibition $(\mathrm{mL})$ & 11.7 & 7.9 & 11.7 \\
\hline $\mathrm{K}_{\mathrm{w}}$ at $\mathrm{S}_{\mathrm{or}}(\mathrm{md})$ & 37.0 & 10.4 & 9.3 \\
\hline Baseline wettability to water, $I_{w}$ & 0.06 & .01 & .02 \\
\hline
\end{tabular}

Spontaneous imbibition results indicate that more oil was produced using the 500 PPM surfactin than was produced using 500 PPM STEOL CS-330. It is thought that higher permeability of the L7_01 core led to more favorable oil production than that of the L7_03 core. During spontaneous imbibition with surfactin the oil was probably produced by gravity dominated imbibition aided by altered wettability and decreased IFT. As with the STEOL CS-330 
surfactant, it seems that the surfactin was not able to penetrate into the oil wet cores but only produced oil for the first few days from the outer core surface. Calculated wettabilities to water indicate that the cores remain strongly oil wet. The difference between Soltrol CS-330 and surfactin can be accounted for by the lower surface tension of the latter at the concentration studied.

Imbibition experiments were also carried out using surfactant solutions, with 1-inch LKC cores that had initial water saturation but were either clean or had been flooded with surfactant solutions and aged for $24 \mathrm{~h}$ at $45{ }^{\circ} \mathrm{C}$ before being flooded with Soltrol 130 to $\mathrm{S}_{\text {wi }}$. Imbibition of SLS solution into a cleaned core with initial water saturation is shown in Figure 28. SLS was slightly more effective than surfactin in improving the imbibition.

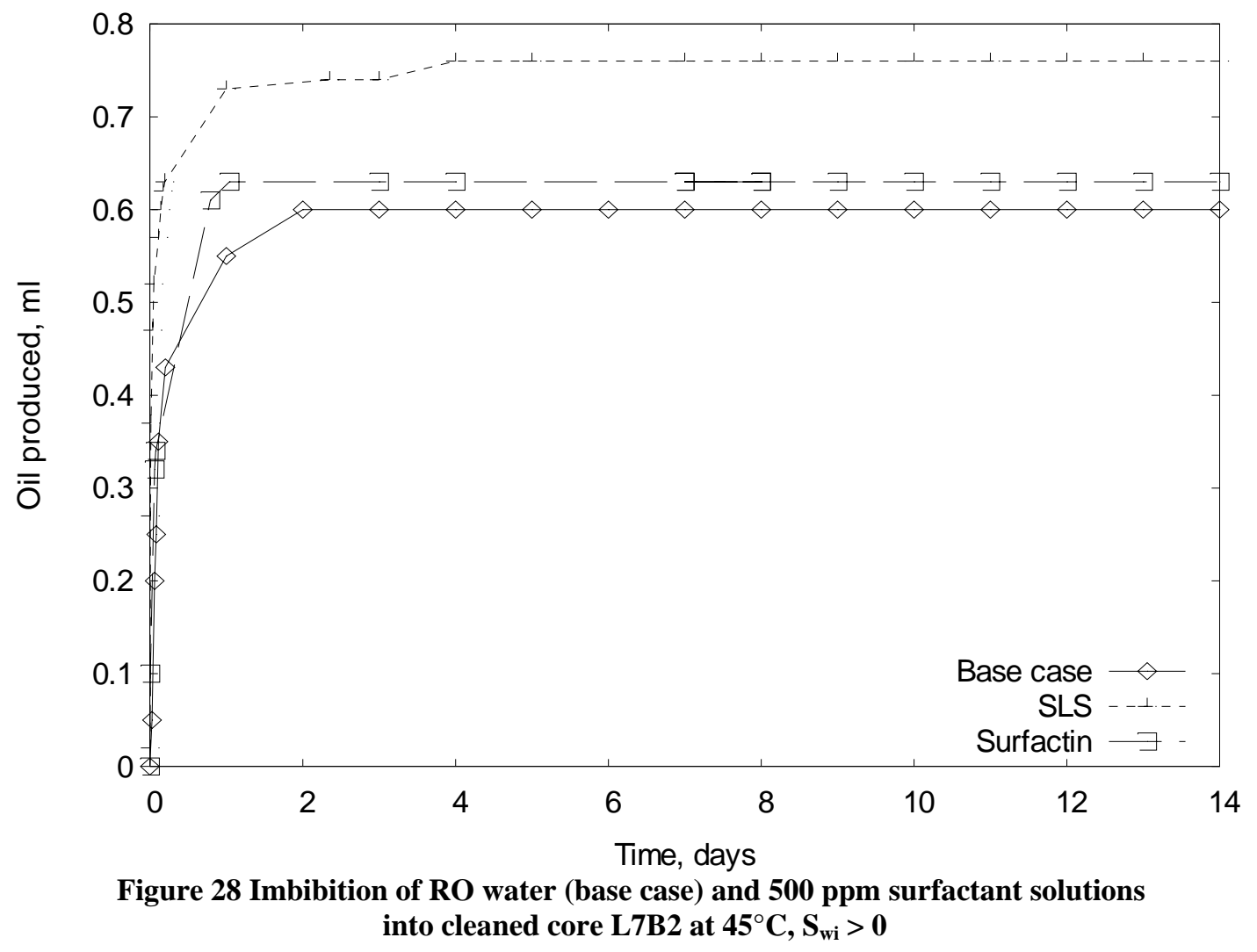


Figure 29 shows imbibition into a cleaned (mixed-wet) core that was flooded with surfactant solution and aged before flooding with Soltrol 130. Imbibition of SLS solution into an SLS-aged core is significantly greater than that of surfactin into a surfactin-aged core. The SLS case also performed better than SLS into a non-aged core at $\mathrm{S}_{\text {wi }}$. In the case of surfactin, imbibition is slower than in the non-aged core and the final volume of oil produced is no greater. SLS is therefore more effective in a mixed -wet core.

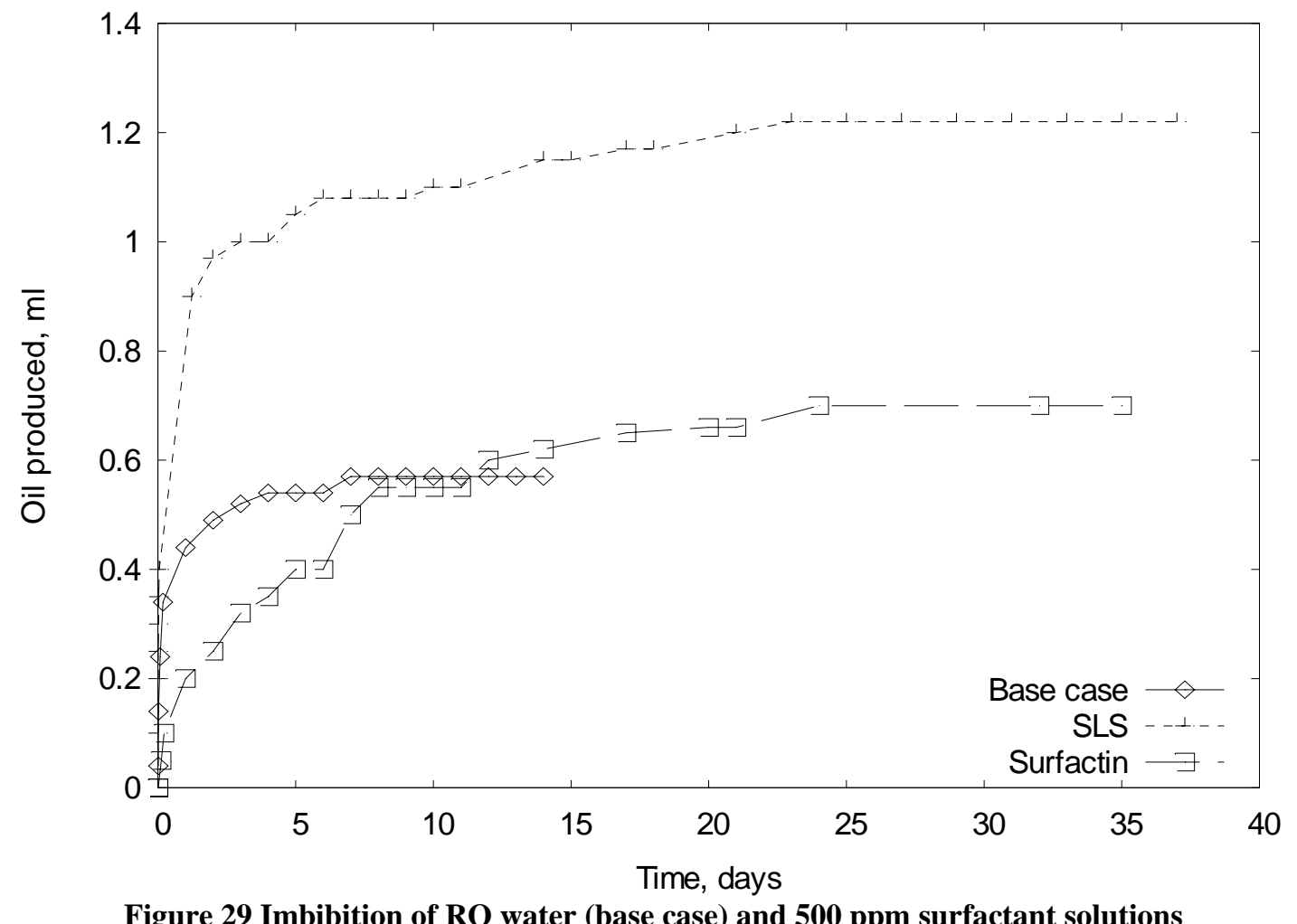
into core L7B3, cleaned, then aged with imbibing fluids for $24 \mathrm{~h}$ at $45^{\circ} \mathrm{C}$, from $\mathrm{S}_{\mathrm{wi}}>0$

In Figure 30, a core was rendered oil-wet by aging with crude oil as previously described. The core was then flooded with $500 \mathrm{ppm}$ surfactant solution and aged at $45{ }^{\circ} \mathrm{C}$ for 24 before being placed in an imbibition cell with 


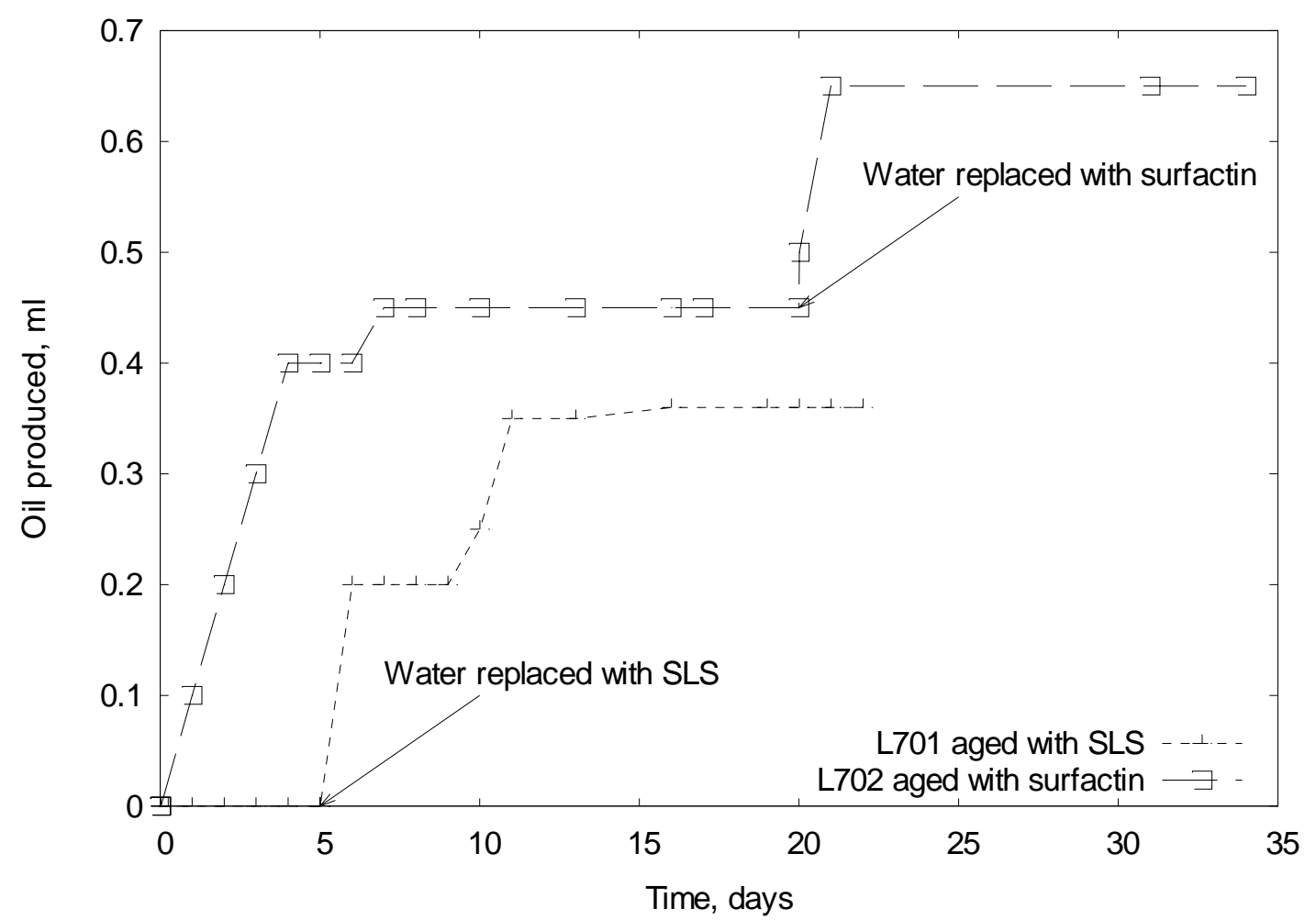

Figure 30 Imbibition of RO water followed by $500 \mathrm{ppm}$ surfactant solutions water into surfactant-aged oil-wet cores from $S_{w i}>0$

\subsection{Surfactant Loss Due to Adsorption and Retention on Reservoir Rock}

Propagation of surfactant through the reservoir is very important in EOR processes. Several factors can reduce the rate of propagation, including partitioning into immobile phases, precipitation and adsorption ${ }^{29}$. Adsorption is probably the most important mechanism affecting retention. In this study, we first reviewed the literature to survey the adsorption models that have been developed to describe surfactant adsorption in porous media. These models were then evaluated using the experimental data from this study. The goal is to develop an adsorption model that can accurately describe the biosurfactant adsorption on carbonate rock. The following is a summary of the two most commonly used models for surfactant adsorption - the Langmuir and the Surface Excess models.

Figure 31 shows adsorption isotherms for two surfactants, sodium $p$-3-nonylbenzene sulfonate (SNBS) and dodecyl pyridinium chloride (DPC), on rutile $\left(\mathrm{TiO}_{2}\right)$ reported by Koopal et al. ${ }^{30}$ The authors identified four distinct regions of surfactant adsorption behavior. In region I, there is a linear relationship between adsorption and concentration. Region II has a slope much larger than unity and is explained by the combination of electrostatic interactions between the head groups and the surface; and the lateral attraction between adjacent tails. Region III is believed to be due to micellar adsorption. In region IV, the surfactant solution is above the CMC, and increasing concentration has no effect on adsorption. 


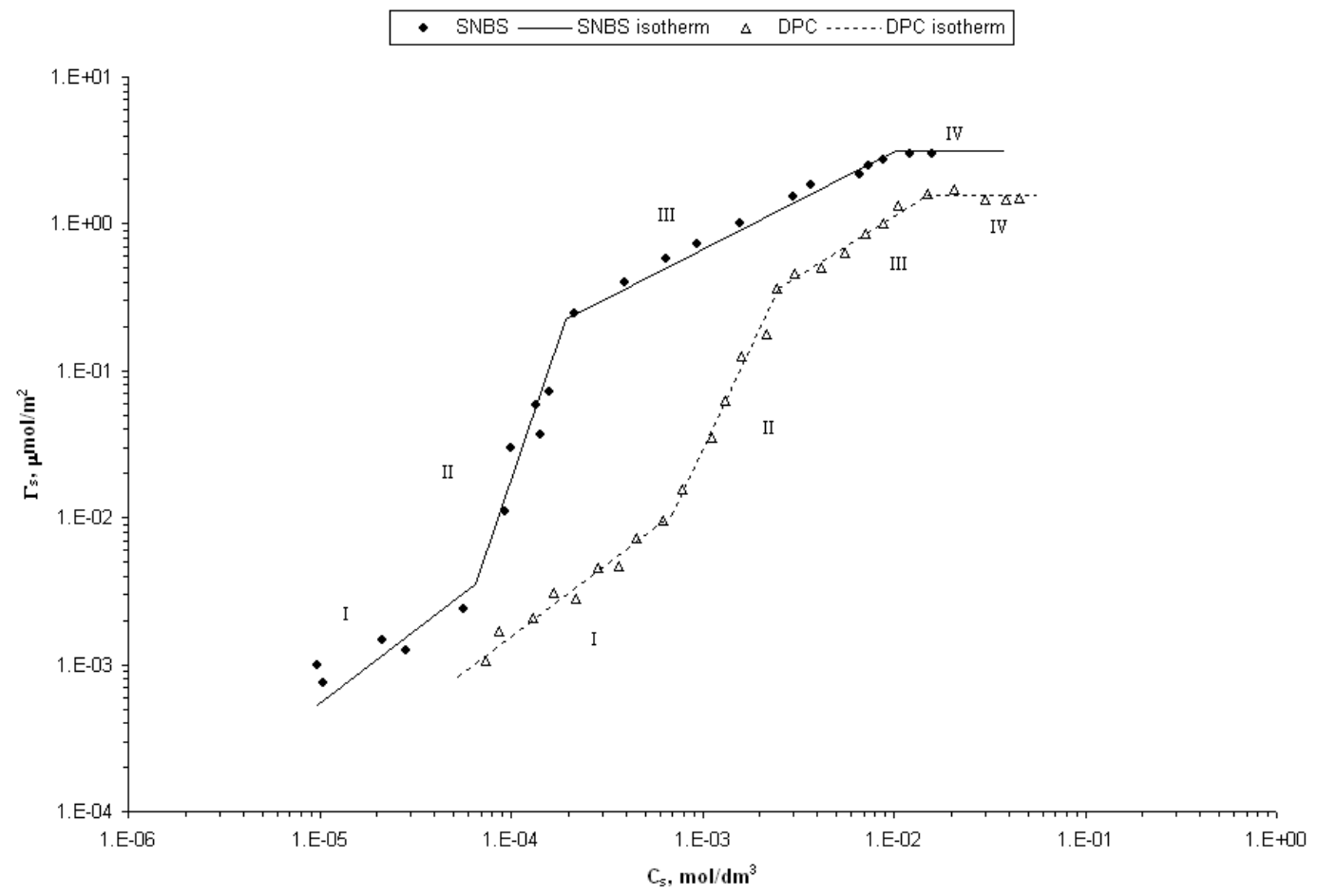

Figure 31 Adsorption isotherms for two surfactants showing different regions of surfactant adsorption behavior (I - IV). Graph digitized ${ }^{26}$ from Koopal et al. ${ }^{30}$

Surfactant adsorption at the solid/liquid interface can be modeled with either the Langmuir model or surface excess theory. The Langmuir equilibrium isotherm can be expressed as

$$
C_{r}=\frac{a C}{1+b C}
$$

where $C_{r}$ is the amount of adsorbed surfactant per gram of solid $(\mathrm{mg} / \mathrm{g}), C$ is surfactant concentration, and $a$ and $b$ are constants. A mass transfer equation describing dispersion and adsorption of a chemical component in a solution flowing through a porous medium can be derived as

$$
D \frac{\partial^{2} C}{\partial x^{2}}-\frac{q}{A \phi} \frac{\partial C}{\partial x}=\frac{\partial C}{\partial t}+\frac{(1-\phi)}{\phi} \rho_{r} \frac{\partial C_{r}}{\partial t}
$$

Using the Langmuir model, the adsorption kinetics term can be expressed as

$$
\frac{\partial C_{r}}{\partial t}=\frac{\partial C_{r}}{\partial C} \frac{\partial C}{\partial t}=\frac{a}{(1+b C)^{2}} \frac{\partial C}{\partial t} .
$$


To obtain the adsorption isotherm, Eqs. 5 and 6 are solved simultaneously. This model has been used successfully in simulating adsorption of some chemical flood EOR processes. ${ }^{29,31,32}$ The Langmuir model is able to represent the general shape of many adsorption isotherms and its two adjustable parameters allow the model to be fitted to many data sets. Huang and Novosad ${ }^{33}$ reported good agreement between the experimental data and simulation results at low levels of surfactant adsorption using both Langmuir and surface excess models. However, at higher levels of adsorption, the surface excess model seems to be a better match to the surfactant effluent profiles obtained in their experiment.

The literature indicates that the surface excess model is a more thermodynamically consistent model of surfactant adsorption at the solid/liquid interface. ${ }^{33-35}$ The surface excess of component $i$ in a binary mixture is defined as

$$
n^{e}{ }_{i}=n^{o}\left(x^{o}{ }_{i}-x_{i}\right),
$$

where $i=1$ denotes surfactant and $i=2$ denotes solvent. By assuming mass balance, Eq. 7 can also be written as

$$
n^{e}{ }_{i}=n^{\prime}\left(x_{i}^{\prime}-x_{i}\right) .
$$

The surface excess can be obtained experimentally without ambiguity, however a more useful quantity is the amount adsorbed $\left(n^{\prime}\right)$. To define the amount adsorbed at the solid/liquid interface, a boundary between the bulk phase and adsorbed phases must be specified. The frequently used monolayer model of adsorption can be used for this purpose:

$$
\frac{1}{n^{\prime}}=\frac{x_{1}^{\prime}}{m_{1}}+\frac{x_{2}^{\prime}}{m_{2}} .
$$

This model is also suitable for simulation of multilayered adsorption. ${ }^{32,33}$ Based on Eq. 8 the surface excess is equal to zero at both $x_{i}=0$ and $x_{i}=1$. So, the adsorption isotherm must go through a maximum between these concentrations, making extrapolation difficult. Selectivity, $S$, a measure of distribution between bulk and adsorbed phases, was suggested as a more convenient variable allowing easier extrapolation of experimental data. ${ }^{33}$ It is defined by

$$
S=\frac{x_{1}^{\prime} / x_{2}^{\prime}}{x_{1} / x_{2}} .
$$

Combining Eqs. 8, 9, and 10 leads to the final expressions for surface excess and amount of surfactant adsorbed $\left(n_{1}{ }^{\prime}=n^{\prime} x_{1}{ }^{\prime}\right)$ as a function of surfactant concentration in the bulk phase 


$$
\begin{gathered}
n_{1}^{e}=\frac{m_{1} x_{1} x_{2}(S-1)}{S x_{1}+\left(m_{1} / m_{2}\right) x_{2}}, \\
\text { and } n_{1}{ }^{\prime}=\frac{m_{1} x_{1} S}{S x_{1}+\left(m_{1} / m_{2}\right) x_{2}} .
\end{gathered}
$$

The mass transfer equation for the flow of an adsorbing chemical through a porous medium can be derived as:

$$
\lambda \frac{q \rho_{l}}{A \phi} \frac{\partial^{2} x_{1}}{\partial x^{2}}-\frac{q \rho_{l}}{A \phi} \frac{\partial x_{1}}{\partial x}=\frac{1-\phi}{\phi} \rho_{r} n^{o} \frac{\partial x_{1}}{\partial t}+\frac{1-\phi}{\phi} \rho_{r} \frac{\partial n^{e a}{ }_{1}}{\partial t}
$$

Using appropriate initial and boundary conditions, along with the kinetic term defined below, Eq. 13 can be solved numerically to get the adsorption isotherm

$$
\frac{\partial n_{1}^{e a}}{\partial t}=k_{i}\left(n_{1}^{e}-n_{1}^{e a}\right)
$$

where $n_{1}{ }^{e}$ is the equilibrium surface excess given by Eq. 11 and $n_{1}{ }^{e a}$ is the actual surface excess. When $n_{1}{ }^{e}>n_{1}{ }^{e a}$, adsorption occurs, and $k_{i}=k_{1}$. Conversely, when $n_{1}{ }^{e}<n_{1}^{e a}$, desorption takes place, and $k_{i}=k_{2}$. The concentrations calculated by solving Eq. 13 are matched to experimental data using the six adjustable parameters: the dispersion coefficient $\lambda$, monolayer coverages $m_{1}$ and $m_{2}$, selectivity $\mathrm{S}$, and kinetic constants $k_{1}$ and $k_{2}$.

Mannhardt and Novosad ${ }^{29}$ suggest that values of $m_{1}$ and $m_{2}$ can be estimated independently from the molecular area of components 1 and 2 and the specific surface area of the rock, reducing the number of parameters to four. They compared the simulation results that they obtained from both the surface excess and the Langmuir models, and they found that the surface excess model performed better in modeling the adsorption of surfactants (Figure 32). 


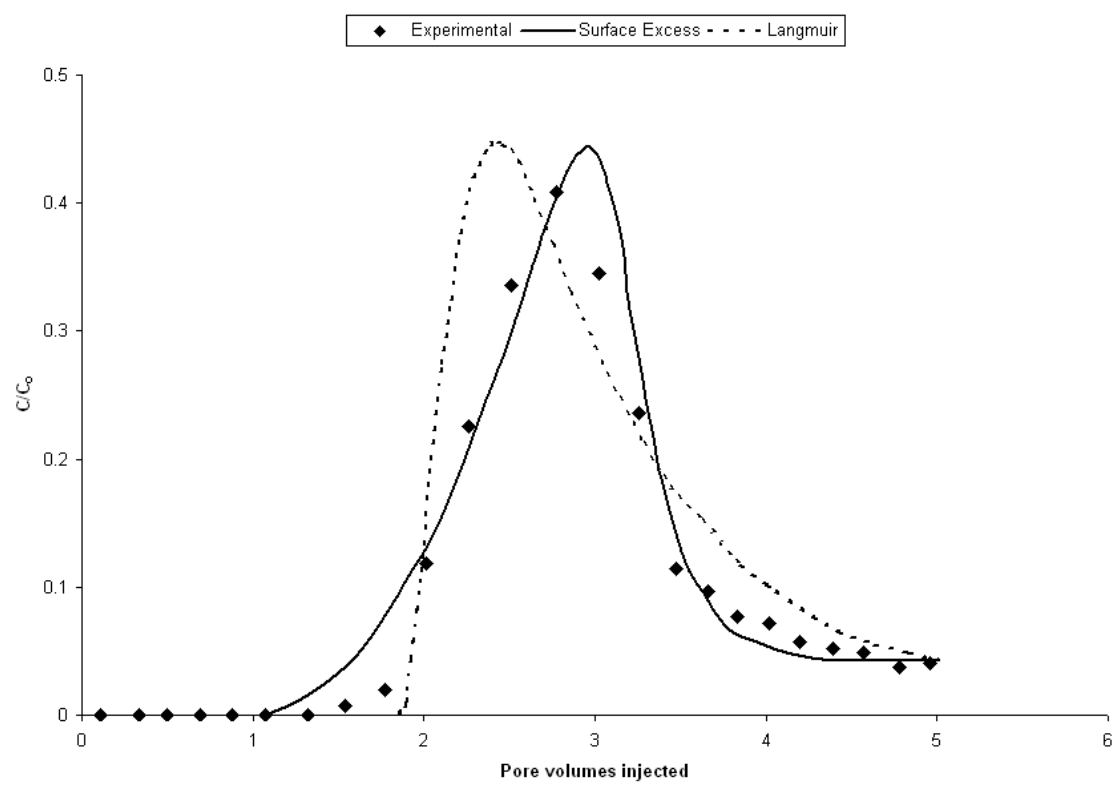

Figure 32 Comparison of Langmuir and Surface Excess models with experimental data. Graph digitized ${ }^{26}$ from Mannhardt and Novosad ${ }^{29}$

\section{Static Adsorption}

Initially, static absorption tests of benchmark surfactants on crushed carbonate material were carried out using total organic carbon (TOC) to determine surfactant concentrations (Figure 33). The data was corrected to account for interference from residual solvents left in the crushed material following cleaning, which highlights the need to ensure that organic solvents are fully displaced during the cleaning process.

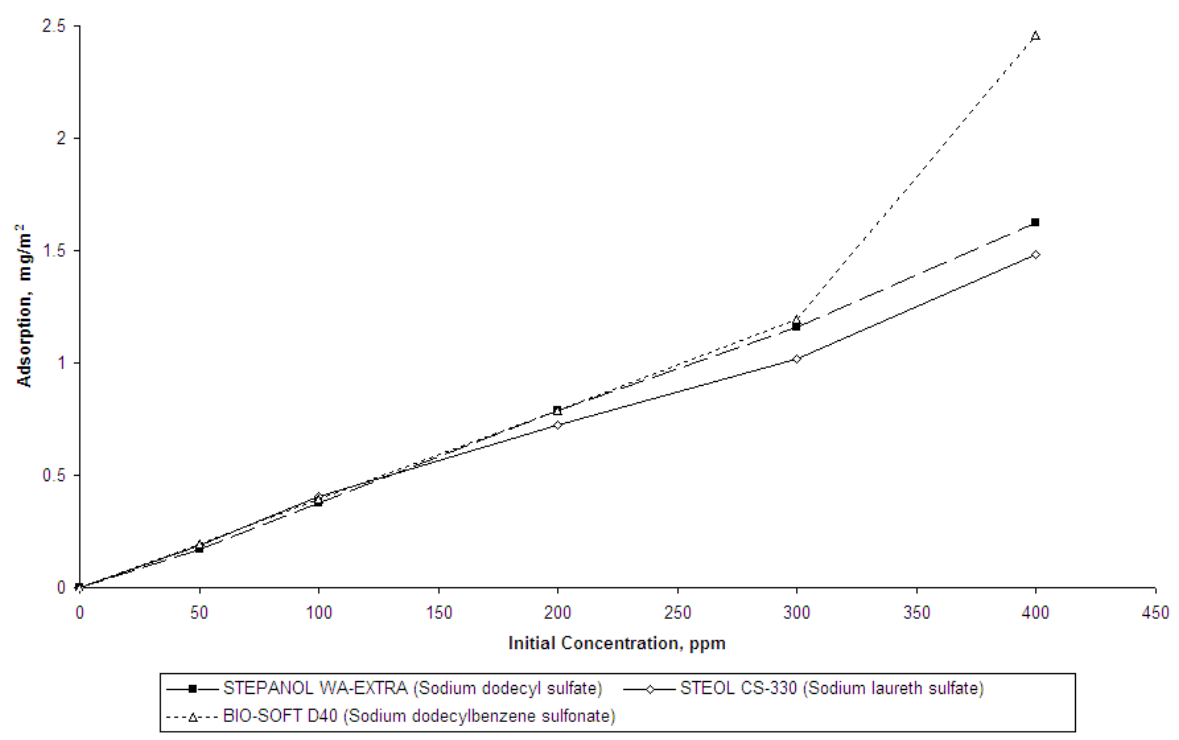

Figure 33 Adsorption of surfactants onto crushed carbonate after 24h 
While TOC was used with some success for synthetic surfactants, it is labor-intensive because the sample must be sparged by hand to avoid foam production seen in the automated sparging performed by the TOC analyzer. Also TOC is not specific to surfactants and hence must be interpreted with caution in systems with additional sources of organic carbon (such as residual solvents or crude oil used to alter wettability to oil-wet). Another potential measurement technique, HPLC, is not sensitive enough to accurately determine surfactin at low concentrations.

To avoid these limitations, a surfactant ion selective electrode (SUR1502 from phoenix Electrode Company, Houston, TX) is used to identify the potentiometric endpoint in titration of the surfactants with Hyamine 1622 (Benzethonium chloride, Figure 34). ${ }^{38}$

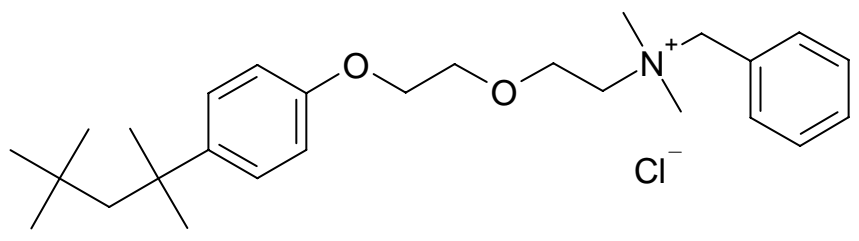

Figure 34 Hyamine 1622 (Benzethonium chloride)

This method has been used successfully by Hirasaki \& Zhang. ${ }^{13}$ The end point is indicated by the inflection point in the curve of $\mathrm{E} / \mathrm{V}$, most easily identified by looking for a maximum in the first derivative or by the second derivative passing through zero (Figure 35).

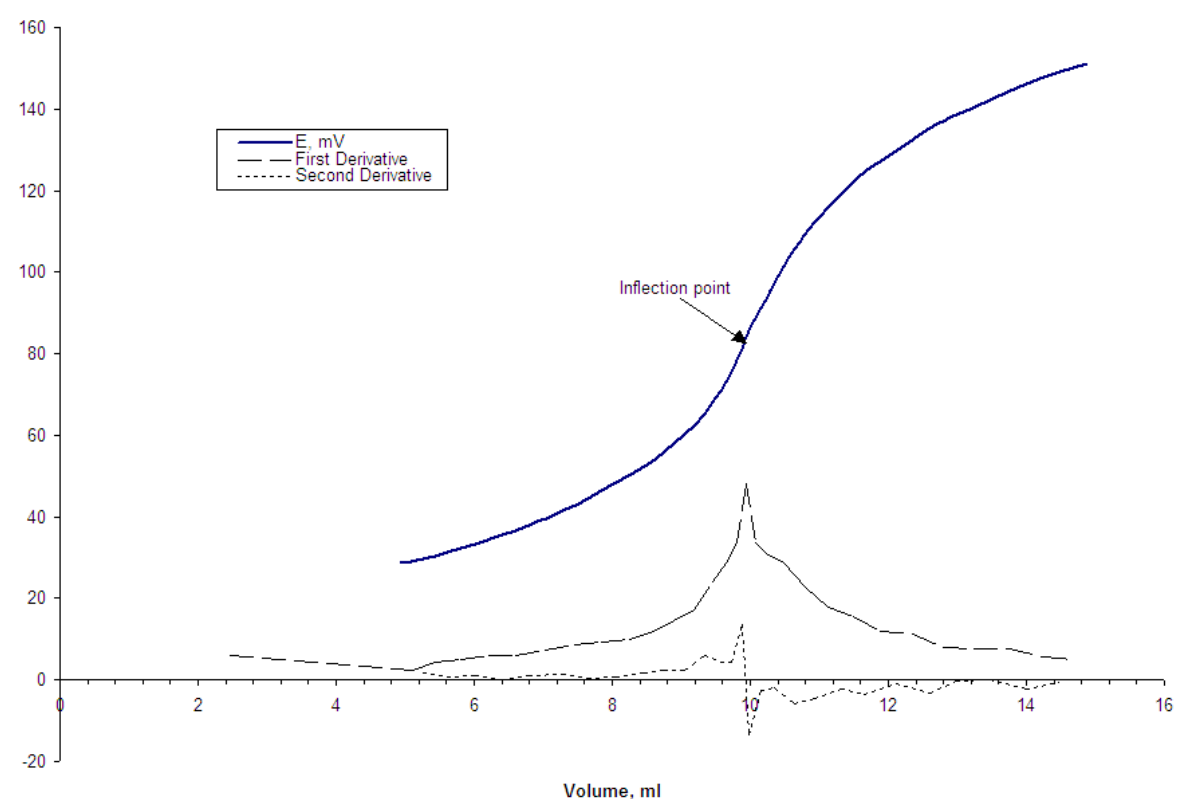

Figure 35 Example titration of anionic surfactant with $0.1 \mathrm{~mol} / \mathrm{l} \mathrm{Hyamine} 1622$ (data digitized ${ }^{39}$ from Radiometer Analytical ${ }^{40}$ ) with derivatives to show inflection point 
Static adsorption isotherms were obtained by measuring surfactant concentration before and after equilibrating with crushed rock. Thirty $\mathrm{ml}$ of the each surfactant solution was added to a $50 \mathrm{ml}$ centrifuge tube containing a known mass of crushed rock. The tubes were capped and shaken horizontally at $50 \mathrm{~min}^{-1}$ for 24 or $48 \mathrm{~h}$ to establish adsorption equilibrium. The samples were then centrifuged for $30 \mathrm{~min}$ at $3000 \mathrm{~min}^{-1}$. Supernatants were separated and analyzed for residual surfactant concentrations. The difference in concentration between the stock solutions and the samples was used to evaluate the adsorption. All adsorption experiments were carried out at room temperature.

Static adsorption experiments were performed with different surfactant solution mass/rock mass ratios to identify whether this affected the degree of adsorption observed. Different masses of cleaned crushed rock were placed in $30 \mathrm{ml}$ of surfactant solutions of known concentration. Figure 36 shows that for a $1.44 \mathrm{mmol} / 1$ solution of STEOL CS-330 adsorption on both Miami and BF rocks, specific adsorption declines with increasing rock mass. More work will have to be done to investigate this phenomenon. The same trend was observed for a $0.37 \mathrm{mmol} / 1$ solution of surfactin on BF rock (Figure 37), but adsorption of surfactin was higher than that of STEOL CS-330. The greater adsorption on Miami compared to BF is consistent with Miami's higher specific surface area.

Figure 38 shows STEOL CS-330 adsorption isotherms obtained using different masses of rock. The results are consistent with the earlier observations that higher masses of adsorbent exhibit lower specific adsorption. Good linear correlations were obtained between residual concentrations and rock masses for the selected initial concentrations (Figure 39). Multiple tests confirmed that this effect was repeatable, and that for a given mass of rock, consistent results were obtained.

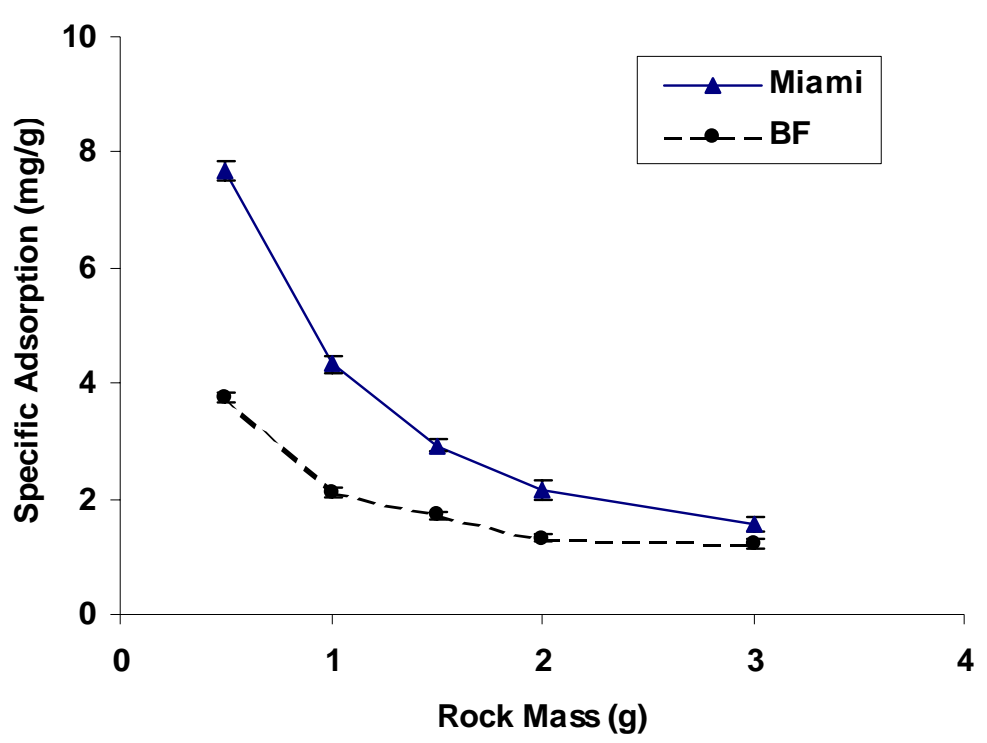

Figure 36 Adsorption of $1.44 \mathrm{mmol} / \mathrm{l}$ STEOL CS-330 vs. mass of crushed BF and Miami rocks. Error bars $=1$ Std. Dev., $n=3$ 


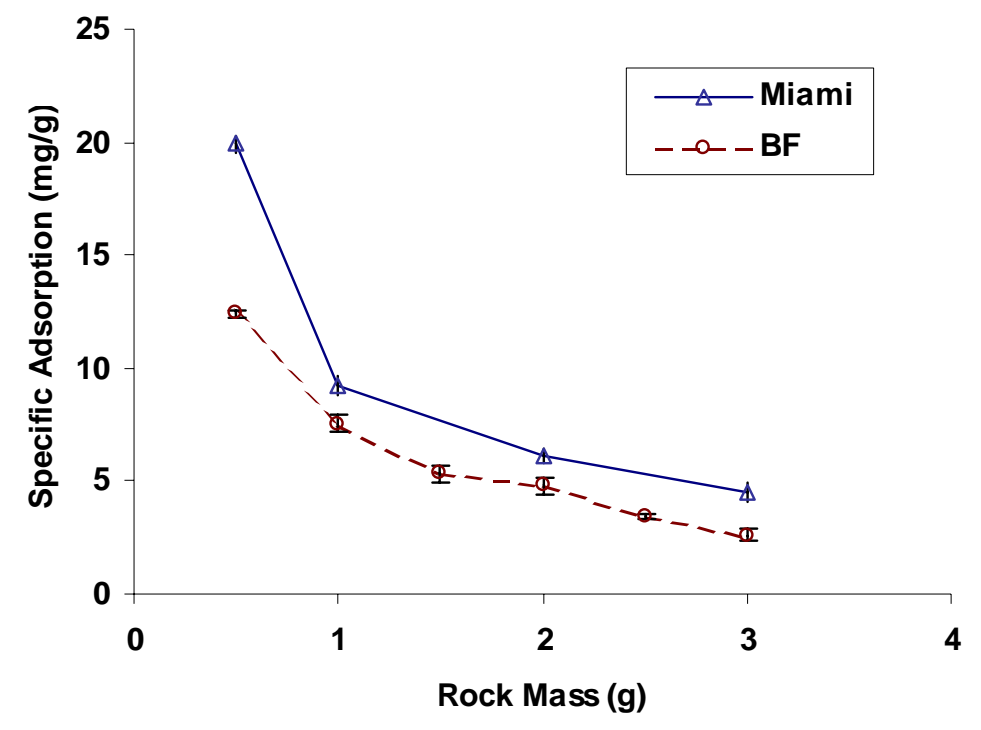

Figure 37 Adsorption of $0.37 \mathrm{mmol} / \mathrm{l}$ surfactin vs. mass of crushed BF and Miami rocks. Error bars $=1$ Std. Dev., $\mathbf{n}=3$

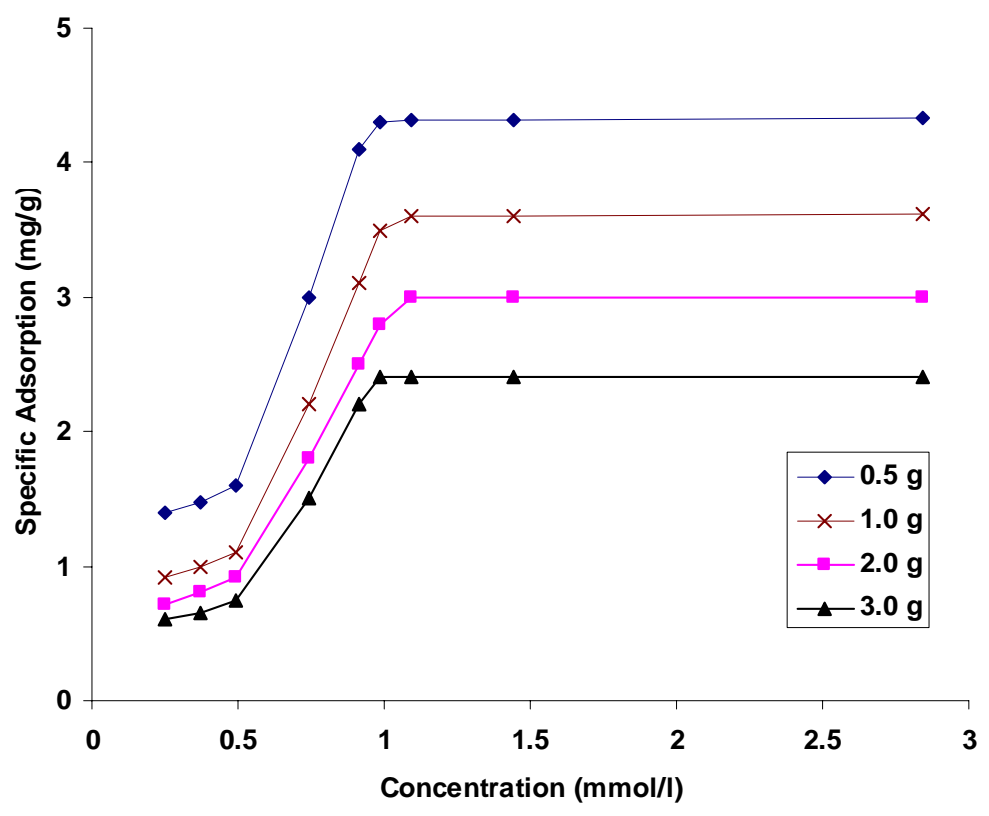

Figure 38 STEOL adsorption isotherms on different masses of crushed BF rock to show decline in adsorption with increasing rock mass 


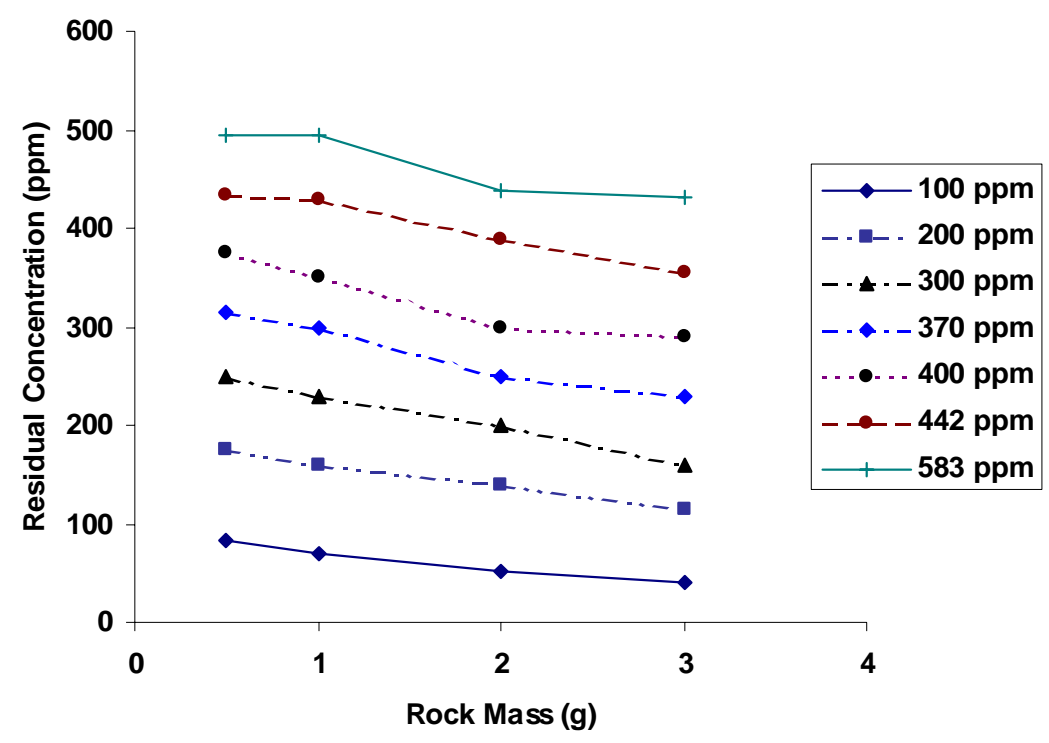

Figure 39 Residual concentrations versus rock mass for various initial concentrations of STEOL CS-330 on crushed BF rock

Since specific adsorption was seen to decline with increasing rock mass, all subsequent experiments were done using a fixed mass of rock $(2.0 \mathrm{~g})$ and surfactant solution $(30 \mathrm{ml})$ to ensure that results were comparable. To compare the adsorption levels of surfactin with STEOL CS-330, adsorption isotherms for both were obtained using crushed BF and L7 rocks (Figure 40). In both cases, surfactin had a higher specific adsorption, and the maximum adsorption density was reached at a lower concentration. This reflects the lower critical micelle concentration (CMC) of surfactin at $25^{\circ} \mathrm{C}$, variously reported as $7.5 \mu \mathrm{mol} / 1,{ }^{26} 9.4 \mu \mathrm{mol} / 1,{ }^{27}$ and $24.1 \mu \mathrm{mol} / 1,{ }^{28}$ ) compared to $100 \mu \mathrm{mol} / 1$ for sodium laureth sulfate (Mukerjee \& Mysels 1971). 


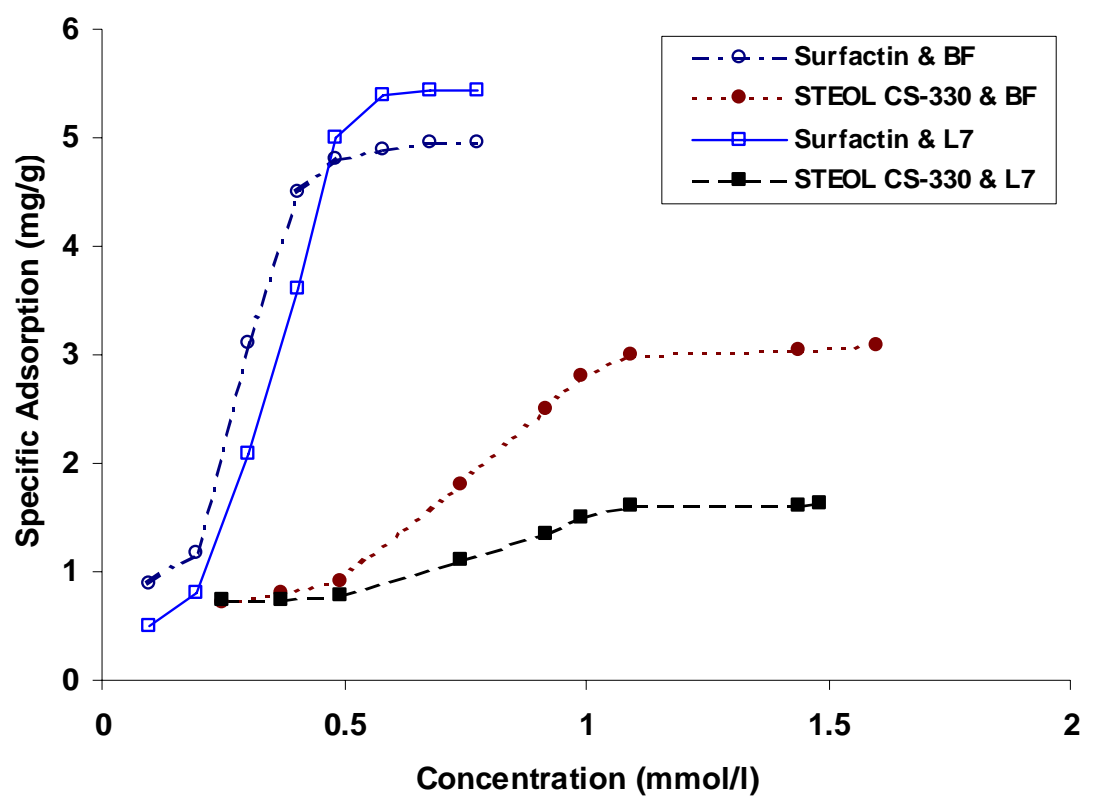

Figure 40 Adsorption isotherms of $30 \mathrm{ml}$ of $420 \mathrm{ppm}$ STEOL CS-330 and surfactin on $2.0 \mathrm{~g}$ of crushed BF and $\mathrm{L} 7$ rocks

The isotherms for surfactin and STEOL CS-330 on both L7 and BF rocks exhibit the four regions seen in a typical adsorption isotherm (Figure 41). ${ }^{41}$ Region I, which is also known as the Henry's law region, corresponds to adsorption of surfactant monomers and there is a linear relationship between the concentration and adsorption density. The main mechanism of adsorption is electrostatic attraction between the charged head group of the surfactant molecule and surface of the rock. Region II is characterized by a sharp increase in the adsorption, corresponding to the formation of bilayers and aggregates on the solid surface. Surfactant tail groups can form aggregates by hydrophobic bonding in this region. In Region III the same forces are responsible for adsorption. However, there is a decrease in the slope of the adsorption isotherm. In this region aggregate-aggregate interactions and formation of hemimicelles (monolayer aggregates) and admicelles (bilayer aggregates) become more important. Region IV shows the attainment of the critical micelle concentration (CMC) and adsorption density reaches a plateau as micelle formation competes with surfactant adsorption. Physical bases for these adsorption regimes are shown schematically in Figure 42. 


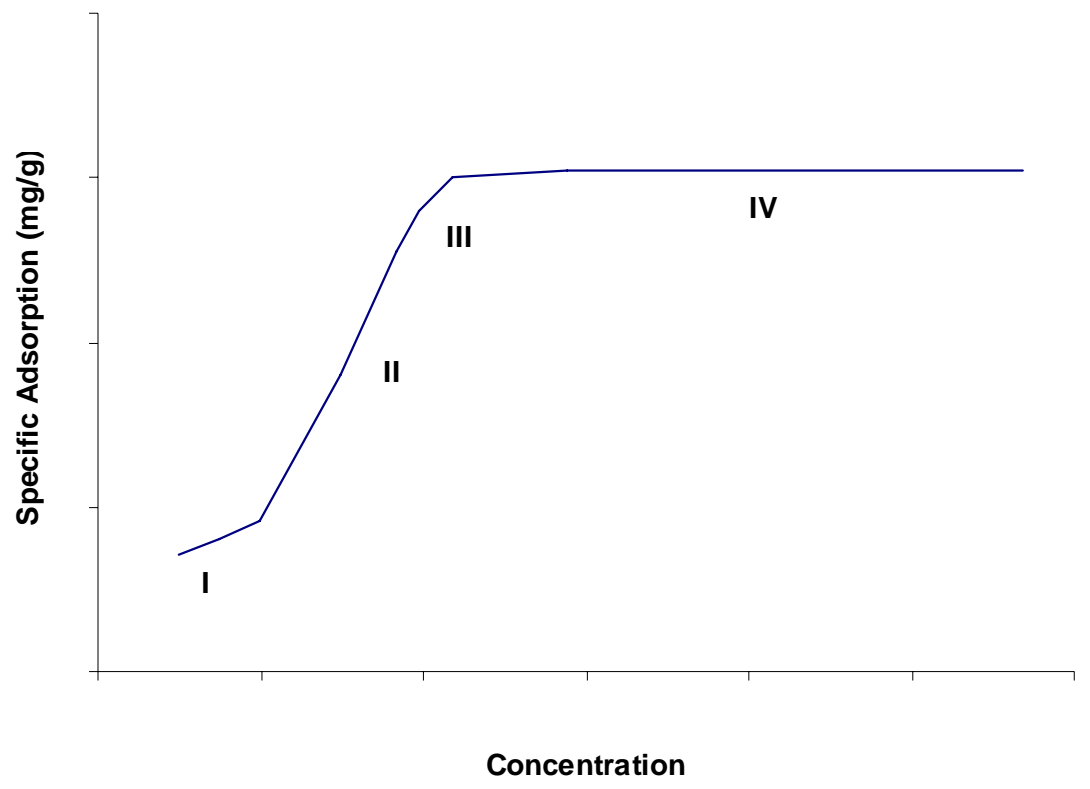

Figure 41 Typical adsorption isotherm of surfactant on rock indicating four regions ${ }^{41}$
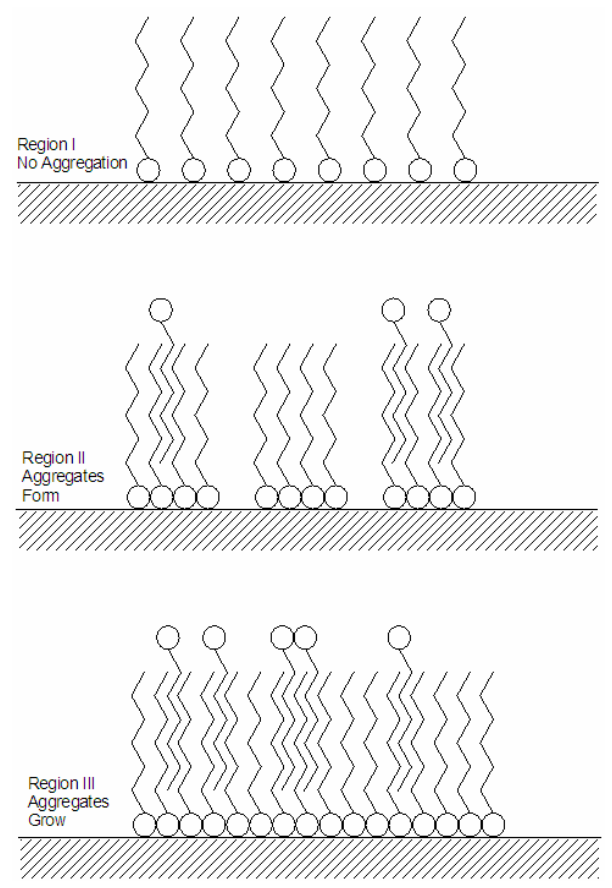

Figure 42 Suggested physical bases for the first three regions seen in a typical adsorption isotherm ${ }^{42}$ 


\section{Dynamic Adsorption}

Dynamic adsorption was measured in a one-inch diameter L7 core plug saturated with RO-water in a Hassler type core holder. A known mass and concentration of surfactant solution was circulated through the core for $24 \mathrm{~h}$ at $2 \mathrm{ml} / \mathrm{min}$. Equilibrium concentration of the solution was determined by potentiometric titration for replicate samples. This was repeated for several concentrations and the relation between adsorption and equilibrium concentration was plotted. The pump and tubing were drained between concentrations and the core holder and pore volume were considered in calculating the dilution factor of the next solution.

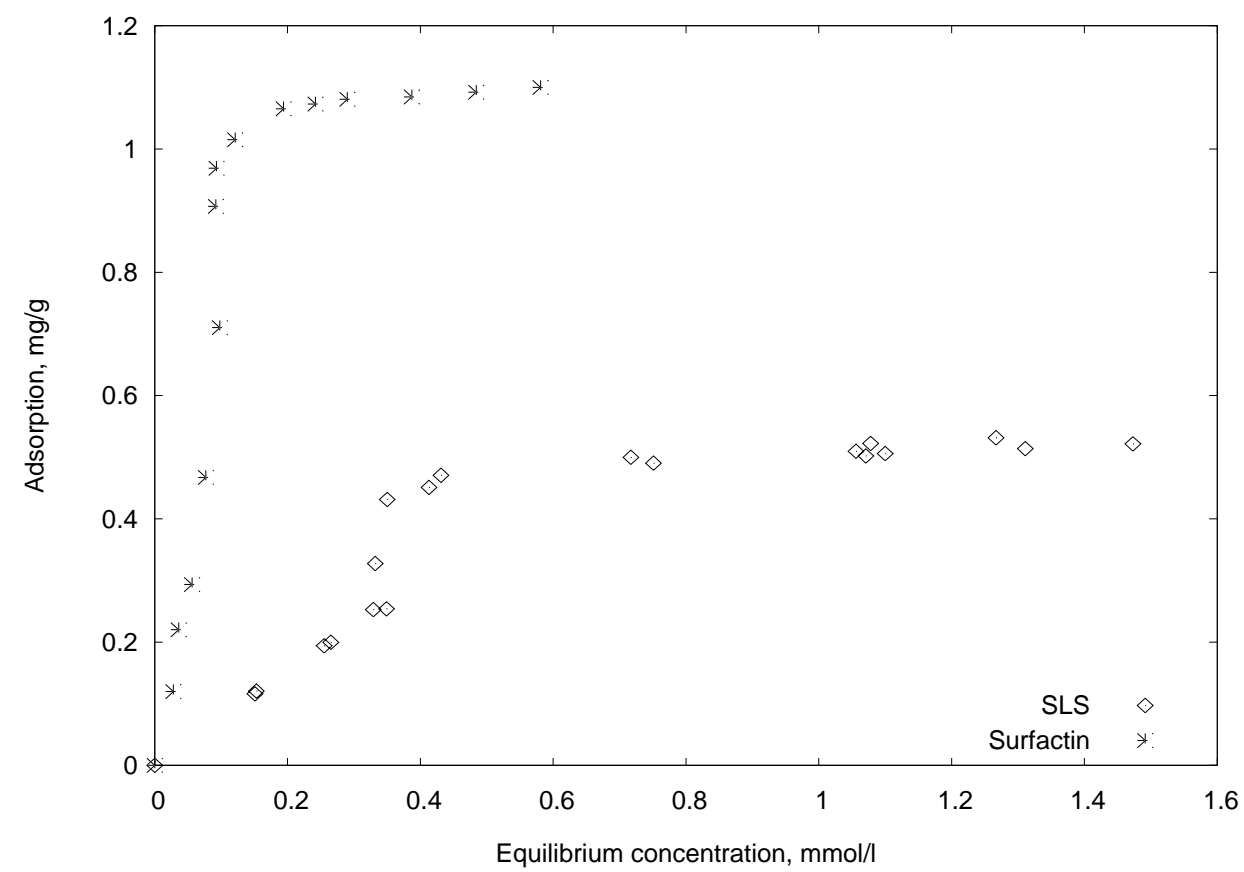

Figure 43 Dynamic absorption of SLS and surfactin on LKC cores (mg/g rock)

Figure 43 shows that at low concentrations, surfactin is more strongly adsorbed onto LKC rock than is SLS. While the affinity for the rock surface at low concentrations indicates potential for wettability change, the large difference in ultimate adsorption was a concern until the data was plotted on a molar basis Figure 44. It is clear that the apparent high adsorption ofsurfactin is an artifact of its high molecular mass compared to SLS. 


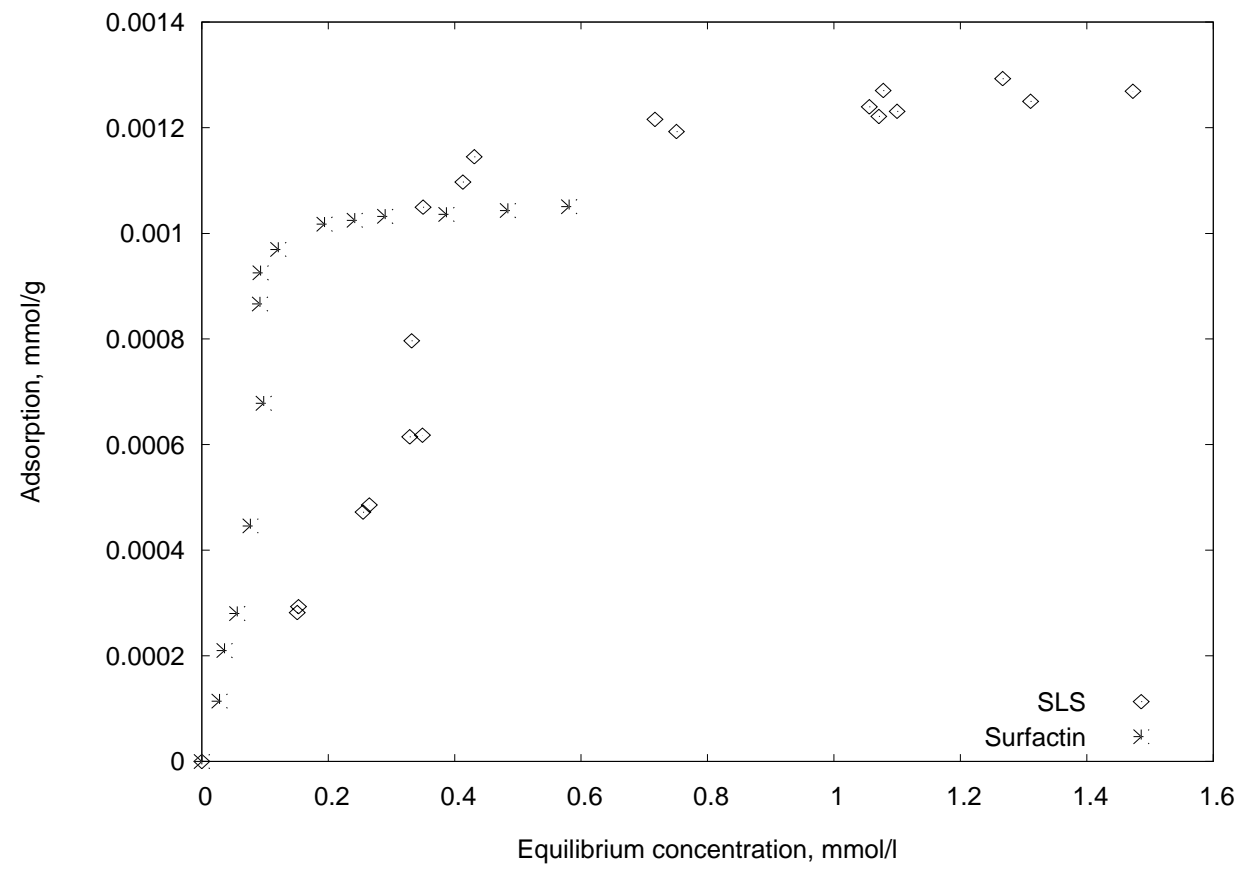

Figure 44 Dynamic adsorption of surfactants on LKC rock (mol/g rock)

\section{Conclusions from Experimental Work}

1. Fresh LKC reservoir material is oil-wet.

2. Cleaned LKC cores are mixed-wet.

3. Aging LKC cores in crude oil for one week at $90{ }^{\circ} \mathrm{C}$ alters wettability to $100 \%$ oil-wet.

4. More oil is produced under spontaneous imbibition of surfactin than of STEOL CS-330 into oil-wet cores at $S_{o}=1$. However, the difference can be accounted for by the lower surface tension of the surfactin.

5. Imbibition of surfactant solutions into cores requires the existence of water-wet pathways and so this approach may not be suitable for strongly oil-wet fractured reservoirs without mobility control.

6. Qualitative tests indicate that on a molar basis, surfactin is more effective than STEOL CS-330 in altering wettability of crushed Lansing-Kansas City carbonates from oil-wet to water-wet state.

7. Both STEOL CS-330 and surfactin exhibit typical adsorption isotherms with four distinct regions.

8. Adsorption isotherms of STEOL CS-330 and surfactin on crushed Lansing-Kansas City outcrop and reservoir material showed that surfactin has higher specific adsorption on 
these oomoldic carbonates. On a molar basis, the ultimate adsorption of surfactin is slightly lower than SLS, but surfactin-rock interaction is more pronounced at low concentrations.

9. It is important to standardize and report the mass of rock, and concentration and volume of surfactant solution used to develop adsorption isotherms.

\section{Technical Transfer}

During the reporting period, several publications have been produced:

1. Regular six-monthly and annual progress reports were submitted to DOE. ${ }^{43-46}$

2. A paper was presented at the $9^{\text {th }}$ International Wettability Symposium $^{47}$ in Bergen, Norway

3. Karl Eisert submitted and defended his Masters thesis ${ }^{48}$

4. A paper was presented at the 2007 Oilfield Chemistry Symposium in Houston, $\mathrm{TX}^{49}$

5. A paper was presented at the Seventeenth Oil Recovery Conference in Wichita, KS. ${ }^{50}$ 


\section{Reference List}

1. Gilliland, H.E. and Conley, F.R. Surfactant waterflooding in Symposium on Hydrocarbon Exploration, Drilling, and Production. 1975. Paris, France.

2. Gogarty, W.B., Oil Recovery with Surfactants: History and a Current Appraisal, in Improved Oil Recovery by Surfactant and Polymer Flooding, D.O. Shah and R.S. Schechter, Editors. 1977, Academic Press Inc.: New York. 27-54.

3. Michels, A.M., Djojosoeparto, R.S., Haas, H., Mattern, R.B., van der Weg, P.B., and Schulte, W.M. Enhanced waterflooding design with dilute surfactant concentrations for North Sea conditions in Symposium on Improved Oil Recovery. 1996. Tulsa, OK: Society of Petroleum Engineers.

4. Bondor, P.L. Dilute surfactant flooding for North Sea applications - technical and economic considerations in 6th European Improved Oil Recovery Symposium. 1991. Stavanger, Norway.

5. Fjelde, I., A Norwegian Research Program on Improved Oil Recovery: Program Summary, 1996.

6. Austad, T., Matre, B., Milter, J., Saevareid, A., and Oyno, L., Chemical flooding of oil reservoirs 8. Spontaneous oil expulsion from oil- and water- wet low permeable chalk material by imbibition of aqueous surfactant solutions. Colloids and Surfaces A, 1998. 137: 117-129.

7. Austad, T. and Milter, J. Spontaneous imbibition of water into low permeable chalk at different wettabilities using surfactants in International Symposium on Oilfield Chemistry. 1997. Houston, TX: Society of Petroleum Engineers.

8. Standnes, D.C. and Austad, T., Wettability alteration in chalk 1. Preparation of core material and oil properties. Journal of Petroleum Science and Engineering, 2000. 28: 111-121.

9. Standnes, D.C. and Austad, T., Wettability alteration in chalk 2. Mechanism for wettability alterations from oil-wet to water-wet using surfactants. Journal of Petroleum Science and Engineering, 2000. 28: 123-143.

10. Standnes, D.C., Nogaret, L.A.D., Chen, H.L., and Austad, T., An evaluation of spontaneous imbibition of water into oil-wet carbonate reservoir cores using a nonionic and a cationic surfactant. Energy \& Fuels, 2002. 16: 1557-1564.

11. Chen, H.L., Lucas, L.R., Nogaret, L.A.D., Yang, H.D., and Kenyon, D.E., Laboratory monitoring of surfactant imbibition using computerized tomography. SPE Reservoir Evaluation and Engineering, 2000. 4 (1): 16-25.

12. Spinler, E.A., Zornes, D.R., Tobola, D.P., and Moradi-Araghi, A. Enhancement of oil recovery using a low concentration of surfactant to improve spontaneous and forced imbibition in chalk in SPE/DOE Improved Oil Recovery Symposium. 2000. Tulsa, OK: Society of Petroleum Engineers.

13. Hirasaki, G. and Zhang, D.L., Surface chemistry of oil recovery from fractured, oil-wet, carbonate formations. SPE Journal, 2004 (June 2004): 151-162.

14. Chillenger, G.V. and Yen, T.F., Some Notes on Wettability and Relative Permeability of Carbonate Rocks. II. Energy and Sources, 1983. 7: 67-75.

15. Roehl, P.O. and Choquette, P.W., Carbonate Petroleum Reservoirs. 1985, New York: Spring-Verlag. 
16. Celik, M.S. The Role of Surfactant Precipitation and Redissolution in the Adsorption of Sulfonate on Minerals in SPE Annual Technical Conference and Exhibition. 1979. Las Vegas, NV.

17. Glover, C.J., Puerto, M.C., Maeker, J.M., and Sandvik, E.L., Surfactant Phase Behavior and Retention in Porous Media. SPE Journal, 1979: 183-193.

18. Trogus, F.J., Schechter, R.S., and Wade, W.H., A New Interpretation of Adsorption Maxima and Minima. Journal of Colloid and Interface Science, 1979. 70: 293-305.

19. Krumrine, P.H., Campbell, T.C., and Falconer, J.S. Surfactant Flooding II: The Effect of Alkaline Additives on IFT, Surfactant Adsorption, and Recovery Efficiency in paper SPE 8998 presented at the 1980 SPE Oilfield and Geothermal Chemistry Symposium. 1980. Stanford, CA.

20. Meyers, K.O. and Salter, S.J., The effect of oil/brine ratio on surfactant adsorption from microemulsion. SPE Journal, 1981: 500-512.

21. Novosad, J., Adsorption of Pure Surfactant and Petroleum Sulfonate at the Solid-Liquid Interface, in Surface Phenomena in Enhanced Oil Recovery, D.O. Shah, Editor. 1981, Plenum Publishing: New York. 675-694.

22. Gallet, X., Deleu, M., Razafindralambo, H., Jacques, P., Thonart, P., Paquot, M., and Brasseur, R., Computer simulation of surfactin conformation at a hydrophobic/hydrophilic interface. Langmuir, 1999. 15: 2409-2413.

23. Dworkin, M. The Prokaryotes: An Evolving Electronic Resource for the Microbiological Community. 1999-2006 1991 [cited 25 October 2006; Available from: http://141.150.157.117:8080/prokPUB/index.htm.

24. Morikawa, M., Hirata, Y., and Imanaka, T., A study on the structure-function relationship of lipopeptide biosurfactants. Biochimica et Biophysica Acta, 2000. 1488: 211-218.

25. Grangemard, I., Wallach, J., Maget-Dana, R., and Peypoux, F., Lichenysin: A more efficient cation chelator than surfactin. Applied Biochemistry and Biotechnology, 2001. 90: $199-210$.

26. Heerklotz, H. and Seelig, J., Detergent-like action of the antibiotic peptide surfactin on lipid membranes. Biophysical Journal, 2001. 81: 1547-1554.

27. Ishigami, Y., Osman, M., Nakahara, H., Sano, Y.I.R., and Matsumoto, M., Significance of beta-sheet formation for micellization and surface adsorption of surfactin. Colloids and Surfaces B: Biointerfaces, 1995. 4: 341-348.

28. Cooper, D.G., MacDonald, C.R., Duff, S.J.B., and Kosaric, N., Enhanced production of surfactin from Bacillus subtilis by continuous product removal and metal cation additions. Applied and Environmental Microbiology, 1981. 42: 408-412.

29. Mukerjee, P. and Mysels, K.J., Critical Micelle Concentrations of Aqueous Surfactant Systems. 1971, Washington, DC: US Department of Commerce.

30. Fisher Scientific, C., Instruction Manual - Fisher Tensiometer Model 20. Undated, Pittsburgh, PA: Fisher Scientific Company.

31. Wardlaw, N.C., Chilingarian, M.S.J., and Rieke, H.H., in Factors affecting oil recovery from carbonate reservoirs and prediction of recovery. 1996, Elsevier: New York. 867.

32. Nguyen, V.H., Sheppard, A.P., Knackstedt, M.A., and Pinczewski, W.V. The effects of displacement rate and wettability on imbibition relative permeabilities in 2005 SPE Annual Technical Conference and Exhibition. 2005. Dallas, TX: Society of Petroleum Engineers. 
33. Watney, L. Location map of Hall-Gurney Field on map of Lansing-Kansas City oil production in Kansas. 2006 [cited 21 May 2007]; Available from: http://www.searchanddiscovery.net/documents/2006/06093watney/images/01.htm.

34. Hirasaki, G.J., Rohan, J.A., Dubey, S.T., and Niko, H. Wettability evaluation during restored state core analysis in 65th Annual Technical Conference and Exhibition of the Society of Petroleum Engineers. 1990. New Orleans, LA: Society of Petroleum Engineers.

35. Somasundaran, P. and Zhang, L., Adsorption of surfactants on minerals for wettability control in improved oil recovery processes. Journal of Colloid and Interface Science, 1997. 191: 202-208.

36. Wu, Y., Shuler, P.J., Blanco, M., Tang, Y., and Goddard III, W.A. A study of wetting behavior and surfactant EOR in carbonates with model compounds in 2006 SPE/DOE Symposium on Improved Oil Recovery. 2006. Tulsa, OK: Society of Petroleum Engineers.

37. Ma, S., Zhang, X., Morrow, N.R., and Zhou, X., Characterization of wettability from spontaneous imbibition measurements. Journal of Canadian Petroleum Technology, 1999. 38 (13): 1-8.

38. Sak-Bosnar, M., Grabaric, Z., and Grabaric, B.S., Electrochemical Sensors in Biotechnology. Food Technology and Biotechnology, 2004. 42 (3): 197-206.

39. Huwaldt, J.A., Plot Digitizer version 2.4.1. Available from: http://plotdigitizer.sourceforge.net/

40. Radiometer, A., Potentiometric Titration of Anionic Surfactants. Undated. Radiometer Analytical: Villeurbanne, France.

41. Tabatabai, A., Gonzalez, M.V., Harwell, J.H., and Scamehorn, J.F., Reducing Surfactant Adsorption in Carbonate Reservoirs. SPE Reservoir Engineering Journal, 1993: 117-122.

42. Somasundaran, P., Krishnakumar, S., and Kunjappu, J.T., Spectroscopic characterization of surfactant and polymer solloids at solid-liquid interfaces, in Surfactants Adsorption and Surface Solubilization, R. Sharma, Editor. 1995, American Chemical Society: Washington DC. 104-137.

43. Liang, J.T., Bala, G.A., Johnson, S.J., and Fox, S.L., DE-FC26-04NT15523 Using Biosurfactants Produced from Agriculture Process Waste Streams to Improve Oil Recovery in Fractured Carbonate Reservoirs: First Semi-Annual Technical Progress Report, 2005.

44. Liang, J.T., Bala, G.A., Johnson, S.J., and Fox, S.L., DE-FC26-04NT15523 Using Biosurfactants Produced from Agriculture Process Waste Streams to Improve Oil Recovery in Fractured Carbonate Reservoirs: First Annual Technical Progress Report, 2005.

45. Liang, J.T., Bala, G.A., Johnson, S.J., and Fox, S.L., DE-FC26-04NT15523 Using Biosurfactants Produced from Agriculture Process Waste Streams to Improve Oil Recovery in Fractured Carbonate Reservoirs: Third Semi-Annual Technical Progress Report, 2006.

46. Liang, J.T., Bala, G.A., Johnson, S.J., Fox, S.L., Eisert, K., and Salehi, M., DE-FC2604NT15523 Using Biosurfactants Produced from Agriculture Process Waste Streams to Improve Oil Recovery in Fractured Carbonate Reservoirs: Second Annual Technical Progress Report, 2006. 
47. Salehi, M., Johnson, S., Bala, G., Fox, S., and Liang, J.-T. Wettability alteration of carbonate rock mediated by biosurfactant produced from high-starch agricultural effluents in 9th International Wettability Symposium. 2006. Bergen, Norway.

48. Eisert, K., Using Biosurfactants Produced from Agriculture Process Waste Streams to Improve Oil Recovery in Fractured Carbonate Reservoirs, M.S. Thesis, Department of Chemical and Petroleum Engineering. 2006. The University of Kansas: Lawrence, KS.

49. Johnson, S.J., Eisert, K.F., Salehi, M., Fox, S.L., Bala, G.A., and Liang, J.-T. SPE 106078: Using biosurfactants produced from agriculture process waste streams to improve oil recovery in fractured carbonate reservoirs in Oilfield Chemistry Symposium. 2007. Houston, TX: Society of Petroleum Engineers.

50. Johnson, S., Saheli, M., Eisert, K.F., Liang, J.-T., Bala, G.A., and Fox, S.L. Potential for Wettability Alteration in the LKC using Biosurfactants from Agricultural Waste in Seventeenth Oil Recovery Conference. 2007. Wichita, KS, USA: Tertiary Oil Recovery Project, University of Kansas. 


\section{Abbreviations and Nomenclature}

$\Delta \mathrm{S}_{\mathrm{wf}} \quad$ Change in water saturation following forced imbibition of brine

$\Delta S_{\mathrm{ws}} \quad$ Change in water saturation after spontaneous imbibition of brine

$\rho \quad$ Surface relaxivity, $\mathrm{cm} / \mathrm{s}$

$\rho_{l} \quad$ Liquid density, $\mathrm{mg} / \mathrm{ml}$

$\rho_{\mathrm{r}} \quad$ Rock density, $\mathrm{g} / \mathrm{ml}$

$\phi \quad$ Core porosity

A Cross sectional area, $\mathrm{cm}^{2}$

BF_nn Bethany Falls outcrop core \# $n n$

C Circumference of tensiometer ring, $\mathrm{cm}$

CMC Critical Micelle Concentration

D Density of lower phase, $\mathrm{g} / \mathrm{ml}$

d Density of upper phase, $\mathrm{g} / \mathrm{ml}$

DOE United States Department of Energy

EOR Enhanced oil recovery

F Surface tension correction factor

HQ_nn Heartland Quarry LKC outcrop core \# nn

IFT Interfacial Tension

INL DOE Idaho National Laboratory

IOR Improved oil recovery

$\mathrm{I}_{\mathrm{w}} \quad$ Amott Wettability to water $=\Delta \mathrm{S}_{\mathrm{ws}} /\left(\Delta \mathrm{S}_{\mathrm{ws}}+\Delta \mathrm{S}_{\mathrm{wf}}\right)$

JC_nn Joulters Cay outcrop core \# $n n$

KGS Kansas Geological Survey

KU University of Kansas

L7 nn Luerman \#7 LKC reservoir core \# nn

LKC Lansing-Kansas City

M_nn Miami oolite outcrop core \# $n n$

MRI Magnetic Resonance Imaging

NA Nutrient Agar

PTFE Polytetrafluoroethene, e.g. Teflon ${ }^{\circledR}$

$\mathrm{P} \quad$ Apparent surface tension, dynw $/ \mathrm{cm}$

$q \quad$ Flow rate of solution injection, $\mathrm{ml} / \mathrm{s}$

$\mathrm{R} \quad$ Radius of tensiometer ring, $\mathrm{cm}$

RO Reverse Osmosis

$\mathrm{r} \quad$ Radius of tensiometer wire, $\mathrm{cm}$

$\mathrm{S} \quad$ True surface tension $=\mathrm{P} \times \mathrm{F}$, dyne $/ \mathrm{cm}$ or surface area, $\mathrm{cm}^{2}$

SDS Sodium dodecyl sulfate

SLS Sodium laureth sulfate

SPE Society of Petroleum Engineers

T1 Spin-lattice relaxation time, $\mathrm{s}$

T2 Spin-spin relaxation time, $\mathrm{s}$

$t \quad$ time, $s$

TDS Total Dissolved Solids

THF Tetrahydrofuran 
TOC Total Organic Carbon

TORP Tertiary Oil Recover Project, University of Kansas

$\mathrm{V} \quad$ Volume, $\mathrm{cm}^{3}$

MIC Minimum Inhibitory Concentration

MW Molecular weight, $\mathrm{g} / \mathrm{mol}$

$\mathrm{w} / \mathrm{v} \quad$ Weight per unit volume 